\title{
TWOZONE \\ Users Manual
}

\section{TWO-WEEK LOAN COPY}

\author{
This is a Library Círculating Copy \\ which may be borrowed for two weeks. \\ For a personal retention copy, call \\ Tech. Info. Division, Ext. 6782
}

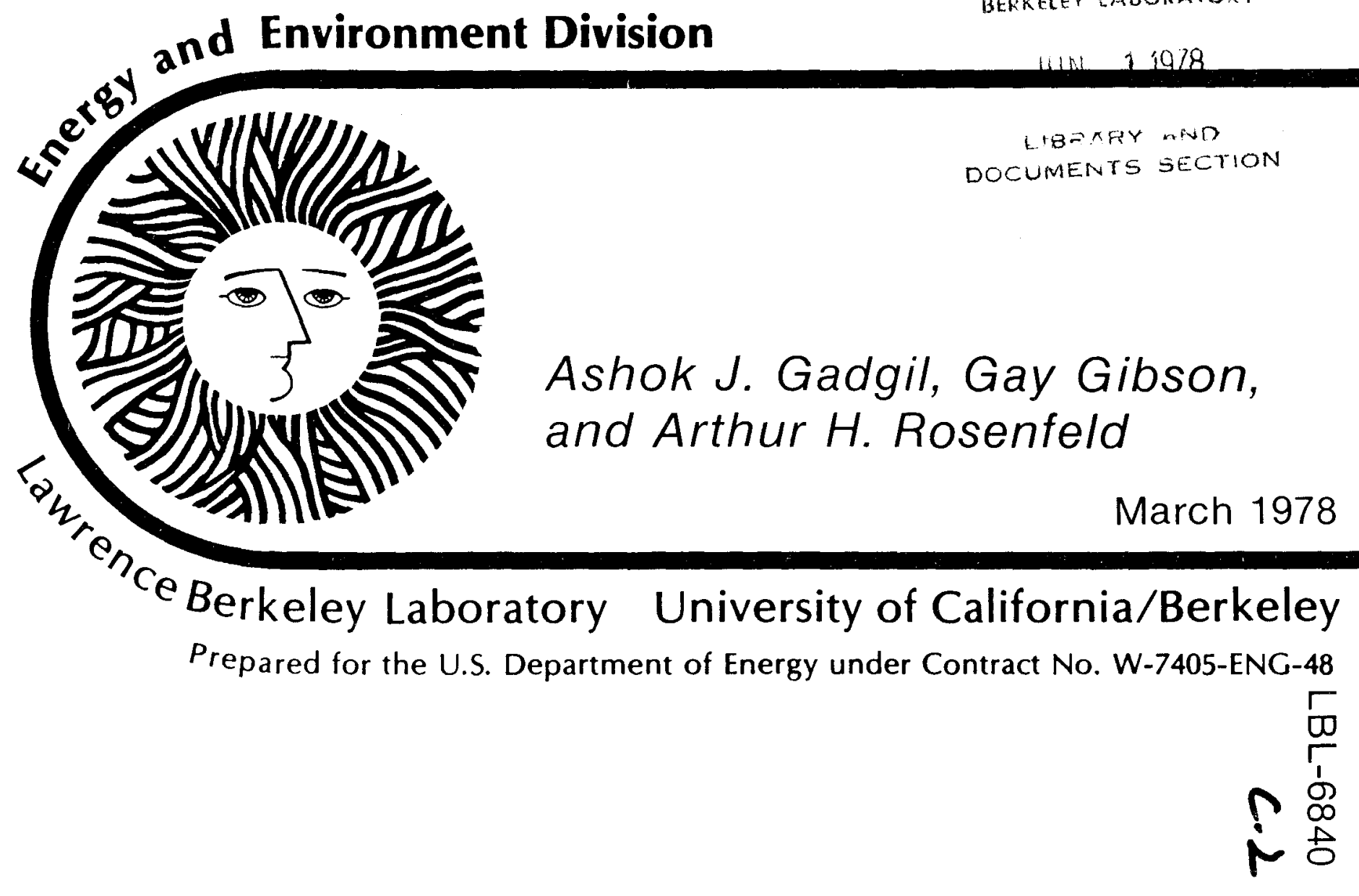

RECEIVED

LAWRENCE

BERKELEY LABORATORY

nd Environment Division

Ashok J. Gadgil, Gay Gibson, and Arthur H. Rosenfeld

March 1978 


\section{TWOZONE Users Manual}

\section{Ashok J. Gadgil, Gay Gibson, and Arthur H. Rosenfeld}

\section{March 1978}

Energy and Environment Division Lawrence Berkeley Laboratory Berkeley, California 94720 


\section{CONTEN'LS}

1. Introduction . . . . . . . . . . . . . . . . 1

2. Program Description. . ................. 1

3. Advantages and Limitations . . . . . . . . . . . 5

4. Input Deck . . . . . . . . . . . . . . . . 7

4.1. General Building Description, Time and Location . . . 8

4.2. Cooling Input ... . . . . . . . . . . 12

4.3. Comment Section ................ 13

4.4. Transfer Functions for Walls and Roof ........ 13

4.5. Internal Heat Loads . . . . . . . . . . 15

4.6. Economic Data ... . . . . . . . . . . 16

5. Output ..................... . 17

5.1. Summary of INPUT DATA . . . . . . . . . . . . 18

5.2. Response of TWO-ZONE House . . . . . . . . . . . 18

5.3. Load Curves . . . . . . . . . . . . . 19

5.4. Sumary for the Entire Run .............. 20

5,5. Economic Analysis . . . . . . . . . . . 21

5.6. Short Summary of Input . . . . . . . . . . . 21

6. Sample Output . . . . . . . . . . . . . . . 22

7. Dictionary of Variables for the Main Program TWOZONE . . . . 39

8. Important Variables in TWOZONE Subroutines and Functions . . 70

9. Subroutine and Function Program Descriptions . . . . . . 76

Appendices . . . . . . . . . . . . . . . . 85

I. Subroutine COOLIT, . . . . . . . . . . . . . 85

Input . . . . . . . . . . . . . . . 85

Output .................... 86

Modes of Operation ............... . 87 
Calculation of Variables Common to the Evaporative Cooling and Air Conditioning Branches ........ 91 Evaporative Cooling Branch ............ 9? Refrigerative Air Conditioning Branch . . . . . . 99

II. BCD Coefficient Generating Program . . . . . . . . 107 Input Deck Format . . . . . . . . . . . 108 Output . . . . . . . . . . . . . 109 III. Weather File.................. 111 Introduction. . . . . ............ 111 Format .................. 112 Inventory of Available NOAA Weather Files...... . 114 Inventory of California weather Files Available at LBL 116 


\section{INTRODUCTION}

TWOzONE was written in the summer of 1975 to analyze the heating and cooling loads of single family residences for the purpose of investigating the effect on energy consumption of various changes in building design, construction and management. 2,7

The program evaluates the annual energy demand taking into account

1) various amounts, types and location of glass areas in a house, 2) different wall and roof constructions, 3) various amounts and locations of insulation, 4) scheduled thermostat settings, 5) other changes in the building envelope. The model differentiates between the thermal behavior of the north and south zones of a house (hence the name TWOZONE).

This manual describes the most recent version of TWOzONE (version BLUEL) implemented in November 1977. This version includes many new features (e.g. ventilation strategies, evaporative cooler, improved air-conditioner algorithm, ability to read Cal-ERDA weather tapes, user-specified tilting of the roof, an economics subroutine etc.)

Without the many requests from current and potential users of TWOZONE, this manual would never have been finished. We thank them for their persistance. We also gratefully acknowledge the help given by Steve Gates and Dave Waltz in writing sections on the Evaporative Cooler and the Economics Subroutine, and of course by Professor Leonard Wall through valuable discussions and descriptions of his contributions to the program.

\section{PROGRAM DESCRIPTION}

A prime motivation for the development of the TWOZONE model was to determine how to maximize usable solar energy collected by windows. The program computes the thermal performance of a building on an 
hourly basis and takes into account the following:

1) The heating and cooling loads on a house, given the hourly weather data.

2) The hourly internal loads (i.e. heat generated by appliances, lights, and people).

3) Strategies for loads management. These include daytime-nighttime thermostat schedules, a schedule for use of shades, curtains or reflecting tint on windows, strategies for cooling the house with air-conditioner, evaporative-cooler or venting (open windows) depending on outside and inside air temperatures and humidity. The model house is a two-zone space, connected thermally by convective air flow. This two-zone feature was included because we were particularly interested in capturing solar heat through large south windows. Many standard plans for houses naturally divide the house into two prominent zones due to a central load-bearing wall and the stair location. The shading on the house is currently modelled as if the house has a backyard and is in a row of similar houses facing a street. When $\operatorname{AzW}(1)=0.0$ in the INPUT deck (see page 10), the street runs EastWest. Then the house is shaded by similar houses on the east and west sides with an approximately 30 degree angle of obstruction. The south side of the house faces the street and in unshaded. The north side is assumed to face the backyard (i.e. not shaded by another house) and a tree which provides some shade. When AzW(1) is not zero, this whole configuration (including the "street" and the "tree" and so on) rotates in a clockwise sense by that many degrees.

Heat losses are due to 1) air infiltration through cracks around construction joints, windows and doorways, and microscopic cracks in 
the house sheathing itself (1/4 airchange per hour at 0 windspeed increasing to $3 / 4$ airchange per hour at windspeed of $10 \mathrm{mph}$ ), 2) conduction/radiation through roof, walls, windows and floors. The heat sources are the furnace, solar heat gain (through fenestration,* walls and roof) and internal heat loads (people, lights, appliances) . The temperature of each zone, $T_{x}$ ( $x=$ south or north), is computed according to the rate of change of temperature, as follows:

$$
\frac{c}{2} \frac{d T x}{d t}=(\text { Heat flow } x
$$

(Heat flow) $\mathrm{x}=$ rate of solar heat gain to ' $\mathrm{x}$ ' zone through fenestration + rate of net heat gain to ' $x$ ' zone walls and roof (solair)

+ heat transfer, by convection, from the other zone

- infiltration losses

$+\frac{\text { internal heat load }}{2}$

$c=$ The effective thermal capacity of entire house. (Typically C (effective) is $3200 \mathrm{BTU} /{ }^{\circ} \mathrm{F}$. A moderately insulated house has a temperature relaxation time of about 4 hours. ${ }^{7}$ ) Using these rates of change, the next hour's temperatures are calculated. Depending on the average temperature, the house switches into one of the modes described below.

*fenestration - window complex; includes number of panes, types of glass, interior and exterior shading. 
1) Should the average house temperature (TTB) rise above the set maximum, (THI), cooling of the house is accomplished in one of two ways;

a. during months when A.C. (evaporative-cooler) is available, and the outside temperature is greater than or equal to THI, A.C. (evaporative-cooler) switches on. Depending on the time of the day, temperatures and humidity, different strategies for using A.C. or evaporative-cooler are available (see Appendix I). b. during the rest of the year, or when the outside temperature is cooler than $T$, windows are opened to vent the house. The program can also simulate houses with forced A.C. (i.e., with fixed closed windows).

2) If T lies between TLOW (the thermostat setting for heating) and THI, the house temperature "floats."

3) If $\mathrm{T}$ is below TLOW, the furnace is "on" until the house temperature reaches the thermostat setting.

The program calculates the hourly heat load and energy consumption required for heating and cooling. The hourly weather data (see Appendix III) consists of the following: outside dry bulb air temperature, outside wet bulb air temperature, cloud amount, cloud type, wind speed, dewpoint, humidity ratio, enthalpy, density and atmospheric pressure for the given location. The standard $\operatorname{ASHRAE}^{3}$ algorithms are used to calculate solar radiation from observed cloud cover, and the solar heat gains through fenestration. The delayed thermal responses of walls and roof are calculatej using the conduction transfer functions of Mitalas and Arsenault 4 (see Appendix II). At the end of the run, the program can make economic comparison (along ERDA guidelines) with a 'base case', using economic and other base case data supplied by the user. 
In summary, the input to the program consists of the following: a weather file with hourly values, building description schedule for internal loads, thermostat settings, fenestration description, calculated transfer function coefficients that characterize wall and roof thermal behavior (see Appendix II) and economic data (optional). Source of these last five input groups is the INPUT DECK.

The typical output consists of 1) hourly furnace and AC load for first four days of each month, 2) a printer plot of hourly energy use (optional), 3) the hourly heating and hourly cooling load distributions averaged over each month (optional), 4) summary output for entire run period, including apportioned heat gains (losses) and apportioned heating and cooling loads from windows, walls, roof, floor and infiltration.

\section{ADVANTAGES AND LIMITATIONS}

There are several public-domain programs available for residential building heating and cooling analysis (e.g. Cal-ERDA, BLAST, NECAP and NBSLD). In comparison to these programs, the following strengths and limitations of TWOZONE arise from the fact that it is a simplified loads, systems and plant simulation while retaining (and sometimes introducing) many sophisticated algorithms for residential building energy simulation.

1) TWOZONE is easy to understand and can be easily modified by the user.

2) There is good agreement between TwOzone results and available field data from Utility surveys. ${ }^{7}$ There is reasonable agreement with the detailed radiation exchange calculations of NBSLD (NBSFAST) ${ }^{2}$ 
3) TWOZONE is inexpensive to run $(\$ 3.00$ on LBL's CDC computer for one year run period, at deferred priority) and doesn't require a large memory $(125,000$ octal on LBL systems).

4) TWOZONE simulates a building's loads and systems-plant complex hour by hour. This unique feature makes TwOzONE attractive for testing new algorithms modelling nonstandard innovations. (To our knowledge all other public domain programs first calculate the loads for the full run-period and then use perturbation techniques to account for changes in loads due to system-plant complex) .

5) The program has attractive and simple input/output.

These stengths are obtained at the expense of accepting the following limitations:

1) As is stands the program cannot simulate non-standard building shapes without extensive modifications.

2) The program uses weighting factors to handle radiation exchange (unlike the almost exact handling of radiation balance equations by some of the public-domain programs like BLAST) .

3) ASHRAE does not recommend one element of our theory (assigning a lumped capacitance to the house).

4) TWOzONE does not have a user-oriented, powerful input-language such as used by Cal-ERDA or BLAST.

5) TWOZONE does not handle HVAC of large buildings or apartments witr separate thermostats for each unit. 
6) The model assumes a constant furnance efficiency of 608 . (In reality the furnace efficiency may vary from say 508 in warm weather to 808 at full load.) simulation of the furnance is a task for the near future.

7) Estimates indicate that the results of TWOZONE may be within 208 of actual energy use for residential houses of conventional design.

8) The results predicted by TwOzONE have not been field verified by an independent-testing group for their accuracy.

The TWOZONE program has demonstrated its reliability as an educational tool and a research model. It was one of the tools used by California Energy Resource Conservation and Development Commission to formulate the current California residential building codes. The user must keep in mind that the results of a single run may not agree exactly with the performance of an actual house. However, the strength of TWOZONE is in its ability to determine the relative energy efficiency of various strategies in building design, construction and management.

4. INPUT DECK

The input data required for this program include: time period of test run, location of building, building design, dimensions and construction materials, thermostat schedule, and hours of building occupancy.

This section presents a detailed explanation of each variable, its position in the INPUT DECK, format, source and units. There are 6 groups of cards (37 cards total.) Al1 37 cards must be present or else the program will abort. 
The INPUT DECK is echoed just before processing of the input data occurs, (see sample OUTPUT). This makes it convenient to check for card punch errors.

4.1 General Building Description, Time and Location.

(cards 1-6), columns 71-80 reserved for comments.

- Card 1 , format $(4(3 x, I 2), 5 x, 2(3 x, I 2), 10 x, 13(I 1,1 X))$

Columns (4-5) RDAY = day of month simulation run begins

$$
\begin{aligned}
& \text { (9-10) } \quad \text { MO = month of year } \\
& \text { (14-15) KDAYND = day of month simulation run ends } \\
& \text { (19-20) MOEND = month of year " " " } \\
& \text { program can run for } 365 \text { days } \\
& \text { (29-30) ACSTART = starting month of air-conditioner (AC) operation. } \\
& \text { (34-35) ACEND = ending month of AC operation. } \\
& (36-45) \quad B l a n k
\end{aligned}
$$

The following columns should have $1 / 0$ to activate/skip options. Inbetween columns are always blank.

(46) IFLAGI = puts degree-hour and degree-day data on tapes for use by a plotting program.

(48) IFLAG4 = punches card with load apportioning data for use by a bar graph program (APPLEPLOTS) .

(50) IFLAG5 = gives graph of house temperature, outside temperature, heating and cooling loads in Btuh for each hour of the first 4 days of each month.

(52) IFLAG6 = gives hourly heating and hourly cooling load distributions averaged over each month.

Instead of $1 / 0$, the following three columns should have integer $/ 0$.

(56) IFLAG8 controls evaporative cooler operation.

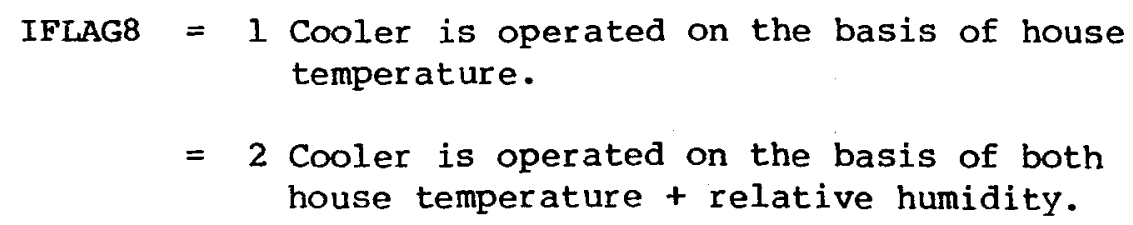


$=3$ Like 2, but also specifies a minimum air temperature from the evaporative cooler.

$=4$ Determines the size of a thermostatcontrolled evaporative-cooler needed to cool the house.

$=5$ Determines the size of a thermostat-andhumidistat controlled evaporative cooler needed by the house.

See Appendix I for more detail.

(58) IFLAG9 controls air conditioner operation

IFLAG9 $=1$ Allows air conditioning.

$=2$ Sizes the air conditioner.

See Appendix I for more detail.

(60) IFLAG10 governs nightime cooling options between the hours of BED and BRKFST (midnight-8 a.m.)

IFLAG10 = 1 vents the house to TAMCOL (see next card, columns $51-60$ ) at night.

$=2$ resets cooling thermostat to TAMCOL at night.

$=3$ runs evaporative cooling only at night, air conditioning during the day. At night the thermostat is set to TAMCOL.

See APPENDIX I for more detail and allowable combinations of IFLAG8, IFLAG9, IFLAG10.

(62) IFLAGll = 1 will produce economic analysis.

See the description of Subroutine ECON for more detail.

- Card 2, format (8Fl0.4)

Columns (1-10) THI = maximum temperature allowed, $\left({ }^{\circ} \mathrm{F}\right)$. If A.C. is available and outside temperature is warmer than house temperature, A.C. Switches on, otherwise house vents (i.e. windows 'open'). ( $\mathrm{T}-\mathrm{HI})$

(11-20) TDAYMN = lowest temperature allowed during day, $\left({ }^{\circ} \mathbf{F}\right.$, thermostat setting). Furnace switches on if house temperature drops below this setting. ( $\mathrm{T}-\mathrm{DAY}-\mathrm{MN}$ ) 


$$
\begin{aligned}
& (21-30) \text { TNIGHT = nighttime thermostat setting (midnight-8am), } \\
& \left({ }^{\circ} \mathrm{F}\right) \quad(\mathrm{T}-\mathrm{NIGHT}) \\
& \text { (31-40) THOLDY = daytime thermostat setting during holiday } \\
& \text { periods, ( }{ }^{\circ} \text { ) (i.e. Sat, Sun, and all Federal } \\
& \text { holidays) } \cdot \text { (T-HOLDY) } \\
& \text { (41-50) THOLNT }=\text { nighttime thermostat setting (midnight-8am) } \\
& \text { during Holiday periods, }\left({ }^{\circ} \mathrm{F}\right) \text {. (T-HOL-NT) } \\
& \text { (51-60) TAMCOL = temperature at which the house will be vented } \\
& \text { or cooled at night during the cooling season } \\
& \text { if IFLAG10 allows it. (T-AM-COL) } \\
& (61-70) \text { TLOWAC = temperature to which the heater thermostat } \\
& \text { is set during the cooling season. (T-LOW-AC) }
\end{aligned}
$$

- Card 3, format (8F10.4)

Columns $(1-10)$ PCTGLS $=$ percent of south wall that is glass

$$
\begin{aligned}
& \text { (1.1-20) PCTGLW = " " west " " } \\
& \text { (21-30) PCTGL, = " "north " " } \\
& \text { (31-40) PCTGLE = " " east " " } \\
& \text { (41-50) SHDCF = "shading coefficient" of glass i.e. fraction } \\
& \text { of incident solar heat transmitted. Perfectly } \\
& \text { clean } 1 / 8 \text { " window glass has coefficient = } \\
& 1 \text { by definition. Typically shading coefficient } \\
& \text { of } .95 \text { is used for } 1 / 8^{n} \text { regular glass, without } \\
& \text { drapes. Drapes, blinds, and tinted glass } \\
& \text { also affect the shading coefficient. See } \\
& \text { Ashrae Handbook (3) for details. } \\
& \text { (51-60) GLTYP = currently use 1. Eventually will call specific } \\
& \text { properties of glass such as reflection, } \\
& \text { transmission and absorbtion coefficients } \\
& \text { from a library (to be installed). (GL-TYP) } \\
& \text { (61-70) GLAZE = Defines number of layers of glass in windows: } \\
& 1 \text { for single pane, } 2 \text { for double pane. }
\end{aligned}
$$

- Card 4, format (8F10.4)

$$
\text { Columns } \begin{aligned}
(1-10) \text { UDAY }= & \text { U-value of window glass during day, Btuh/sq. } f t .-O_{F} . \\
& \text { Use } 0.6 \text { for double-paned windows, } 1.1 \text { for } \\
& \text { single paned (Btuh/Sq.Ft. } \left.-O_{F}\right) \\
(11-20) \text { UNIGHT }= & \begin{array}{l}
\text { U-value of window glass at night. Dependent } \\
\text { on window construction, glass tint, shades } \\
\text { and curtains. }
\end{array}
\end{aligned}
$$




$$
\begin{aligned}
(21-30) \text { UFLOOR = } & \begin{array}{l}
\text { U-value of floor, typically } .05 \text { to } .3 \text { (see } \\
\text { reference } 3 \text { for specific data), } \\
\text { (Btuh/sq.ft. } \left.-O_{F}\right)
\end{array} \\
(31-40) C C= & \text { effective lumped heat capacity of house, } \\
& \text { (Btu/OF). We suggest values in the neighborhood } \\
& \text { of } 3000 \text { Btu/OF for a typical house of } 1200 \\
& \text { square feet floor area. }
\end{aligned}
$$

- Card 5, format (8F10.4)

Columns (1-10) WALLAR(1) = south face, total area sq. ft.

$$
\begin{aligned}
& (11-20) \operatorname{WALLAR}(2)=\text { west } \\
& (21-30) \operatorname{WALLAR}(3)=\text { north " } \\
& (31-40) \operatorname{WALLAR}(4)=\text { east } \\
& (41-50) \operatorname{WALLAR}(5)=\text { area of southern portion of roof, sq. ft. } \\
& (51-60) \operatorname{WALLAR}(6)=\text { area of northern portion of roof, sq. ft. } \\
& (61-70) \operatorname{ARFLOR}=\text { total area of the foundation, sq. ft. }
\end{aligned}
$$

- Card 6, format (8F10.4)

$$
\begin{aligned}
& \text { Columns }(1-10) S(1)= \text { Latitude of house location } \\
&(11-20) S(2)= \text { Longitude of house location } \\
&(21-30) S(3)= \text { Time zone of house location, with Greenwich =1. } \\
& \begin{array}{l}
\text { Eastern standard }=5 . \\
\text { Central }=6 . \\
\text { Rocky Mountain }=7 . \\
\text { Western }=8 .
\end{array} \\
&(31-40) \text { AZW }(1)= \begin{array}{l}
\text { Azimuth of southernmost wall, degrees clockwise } \\
\text { from south. }
\end{array} \\
&(41-50) \text { AZW (5) }= \begin{array}{l}
\text { Azimuth of southernmost roof section, degrees } \\
\text { from south. }
\end{array} \\
&(51-60) \text { RFTILT5 }= \text { tilt of southernmost roof section, angle } \\
& \text { between the outward normal of the roof and } \text { the vertical axis, degrees. (RF-TILT-5) } \\
&(61-70) \text { RFTILT6 }=\quad \text { tilt of northernmost roof section. (RF-TILT-6) }
\end{aligned}
$$




\subsection{Cooling Input}

(cards 7-9)

- Card 7, format (8F10.4)

Columns (1-10) ACAPAC = maximum cooling capacity of air-conditioner, Btuh

(11-20) FANVOL $=$ air flow rate through air conditioner, cfm

$(21-30) \mathrm{TCOIL}=$ minimum temperature of cooling coil (typically $\left.50^{\circ} \mathrm{F}\right), \mathrm{O}_{\mathrm{F}}(\mathrm{T}-\mathrm{COIL})$

- Card 8 , format $(8 \mathrm{~F} 10.4)$

Columns $(1-10)$ ECVOL $(1)=$ lowest fan speed of the evaporative cooler, cfm (EC-VOL)

(11-20) EWATT $(1)=$ electrical consumption of fan motor at lowest speed, watts (E-WATT)

$(21-30) \operatorname{ECVOL}(2)=$ next highest speed, cfm

$(31-40) \operatorname{EWATT}(2)=$ next highest wattage, watts

$(41-50) \operatorname{ECVOL}(3)=$ etc.

$(51-60) \operatorname{EWATT}(3)=$ etc.

$(61-70) \operatorname{ECVOL}(4)=$ etc.

$(71-80) \operatorname{EWATT}(4)=$ etc.

enter data from the lowest to highest setting, leave extra settings blank (i.e. for a twospeed cooler, leave (4l-80) blank).

- Card 9, format (8F10.4)
Columns $(1-10)$ TOFFEC $=$ temperature the evaporative cooler shuts off at. (usually a few degrees below THI) (T-OFF-EC)
(11-20) EFFECT = effective wetbulb depression attainable with the evaporative cooler (usually 0.8 ). See ASHRAE (3) for more detail.
(21-30) RHSET = maximum \& relative humidity desired in house, with evaporative cooling. RHSET corresponds to the humidistat setting. (RH-SET)
$(31-40)$ RHSENS = sensitivity of humidistat, 8 . Humidity is controlled to RHSET \pm RHSENS. (5.0 is good) (RH-SENS) 


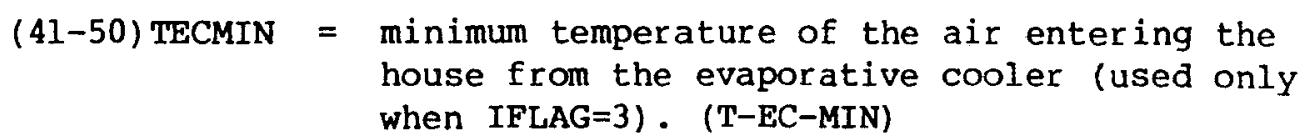

\subsection{Comment Section}

- Cards 10-14 Columns 1-80, format (8Al0)

This set of 5 comment cards can be used to describe the input variables. Each of these cards will be directly echoed above the graph in OUTPUT. (See sample OUTPUT.) All 5 cards must be included in the INPUT DECK, even if they are blank.

\subsection{Transfer Functions for walls and roof}

- Cards $15-30$

These 16 cards provide thermal properties of the walls and roof which are needed to evaluate conduction heat transfer from a room to the outdoors. This heat transfer is computed using the conduction transfer functions ( $B, C, D$ coefficients, see Appendix II) and the eighthour history of heat flux through each surface. Frame walls typically consist of two "components": 20-258 studs, 80-758 air space or insulation. The program assumes parallel heat flow paths through these two components. Frame roofs typically also consist of two components: 108 studs, 908 air space or insulation. The $B, C, D$ coefficients depend on the type and amount of building materials used in the construction (i.e. insulation, air-gaps, dry wall, stucco, etc.). A preprogram is available to generate the $\mathrm{BCD}$ coefficients appropriate to a given construction (see Appendix II). A set of 4 cards is used for each of the two components of the wall and roof, (i.e. $4 \times 4=16$ cards total). These are entered in the INPUT DECK as follows; 
Walls: Air space or insulation component

- Card 15, format (A10, F10.1)

$$
\begin{array}{ll}
\text { Column (1-10) } & \begin{array}{l}
\text { Names of component (e.g. "air space, or } \\
\text { "insulation } R-x ")
\end{array} \\
(11-20) & \begin{array}{l}
\text { component fraction of whole wall, typically } \\
0.75
\end{array}
\end{array}
$$

- Card 16, format (8F10.7)

$$
\begin{aligned}
& \text { " } B \text { " coefficients } B_{1}, B_{2}, \ldots B_{N} \text { (maximum is } 8 \text { ) } \\
& \text { beginning with the } B \text { coefficient of the current } \\
& \text { hour and working back one hour at a time }
\end{aligned}
$$

o Card 17, format (8F10.7)

$$
\text { "C" coefficients } C_{1}, C_{2}, \ldots C_{N} \text { (maximum is } 8 \text { ) }
$$

- Card 18, format (8F10.7)

" $D$ " coefficients $D_{1}, D_{2}, \ldots D_{N}$ (maximum is 8)

Stud component

o Card 19, format (Al0, Fl0.2)

$$
\begin{aligned}
& \text { Column (1-10) comment space, names component (i.e. "stud") } \\
& (11-20) \text { component fraction of wall, typically } 0.25
\end{aligned}
$$

- Cards 20-22, format (8F10.7)

Format same as Cards 16-18.

Roof: Air space or insulation component

- Card 23, format (Al0, F10.2)

$$
\begin{aligned}
& \text { Column (1-10) comment space, names component (i.e. "air space" } \\
& \text { or "insulation } \left.\mathrm{R}=\mathrm{x}^{\prime}\right) \\
& (11-20) \text { component fraction of roof, typically } 0.9
\end{aligned}
$$

- Cards 24-26, format (8F10.7)

Format same as Cards 16-18. 


\section{Stud component}

- Card 27, format (A10, F10.2)

$$
\begin{aligned}
& \text { Column (1-10) comment space, names component (i.e. "stud") } \\
& (11-20) \text { component fraction of roof, typically } 0.1
\end{aligned}
$$

- Cards 28-30, format (8F10.7)

$$
\text { Format same as Cards 13-15. }
$$

\subsection{Internal Heat Loads}

- (Cards 31-33)

The hourly internal heat load is the cumulative heat released into the house during the hour by inhabitants and their activities, including use of appliances (TV, vacuum, cooking, fraction of heating water which does not go down the drain, etc.) The amount of heat generated can be significant, and varies considerably hour by hour. Data we use is scaled from the estimates used by the National Bureau of Standards. (8)

- CARD 31 , format $(8 \mathrm{x}, 8 \mathrm{~F} 9.2)$

Column (1-8) Comment phrase e.g. HR 01-08 means 1 a.m. through 8 a.m. (9-80) Internal loads for each of those 8 hours (BTUh).

- CARD 32, format $(8 \mathrm{x}, 8 \mathrm{~F} 9.2)$

(1-8) e.g. HR 9-16 means 9 a.m. - 4 p.m.

(9-80) Internal loads for each houx, (Btuh).

o CARD 33, format $(8 \mathrm{x}, 8 \mathrm{F9} 9.2)$

$$
\begin{aligned}
& \text { (1-8) e.g. HR 17-24 means } 5 \text { p.m. - } 12 \text { midnight. } \\
& \text { (9-80) Internal loads for each hour, (Btuh). }
\end{aligned}
$$


4.6 Economic Data. The following three cards may be left blank if no economic analysis is desired (IFLAGll $=0$ ).

- CARD 34, format (8F10.4)

Columns (1-10) BLF, years. The lifetime of the base configuration. $(B-L F)$

(11-20) REMLF, years. The remaining years of useful life of existing equipment. (REM-LF)

(21-30) ALTF, years. The lifetime of the alternative equipment or strategy. (ALT-F)

(31-40) BRC, \$. The Replacement Cost of Baseline equipment. (Note: includes the cost of removal of old equipment, less the scrap value.) (B-R-C)

(41-50) AREPCO, \$. The replacemt cost of equipment for the replacement case. (A-REP-CO)

(51-60) CGAS, $\& /$ therm. The current cost of natural gas. (C-GAS)

(61-70) CoIL, \&/gal. The current cost of fuel oil. (C-OIL)

(71-80) CELECT, \&/kwh. The current cost of electricity. (C-ELECT)

CARD 35, format (8F10.4)

Columns (1-10) BGAS, therms. Base case gas use. (B-GAS)

(11-20) BoIL, gal. Base case oil use. (B-OIL)

(21-30) BELECT, kwh. Base case electricity use. (B-ELECT)

(31-40) GNF, \& per year (i.e. 7.0 for seven per cent) The general inflation rate during the time of the study.

(4l-50) DNF(1), \& per year (as above) The differential rate of price inflation for natural gas; that is, the amount above the general rate of inflation.

(51-60) DNF(2), \& per year (as above) ... for fuel oil

(61-70) DNF(3), \& per year (as above) ... for electricity

(71-80) DSCR, \& per year (as above). The discount rate, the annual rate at which a future sum of money is discounted to its present value. (DSC-R) 
- CARD 36 , format $(6 \mathrm{~F} 10.4,4(\mathrm{I} 2,1 \mathrm{X}), \mathrm{I} 4)$

(1-10) DMAINT, $\$$. The annual maintenance differential (addition or reduction of annual maintenance costs)

(11-20) FTYPE, fuel type: 1 = natural gas, 2 = fuel oil, 3 = electricity

(21-30) FEF, 8, furnace efficiency (F-EF)

(31-40) EER, BTU/watt, energy efficiency ratio

(41-50) COMPP, watts, power to drive compressor of the air-conditioner

(51-60) FANP, watts, air-conditioner fan power

(61-62) KDAYB, the day of the month on which the base run starts.

(64-65) МOB, the month $(01-12)$ of the year on which the base run starts.

(67-68) KDYNDB, the day of the month on which the base run ends.

$(70-71)$ MOENDB, the month $(01-12)$ of the year on which the base run ends.

(73-76) IYRB, the year of the base run

- $\quad \underline{\text { Card } 37}$

"END" in columns 1-3. Without this END card program assumes INPUT DECK error and aborts.

\section{OUTPUT}

Typically, output from a run of Twozone consists of the following:

1 Summary of INPUT data

2 Sample hourly response of TWOzONE house (optional, see INPUT DECK)

A. Hourly Data for the first four days of each month

B. Hourly printer plots of above data

3 Loads curve (optional, see INPUT DECK)

4 Summary of loads for whole run.

5 Economic Analysis

6 Short summary of INPUT 


\subsection{Summary of INPUT DATA}

The INPUT DECK is first echoed exactly as it was read in. A summary of the INPUT variables is then printed out along with a table of the transfer function coefficients and the resulting U-values for the walls and roofs, (see sample OUTPUT) .

\subsection{Response of TWO-ZONE house}

A. Detailed hourly data is given for the first four days of each month of the run, (see sample OUTPUT) .

The table headings are:

MONTH

DAY

ZST - hour of the day

QDX (KBTUH) - rate of heat gain (loss) in KBTUH for each hour

QTOTAL(THERMS) - cumulative heat energy provided by furnance

ACTOTAL(THERMS) - cumulative cooling energy provided by AC

ECTOTAL(KWH) - cumulative cooling energy required by evaporative cooler.

TOUT - temperature outside $\left(O_{F}\right)$

TBAR - average temperature in house $\left({ }^{\circ}\right)$

TSOUTH - temperature in $S$ zone of twozone house $\left({ }^{\circ} \mathrm{F}\right)$

TNORTH - temperature in $\mathbf{N}$ zone of twozone house $\left({ }^{\circ} \mathrm{F}\right)$

SHG $(s)$ south
SHG (w)west SHG(n)north $\left\{\begin{array}{l}\text { solar heat transmitted through the } \\ \text { fenestration on each of the } 4 \text { house } \\ \text { faces, BTUH/sq.ft. (independent } \\ \text { of window area) }\end{array}\right.$


In addition, symbols are printed by the DAY column to indicate which system in the house was operating that hour.

$$
\begin{aligned}
& \$=\text { heater on } \\
& +=\text { house venting } \\
& *=\text { air conditioner or evaporative cooler on } \\
& * *=\text { air conditioner or evaporative cooler on but overloaded }
\end{aligned}
$$

If no symbol is printed, the house temperature is floating.

B. Data for the first four days of each month of the test period is plotted on a graph if IFLAG5 $=1$ in the INPUT DECK. The comment cards 7-11 entered in the INPUT DECK appear at the top of the graph, (see sample OUTPUT) .

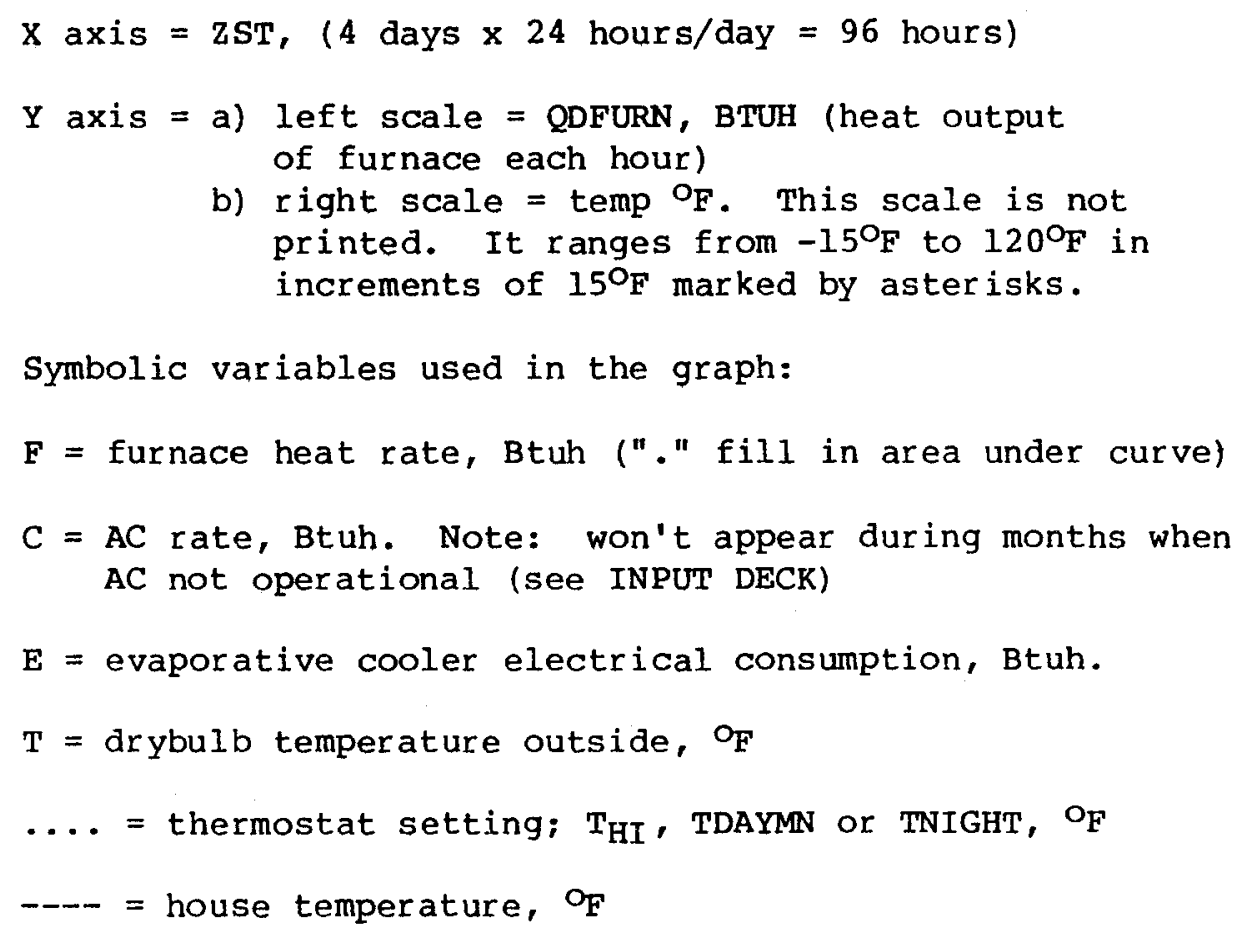

\subsection{Load Curves}

If IFLAG6 $=1$ in INPUT DECK, twenty-four hour load curves averaged for each month will be generated, (see sample OUTPUT).

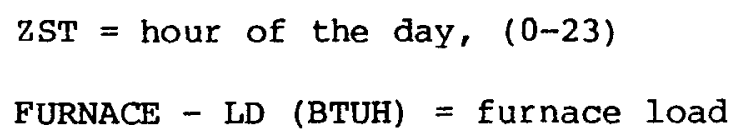




$$
\begin{aligned}
& \text { AC - LOAD (BTUH) }=\text { air-conditioner load } \\
& \text { EC - LOAD }(\mathrm{KWH})=\text { electrical consumption of evaporative cooler }
\end{aligned}
$$

Total heat delivered by furnace, extracted by the air conditioner, and KWH used by the evaporative cooler, for the whole month are printed on the bottom line. Response of TWOZONE house and the Load curves are repeated for each month, or portion thereof, for the entire length of the run period.

\subsection{Summary for the entire run (See sample OUTPUT)}

1. Total heat (therms) delivered to the house.

2. Net gains (or losses), (BTUH) during furnace operation apportioned into windows, walls, roof, floor, infiltration and internal loads. (Negative values indicate losses from building.)

3. Apportioning of furnace load (BTUH) to windows, walls, roof, floor and infiltration.

4. Hours and amount of useful solar heat gain through windows. 5. Solar heat gain (BTUH) through windows of $S, W, N$ and $E$ sides respectively.

6. The inefficiency of the house, $K$, is defined to be the total heat per sq. ft. delivered over the test period/degree days in that

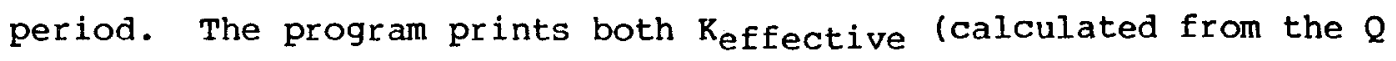
total computed above) and $\mathrm{K}_{\text {theory }}$ (calculated using the $\mathrm{U}$-values of the building envelope).

7. Heating season comfort chart, temperature vs. hour of day. 8. The same information as above is given separately for air conditioning and evaporative cooling. In addition, there is a chart of temperature vs. relative humidity for the hours during which cooling was used. 
9. Sizing charts for air conditioning and evaporative cooling.

10. The comfort chart for the full period of the run is printed.

Sections of output are printed only if they contain non-zero data.

For example, if the evaporative cooler did not operate, then no evaporative cooler information is printed.

5.5 Economic Analysis

If IFLAGll is set different from 0 in the input deck, economic analysis of the run is printed (see sample OUTPUT) .

First the physical and economic data used in the analysis are printed. Using these, life cycle cost comparisons and other useful economic parameters (such as: Btu's saved per discounted dollar etc.) are calculated according to DOE guidelines and printed.

5.6 Short Summary of Input

The comment section from the INPUT deck is repeated, followed by a compact summary of INPUT for the given run. 
6. SAMPLE OUTPUT

(Sample OUTPUT) 6.1. Summary of input data. See Section 5.1 (pg. 18) .

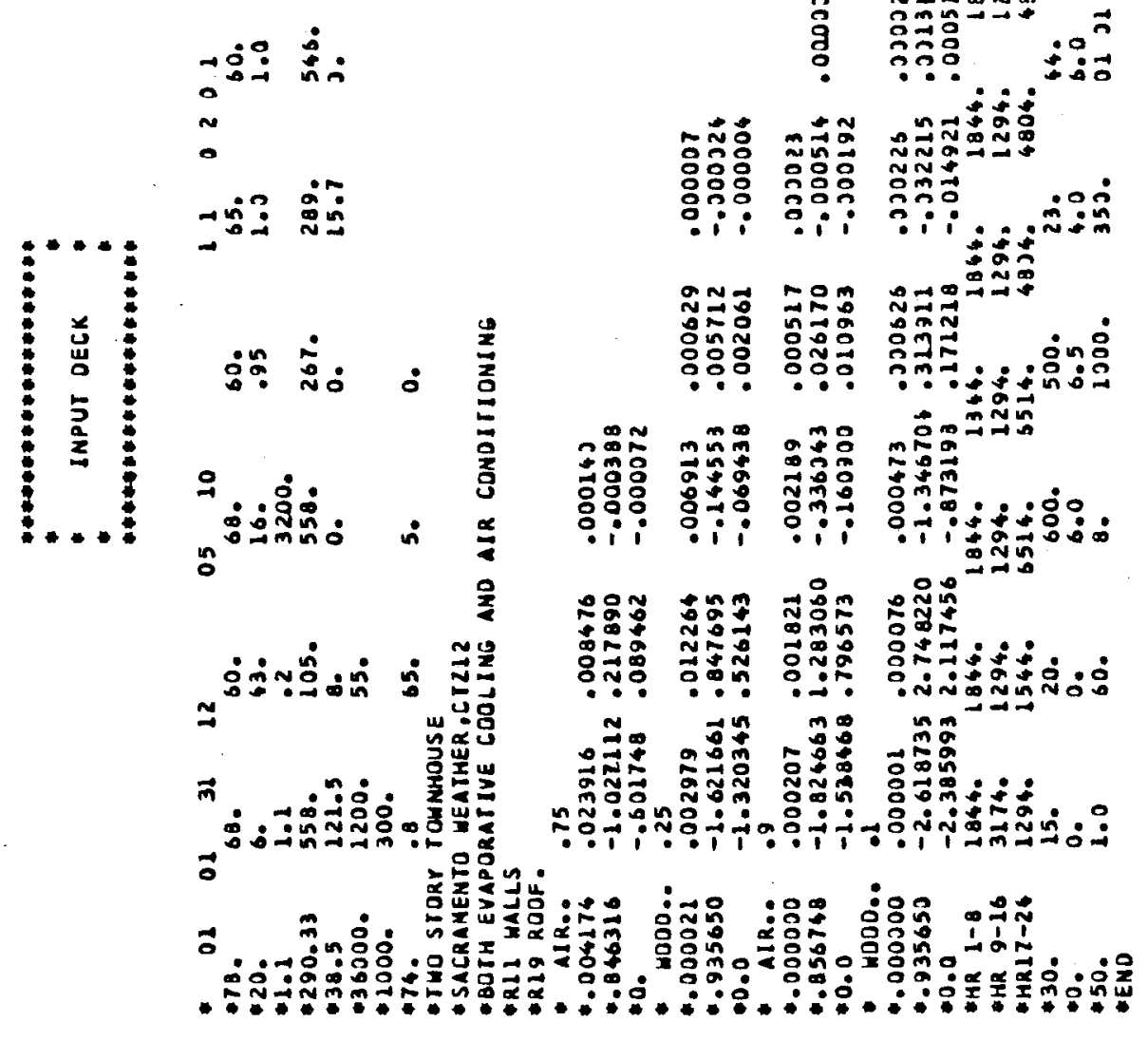

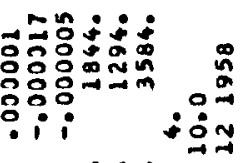

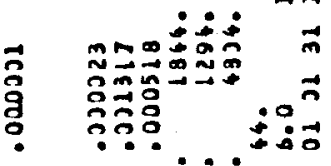


AC STARTS IN MONTH 5 AC ENOS IN MONTH 10

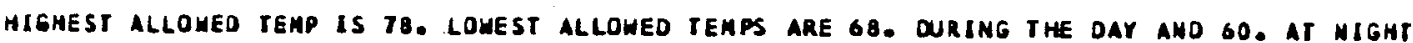
ON HOLIDAYS IHE THERMOSTAI SETTINGS ARE 68. FOR DAY ANO 60. FOR NIGHT.

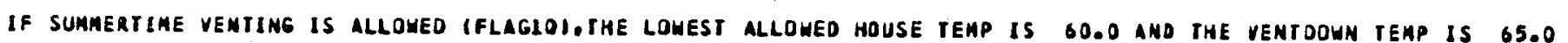
THE heAT CAPACITY DF THE hOUSE IS = 3200. (BTU/F)

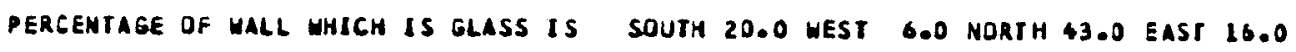
u-VAlues for glass are daY l.1 hight 1.1

WALL IREAS ARE S,WON,E,ROOF HALVES,FLODR 290. 558. 105. 558. 267. 289. 546. UFLOOR IS .2

lat,long, time lome are 39. 122. 8.

SHADIMG COEFF.- $\quad .950$ GLASS TYPE

L. GLAZE 1.

WALL AND ROOF ALIMUTHS ARE,SHNES6, 0. 90. 180. 270. 0.180.

ROOFIILIS FROM HORIZONTAL ARE, 16. O.

otus alR CONDITIONING= 36000.0, CFME 1200.0 TCOLL= 55.0

1 SPEEO COOLER FAN VOLUMES ANo ELECTRICAL REQTS ARE 1000. CFA AND 300. matrS

THE EVAP COOLER TURNS ON AT 78.0 AND OFF AT 74.0 DEGREES F.

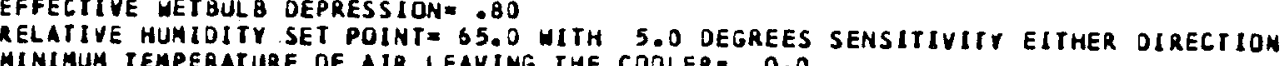
MiNIMUM temperature of AIR LEAVING THE COOLER= 0.0 
(Sample OUTPUT) 6.1 (Continued) .

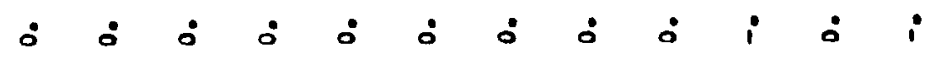

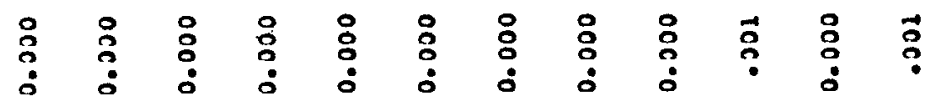

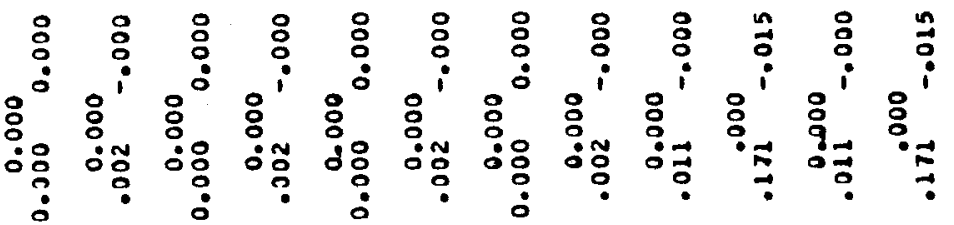

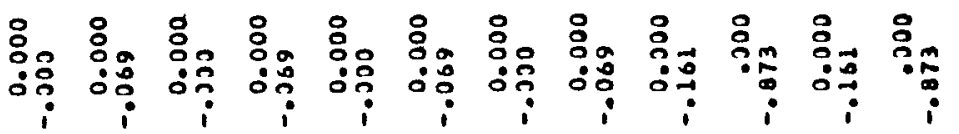

罚

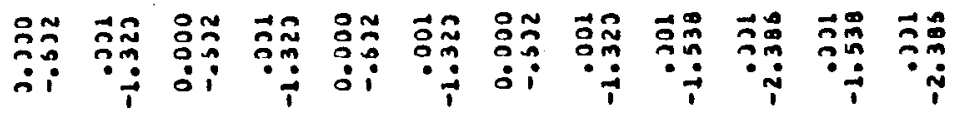

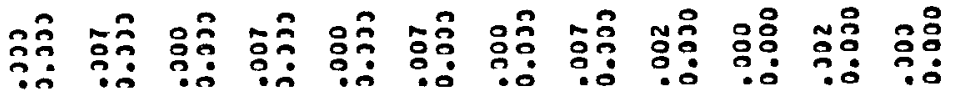

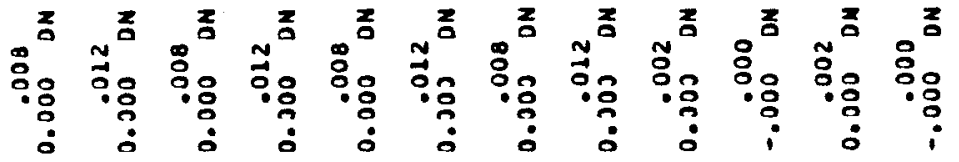

颉

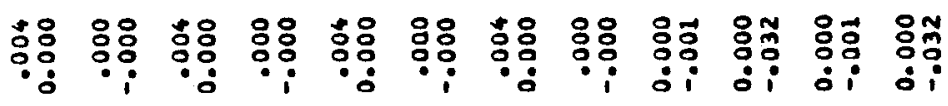

重

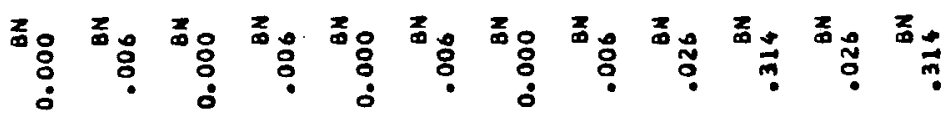

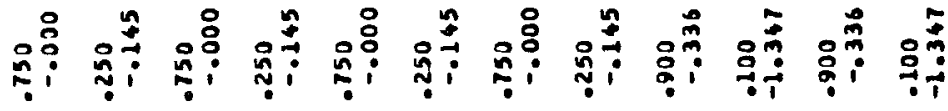

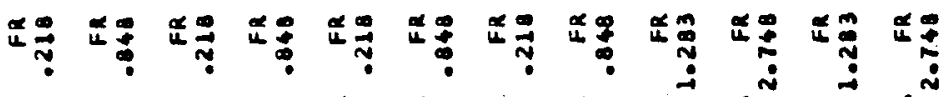

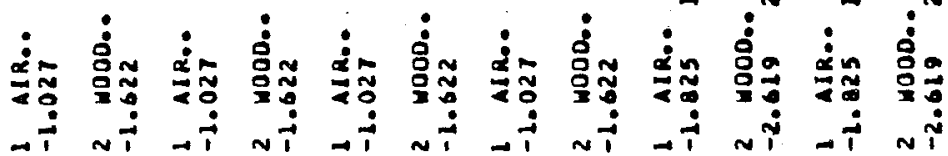

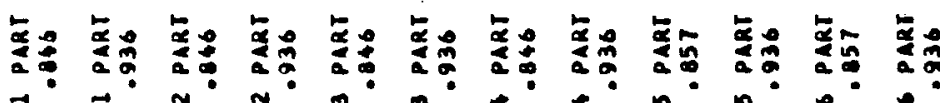

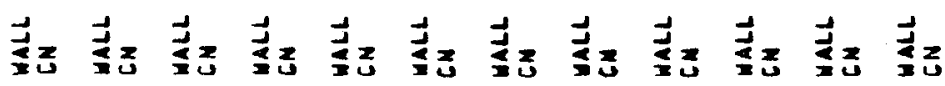


(Sample OUTPUT) 6.2A. Hourly data for the first four days of July. Refer to Section 5.2A (pg. 18) for explanations.

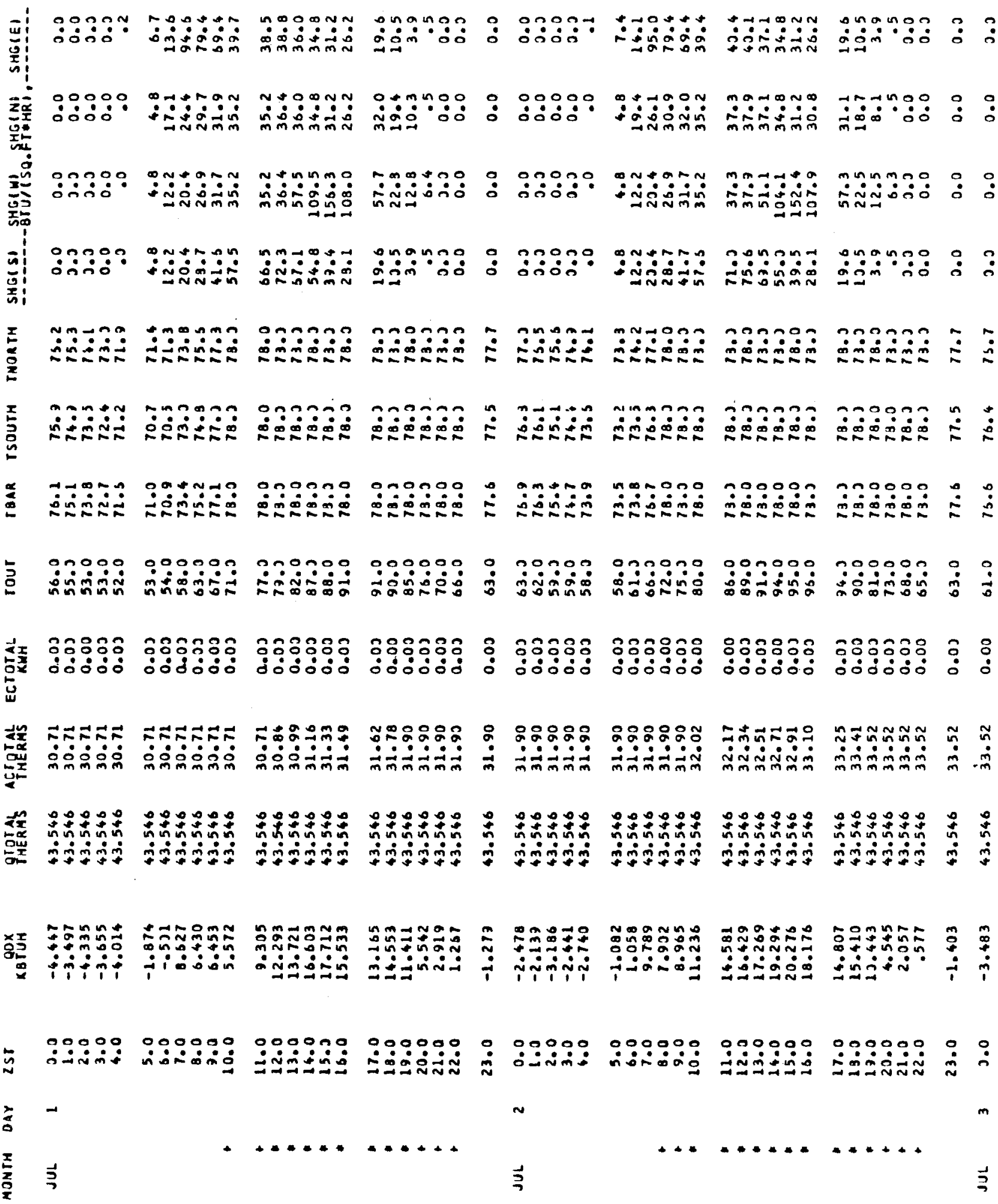




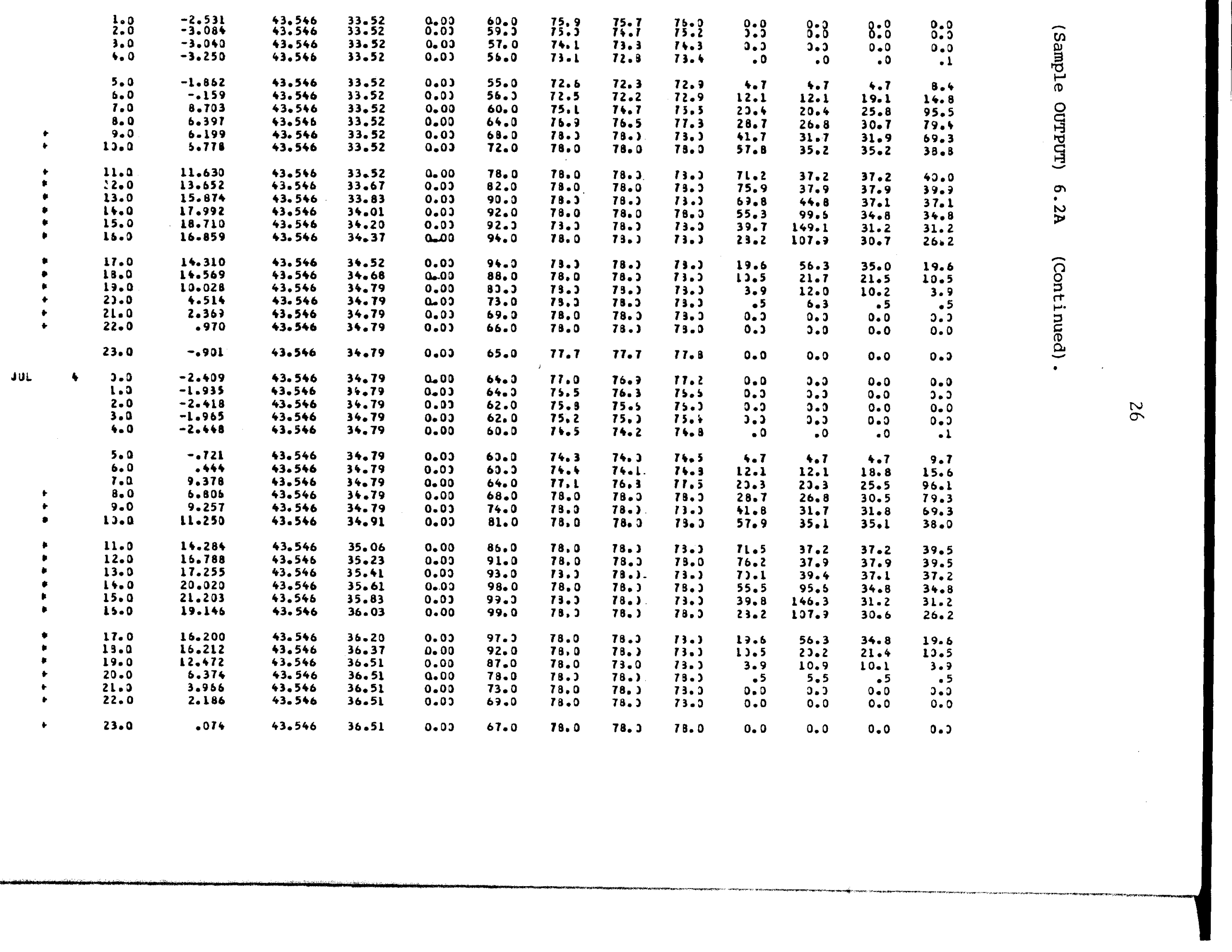


(Sample OUTPUT) 6.2B. Hourly printer plot of data in Section 6.2A. Refer to Section 5.2B (pg. 19) for explanations.

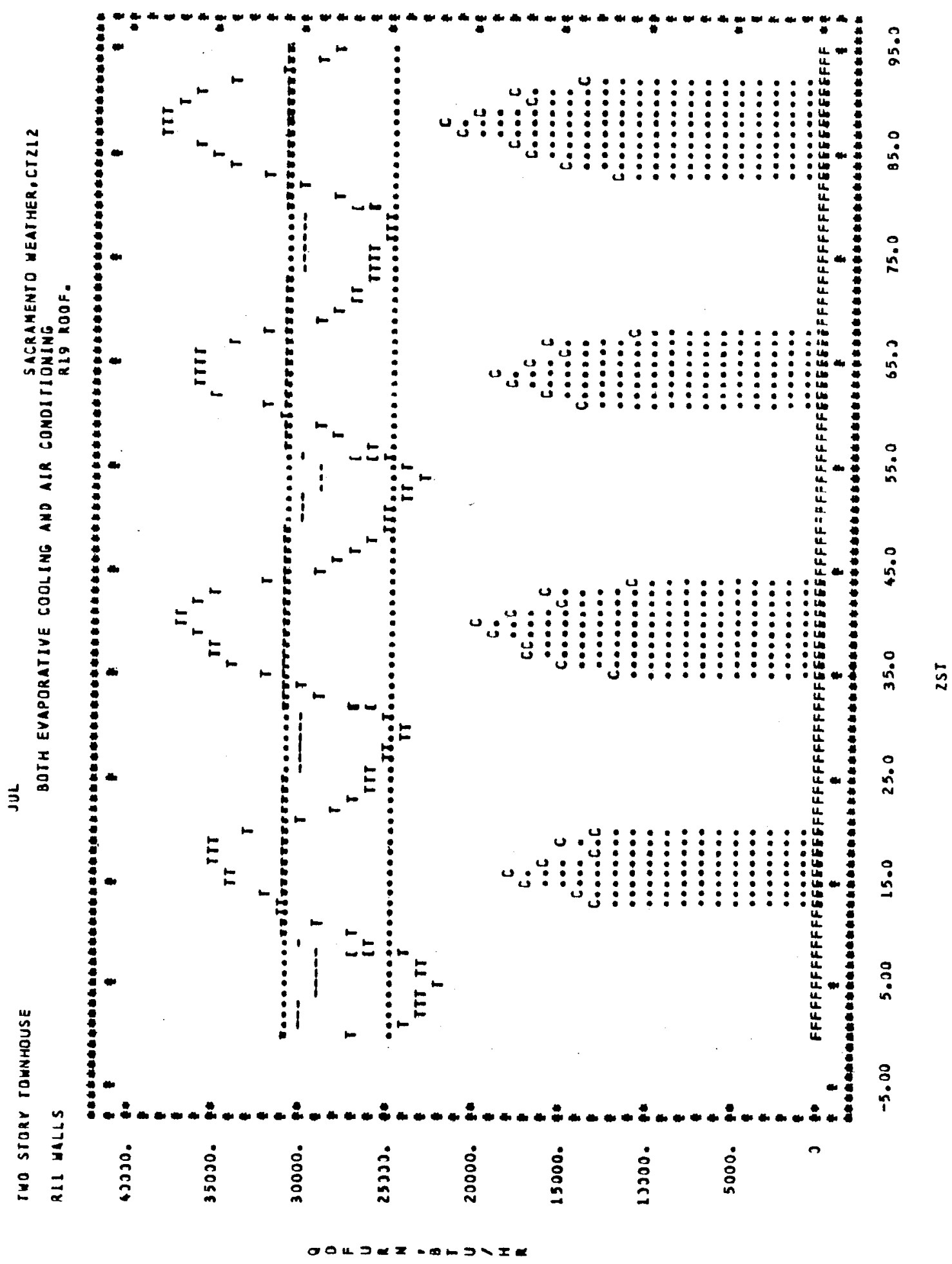


(Sample OUTPUT) 6.3. Load curves for the month of July. Refer to Section 5.3 (pg. 19) for details.

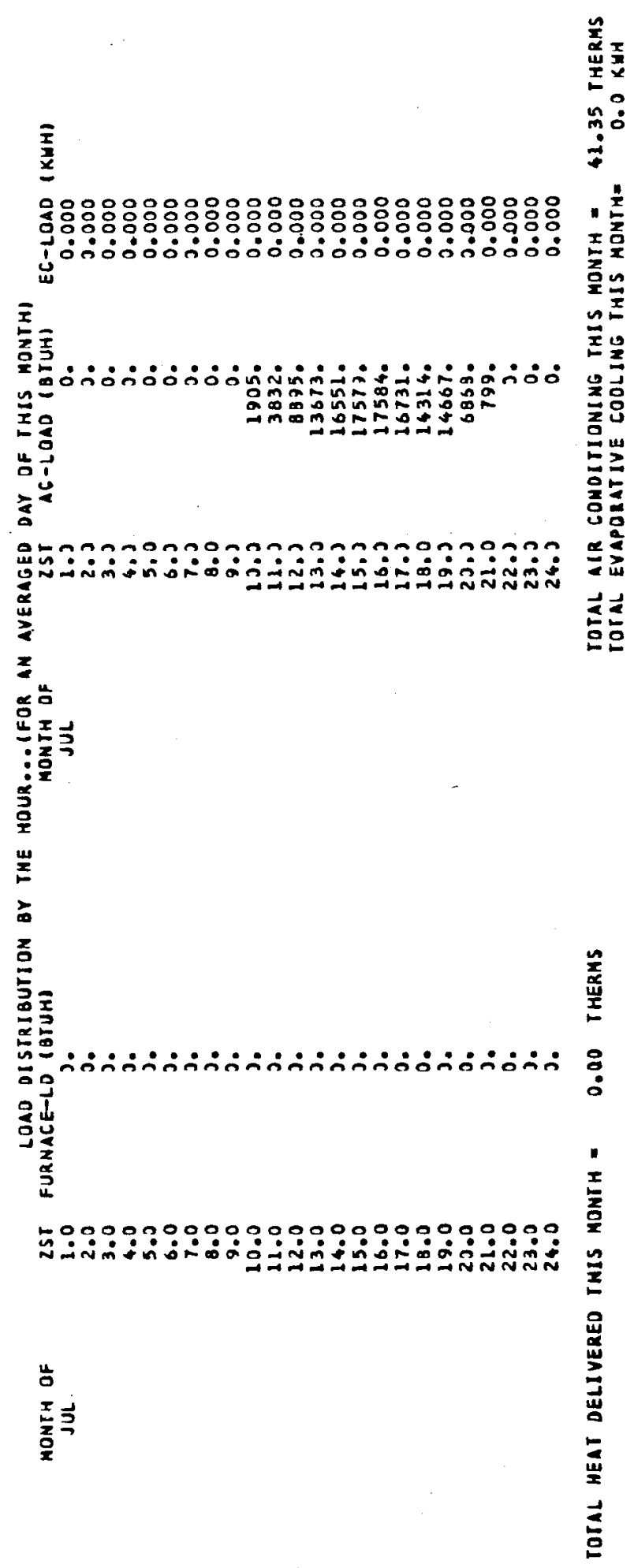




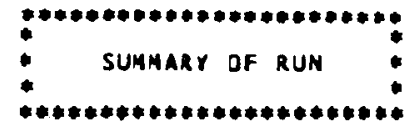

*a*HFURMAGE DPERATIOM****

TOTAL heAT DELIVERED to hOUSE= 71.6 IHERMS (ROUGHLY TWO-THIROS OF FUEL CONSUMED)

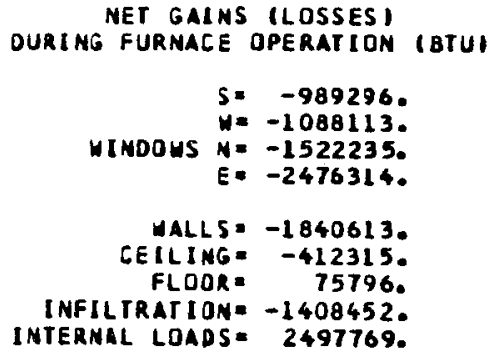

HOURS OF MET HIMDOW GAIN IHEATING SEASONI= 1384

DIRECTIONAL SOLAR HEAT GAIM SUAS IBTUI PER SQUARE

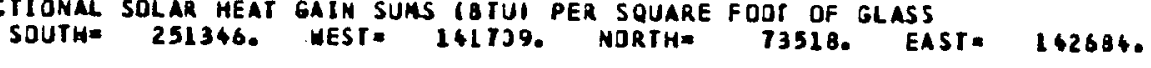

THE EFFECTIVE $K$ VALUE of THE hOUSE= 2.842 B TU/DDAY/SQ FT THE THEORETICAL $K$ YALUE IS 25.034 BTU/ODAY/SO FI

2033.2 DEGREE DAYS $3332.0 \times 24$ DEGREE HOURS FOR PERIOD

HEATING SEASON COMFORT CHART

TEMPERATURE YS. HOUR OR

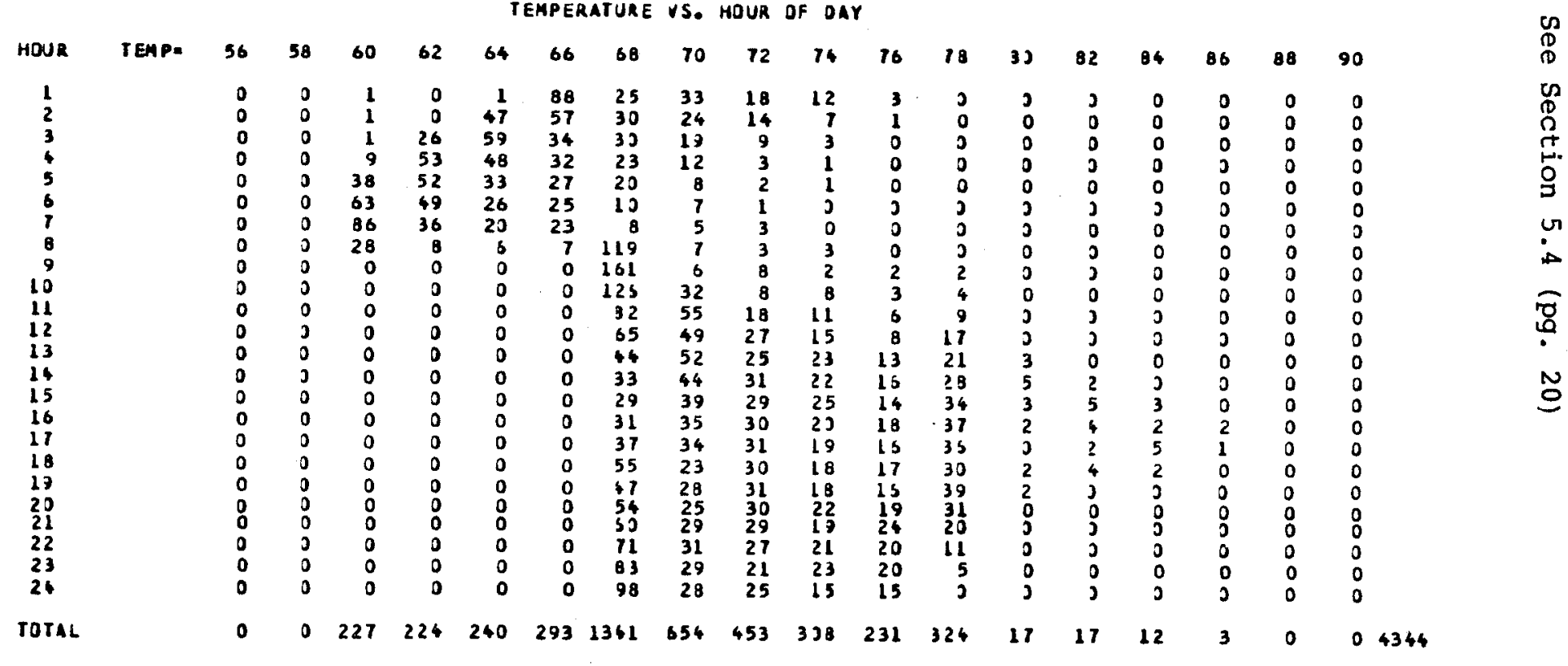


TOTAL AIR CONOITIONER LOADE 117.6 IHERKS, OF WHCH 2.9 THERMS IS LATENT TOTAL SENSIBLE BUILOING LOAD FOR COOLING= 114.9 THERMS

TO CALCULATE KHH OF ELECTRICTY CONSUMED, MULTIPLY THE AIR CONOITIONER LOAO OY 100 and DIVIDE BY THE ENERGY EFFICIENCY RATIO IEER). THE EER VARIES WITH THE AC UNIT USED. A IYPICAL VALUE IS ABOUT 6 (1976) NET SENSIBLE GAINS (LOSSESI
DURING AIR CONOITIONER OPERATION (BTU) APPORTIONING OF TOTAL AIR CONDITIONER LOAD (BTU)

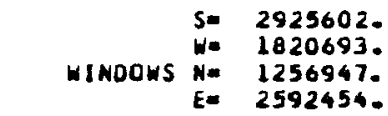

$\begin{array}{rr}\text { WALLSE } & \text { E50766. } \\ \text { CEILINGE } & 366316 . \\ \text { FLOOR= } & -132888 . \\ \text { INFILTRAIION= } & 438698 . \\ \text { INTERMAL LOAOSE } & 1533629 .\end{array}$

.

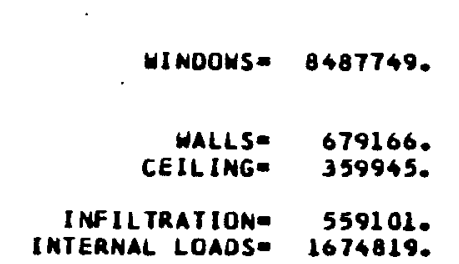

MOTE APPORTIONING IS DONE ONLY HHEN THE hOURLY SUA OF THE ABOVE TERHS IS POSITIVE.

NUMAER OF HOURS OURING WHICH THE AIR CONOITIONER TURNEO ON AT LEAST ONCE= 753
THE ALR CONOITLONER RAN A TOTAL OF 418.5 HOURS, DURING WHICH THE COMPRESSOR RAN 326.7 HOURS

\begin{abstract}
49.1 COOLING oegree days, $375.0 \times 24$ COOLING degree hours (Base temperature - 7afi
\end{abstract}
tAIR CONDITIONING HOURS +

IEMPERATURE VS. RELATIVE HUHIOITY

\begin{tabular}{|c|c|c|c|c|c|c|c|c|c|c|c|c|}
\hline IEAP & $\mathrm{RH}=$ & $0-10$ & $10-20$ & $20-30$ & $30-40$ & $40-50$ & $50-60$ & $60-70$ & $70-80$ & $80-90$ & $90-100$ & TOTAL \\
\hline $\begin{array}{l}60 . \\
62 . \\
64 . \\
66 . \\
68 . \\
70 . \\
72 . \\
74 . \\
76 . \\
78 . \\
80 . \\
82 . \\
84 . \\
86 . \\
88 . \\
90 .\end{array}$ & & $\begin{array}{l}0 \\
0 \\
c \\
0 \\
0 \\
0 \\
0 \\
c \\
0 \\
0 \\
0 \\
0 \\
0 \\
0 \\
0 \\
0\end{array}$ & $\begin{array}{l}0 \\
0 \\
0 \\
0 \\
c \\
c \\
0 \\
c \\
0 \\
0 \\
c \\
0 \\
c \\
0 \\
0 \\
0\end{array}$ & $\begin{array}{l}0 \\
0 \\
0 \\
0 \\
0 \\
0 \\
0 \\
0 \\
0 \\
4 \\
0 \\
0 \\
0 \\
0 \\
0 \\
0\end{array}$ & $\begin{array}{l}0 \\
0 \\
0 \\
0 \\
0 \\
0 \\
0 \\
0 \\
0 \\
1 \\
0 \\
0 \\
0 \\
0 \\
0 \\
0\end{array}$ & $\begin{array}{r}0 \\
0 \\
0 \\
0 \\
0 \\
0 \\
0 \\
0 \\
0 \\
742 \\
0 \\
0 \\
0 \\
0 \\
0 \\
0\end{array}$ & $\begin{array}{l}0 \\
0 \\
0 \\
0 \\
0 \\
0 \\
0 \\
0 \\
0 \\
0 \\
0 \\
0 \\
0 \\
0 \\
0 \\
0\end{array}$ & $\begin{array}{l}0 \\
0 \\
0 \\
0 \\
0 \\
0 \\
0 \\
0 \\
0 \\
0 \\
0 \\
0 \\
0 \\
0 \\
0 \\
0\end{array}$ & $\begin{array}{l}0 \\
0 \\
0 \\
0 \\
0 \\
0 \\
0 \\
0 \\
0 \\
0 \\
0 \\
0 \\
0 \\
0 \\
0 \\
0\end{array}$ & $\begin{array}{l}0 \\
0 \\
0 \\
0 \\
0 \\
0 \\
0 \\
0 \\
0 \\
0 \\
0 \\
0 \\
0 \\
0 \\
0 \\
0\end{array}$ & $\begin{array}{l}0 \\
0 \\
0 \\
0 \\
0 \\
0 \\
0 \\
0 \\
0 \\
0 \\
0 \\
0 \\
0 \\
0 \\
0 \\
0\end{array}$ & $\begin{array}{r}0 \\
0 \\
0 \\
0 \\
0 \\
0 \\
0 \\
0 \\
0 \\
753 \\
0 \\
0 \\
0 \\
0 \\
0 \\
0\end{array}$ \\
\hline TOTAL & & 0 & 0 & 4 & 7 & 742 & 0 & 0 & 0 & 0 & 0 & 753 \\
\hline
\end{tabular}


- Evaporative COOLER+*

TOTAL ENERGY USED IN EVAPORATIVE COOLING=

$61.4 \mathrm{KHH}$

TOTAL GATER USED IN COOLER=

NET TOTAL BUILOING LOAD FOA COOLING 2147185 . BT

NET GAINS (LOSSES)

APPORTIONING OF

DUR ING EVAPORATIVE COOLER OPERATION (BTUI

EVAPORATIVE COOLER LOAD (KHH)

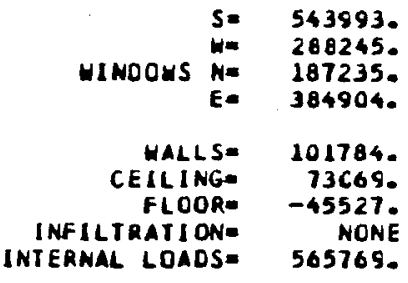

$\begin{array}{rr}\text { WINDOWS= } & 38 . \\ \text { WALLS= } & 3 . \\ \text { CEILIMG: } & 2 . \\ \text { IMFILTRATION= } & \text { NONE } \\ \text { INTERNAL LOADSE } & 18 .\end{array}$

NOTE APPORTIONING IS DONE ONLY WHEN THE

HOURLY SUA OF THE ABOVE TERAS IS POSITIVE.

- Evaporative cooling hours.

TEMPERATLRE VS. RELATIVE HUMIDITY

\begin{tabular}{|c|c|c|c|c|c|c|c|c|c|c|c|c|}
\hline TEMP & $R H=$ & $0-10$ & $10-20$ & $\begin{array}{c}\text { TEMP } \\
20-30\end{array}$ & $\begin{array}{c}\text { ERATLRE } \\
30-40\end{array}$ & $\begin{array}{l}\text { VS. RE } \\
40-50\end{array}$ & $\begin{array}{c}\text { LATIVE } \\
\text { SO-60 }\end{array}$ & $\begin{array}{c}\text { HUMIDITY } \\
60-70\end{array}$ & ${ }^{7} 70-80$ & $80-90$ & $90-100$ & TOTAL \\
\hline $\begin{array}{l}60 . \\
62 . \\
64 . \\
66 . \\
68 . \\
70 . \\
72 . \\
74 . \\
76 . \\
78 . \\
80 . \\
82 . \\
84 . \\
86 . \\
88 . \\
90 .\end{array}$ & . & $\begin{array}{l}0 \\
0 \\
0 \\
0 \\
0 \\
0 \\
0 \\
c \\
0 \\
0 \\
0 \\
0 \\
c \\
0 \\
0 \\
0\end{array}$ & $\begin{array}{l}0 \\
0 \\
c \\
0 \\
c \\
0 \\
0 \\
0 \\
0 \\
0 \\
0 \\
0 \\
c \\
0 \\
0 \\
0\end{array}$ & $\begin{array}{l}0 \\
0 \\
0 \\
0 \\
0 \\
0 \\
0 \\
0 \\
0 \\
0 \\
0 \\
0 \\
0 \\
0 \\
0 \\
0\end{array}$ & $\begin{array}{l}0 \\
0 \\
0 \\
0 \\
0 \\
0 \\
0 \\
0 \\
1 \\
4 \\
0 \\
0 \\
0 \\
0 \\
0 \\
0\end{array}$ & $\begin{array}{r}0 \\
0 \\
0 \\
0 \\
0 \\
0 \\
0 \\
2 \\
30 \\
37 \\
0 \\
0 \\
0 \\
0 \\
0 \\
0\end{array}$ & $\begin{array}{r}0 \\
0 \\
0 \\
0 \\
0 \\
0 \\
0 \\
6 \\
46 \\
63 \\
0 \\
0 \\
0 \\
0 \\
0 \\
0\end{array}$ & $\begin{array}{r}0 \\
0 \\
0 \\
0 \\
0 \\
0 \\
0 \\
0 \\
6 \\
24 \\
0 \\
0 \\
0 \\
0 \\
0 \\
0\end{array}$ & $\begin{array}{l}0 \\
0 \\
0 \\
0 \\
0 \\
0 \\
0 \\
0 \\
0 \\
0 \\
0 \\
0 \\
0 \\
0 \\
0 \\
0\end{array}$ & $\begin{array}{l}0 \\
0 \\
0 \\
0 \\
0 \\
0 \\
0 \\
0 \\
0 \\
0 \\
0 \\
0 \\
0 \\
0 \\
0 \\
0\end{array}$ & $\begin{array}{l}0 \\
0 \\
0 \\
0 \\
0 \\
0 \\
0 \\
0 \\
0 \\
0 \\
0 \\
0 \\
0 \\
0 \\
0 \\
0\end{array}$ & $\begin{array}{r}0 \\
0 \\
0 \\
0 \\
0 \\
0 \\
0 \\
8 \\
83 \\
128 \\
0 \\
0 \\
0 \\
0 \\
0 \\
0\end{array}$ \\
\hline
\end{tabular}

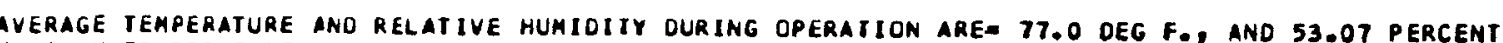
MAXIMUH TEMPERATURE AND CORRESPONDING RELATIVE HUMIOITY ARE= 78.0 OEG F.O AND 60.24 PERCENT

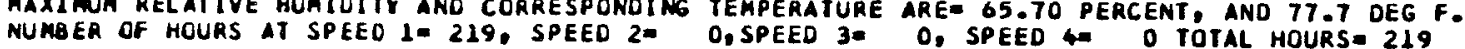

49.1 COOLING DEGREE DAYS,

$375.0 \times 24$ COQLING DEGREE HOURS (BASE TEMPERATURE $=78 F$ I

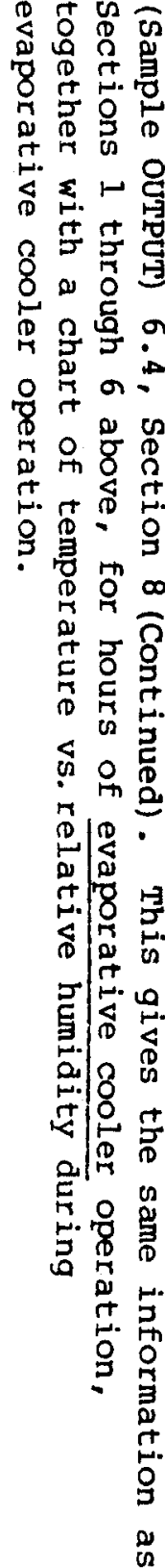


(Sample OUTPUT) 6.4, Section 9. Sizing chart for air conditioner.

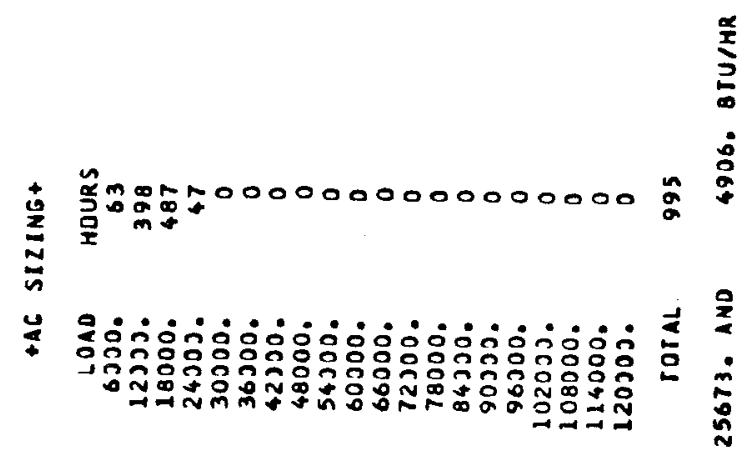

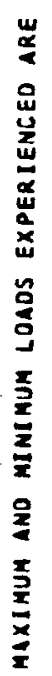




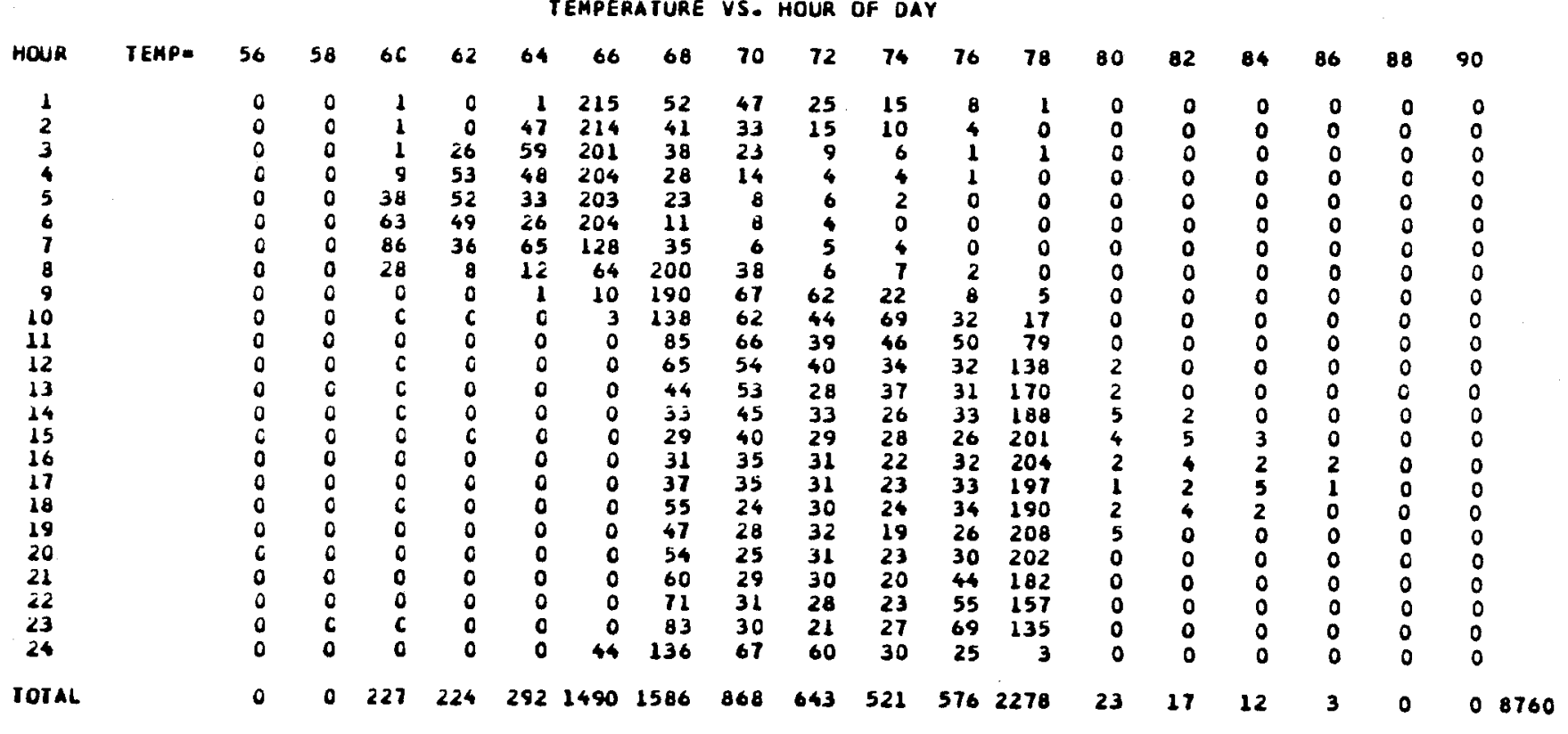




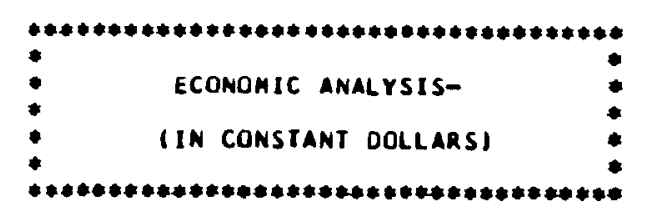

EUUIPMENT PARAMETERS

FURNACE EFFICIENCY- 60.

EER IIF GIVENI-

35.

AC COMPRESSOR POWER-1000. WATTS

AC FAN POWER-

350. watts

EC wattages- 11- $300.12-0$.

31- 0.. 41- 0.

FURAACE FUEL - NATURAL GAS.

INITIAL FUEL PRICES-

NAJ GAS- 23.0 CENTS/TH
FUEL OIL- 44.0 CENTS/GAL
ELEC-

base CASE ENERGY USE AND COST

FUEL USE- GAS- 1000.0 THERMS, FUEL OILFUEL COST- GAS- $\$ 230.00$, FUEL OLLIOTAL ENERGY USE- 108532.50 KBTU

TOTAL ENERGY COST- 330.00
THE LENGTH OF THIS RUN IS "a* DAYS.

FUEL USE- GAS- 119.40 THERMS, FUEL OLL-

$0.00 \mathrm{GAL}$, ELECTRICITYFUEL COST- GAS- \$ 27.46 , FUEL OIL- \$ 0.00 . ELECTRICITY- \$ 15.90

398. KWH TOTAL ENERGY USE- $13296.46 \mathrm{KBTU}$

\section{TOTAL COST- 43.36}

COOLING SYSTEM ENERGY REQUIREMENT- 1356.84 KBTU

COOLING SYSTEM FUEL COST- \$ 15.90

HEATING SYSTEM ENERGY REQUIREMENT-11939.62 KBTU

HEATING SYSTEM FUEL COST- 27.46

D.GAL, ELECTRICITY- $2500.0 \mathrm{KHH}$

0.00 ELECTRICITY $\$ 100.00$ 


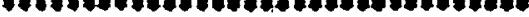 \\ - Life crcle cost comparlsons

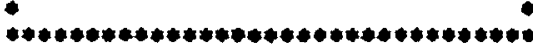

ECONOMIC PARAMETERS-

YEARS UNTIL MAJOR REPLACEAENT IN BASE CASE- 15.0YRS.

LIFEIJME OF REPLACEMENT 30.0 YRS.

COST OF REPLACEMENT- 600.00

LIFETIME OF CONSERYATION OPI LON- 20.0 YRS.

COST OF OPTION \$\$500.00

change in ameual maintenance from base case- 50.00

GENERML RATE OF PRICE INFLATIOH-

DIFFERENTIAL PRICE INFLATION (NATURAL GAS)-

DIFFERENTLAL PRICE INFLATION (FUEL OIL

DIFFERENTIAL PRICE INFLATION GELECIRICIITY-

DISCOUNT RATE-
6. PER CENT

7. PER CENT

4. PER CEnt

6. PER cent

o. PER CENT

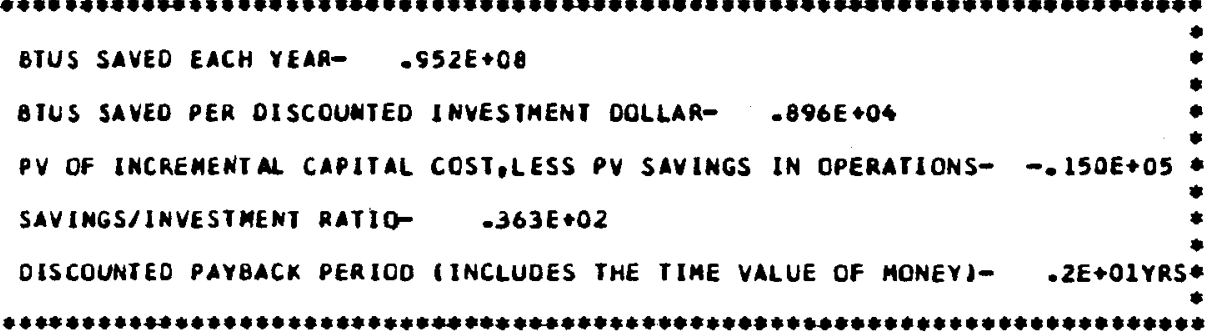


(Sample OUTPUT) 6.5 (Continued). Economic data are printed like this if the base-case fuel uses are set equal to zero in the input deck. (See the description of subroutine ECON, pg.77.)

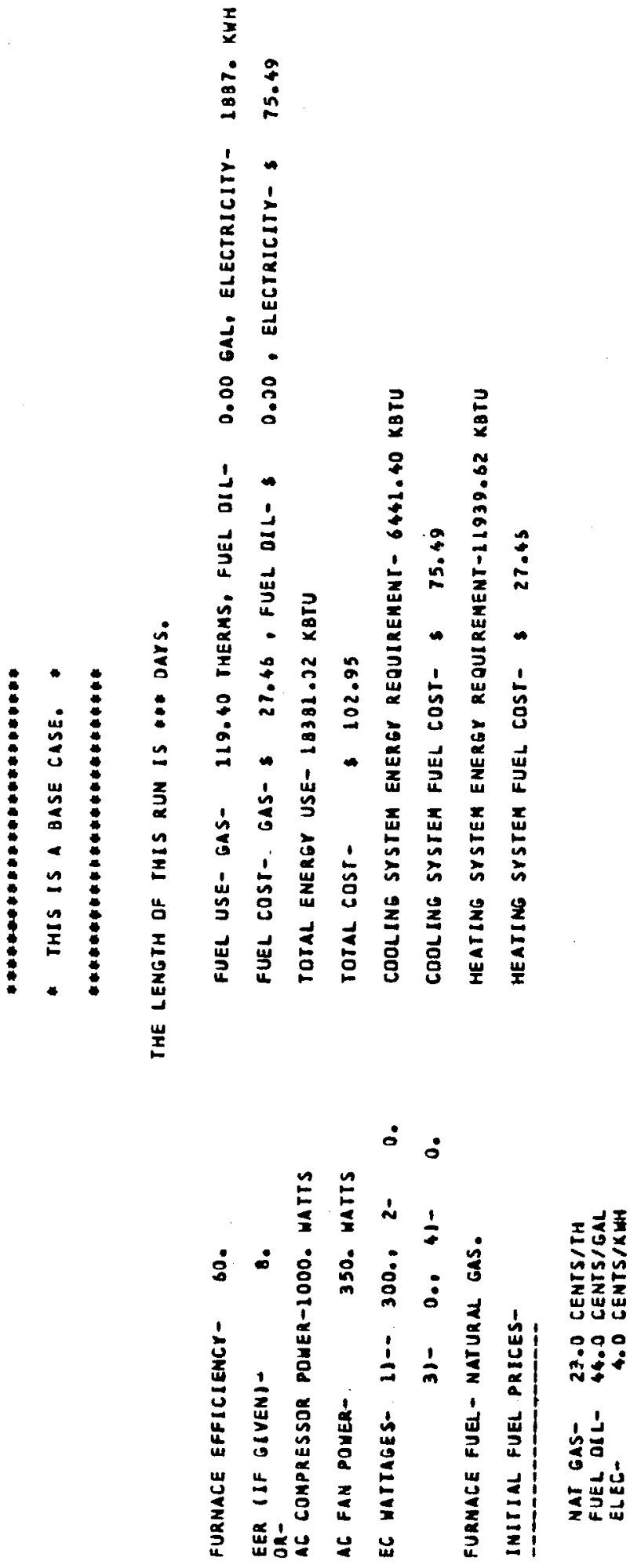


TWO STOAY TOMNOUSE

\section{SACRAMENTO HEATHER,CTZ12}

BOTH EVAPORATIVE COOLING ANO AIR CONOITIONING

RLI HALLS

A19 ROOF.

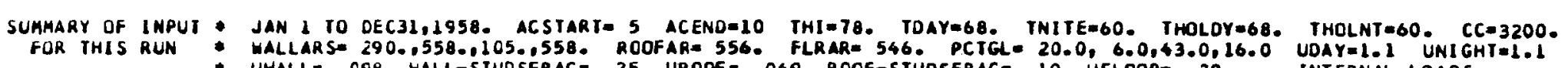

- UHALL= .098 HALL-STUDSFRAC= .25 UROOF= .049 ROOF-STUDSFRAC= .10 UFLOORE .20. INTERNAL LOADS.

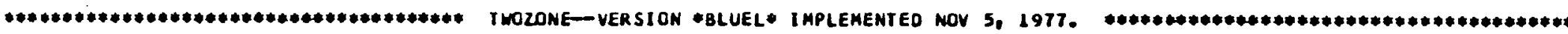

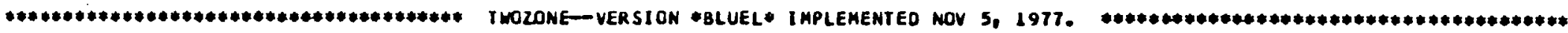




\section{DICTIONARY OF VARIABLES FOR THE MAIN PROGRAM TWOZONE}

$$
\text { 'A' }
$$

A

AA

ACAPAC

ACDD

$\mathrm{ACDH}$

ACEND

ACS IZE

ACSTART

ACTOTAL

AG (1)

AG (2)

AG (3)

$\mathrm{AG}(4)$

ALAT

ALOAD (NHR)

ARFLOR

ARGLAS

AZW
$=$ natural convection component of infiltration, insures that at windspeed $=0$, airchange is $1 / 4$ of house volume per hour and at windspeed $=10 \mathrm{mph}$, airchange is $3 / 4$ of house volume per hour.

= heat gains to the house, Btuh

= air conditioner capacity, Btuh

= cooling degree-day sum (temporary for ACDGDY)

= cooling degree-hour sum (temporary for ACDGHR)

= month in which cooling ends (user supplied data)

= storage array for air conditioner sizing

= month in which cooling starts (user supplied data)

$=$ total air conditioner load

= glass on south face of house--SqFt

= " " west " " "

$=$ " north " " " "

$=$ " $\quad$ east " " "

$=$ latent infiltration constant

= cumulative hourly air conditioning load, for month, KBTU, used to generate load curve

= floor area, SqFt., (user supplied data)

= Total glass area of walls of space house, SQFT

$=A G(1)+A G(2)+A G(3)+A G(4)$

= wall azimuth (user supplied data) 
B

BB

BBCC

BED

BLAT

$\mathrm{BN}(\mathrm{L}, \mathrm{I}, \mathrm{K})$

BRKFST

BI
= constant for component of infiltration due to wind speed

= infiltration-induced heat load + steady-state convective losses at glass + floor losses + wall losses, BTUH/OF

$=\mathrm{BB} / \mathrm{CC}=$ "BB" divided by the house specific heat, in $\mathrm{HR}^{-1}$. $B B C C$ is the time constant used in the argument of the exponential function describing the floating of house mean temperature toward $\mathrm{AA} / \mathrm{BB}$

$=$ the value of ZST at which the house occupants retire for the night

= latent infiltration constant for windspeed dependence

$=$ transfer function coefficient for the particular type construction used in walls or roof; see also CN \& DN (user supplied data)

$=$ the value of ZST at which house occupants awaken to begin a day

= effective ' $R$ ' value of house, Btu/(DGDAY-Sq.Ft.) 


$$
\text { 'C' }
$$

$\mathrm{CC}$

CEE

CHRTIME

CLCPORT

CLCTOT

CLD

CLDMIN

CLDOTQ

CLECPT

CLECT

CLPORT

CLTOT

$\mathrm{CN}(L, I, K)$
= heat capacity of house, Btu $/{ }^{\circ} \mathrm{F}$, (user supplied data)

$=$ the difference between the house temperature one hour ago and the average house equilibrium temperature, ${ }^{\circ}$. "CEE" is effectively $\mathrm{T}_{\mathrm{O}}-\mathrm{T}$

= characteristic time for the house to approach equilibrium temperature.

= heat gain or loss through ceiling due to cooling operation, Btuh

= net gain (loss) through roof during air conditioner operation, Btuh

$=$ air conditioning load on the house. Can be sensible, or sensible and latent load, depending on branch, BTU

= minimum cooling load

= heat gain or loss through roof, Btuh

= ceiling apportioning for evaporative cooling

= total ceiling cooling load for evaporative cooling

= portion of furnace load due to ceiling losses, Btuh

$=$ net heat gain (loss) to house through roof, Btuh

$=$ transfer function coefficient for the construction type used in walls and roof, (user supplied data) 


\section{' $D$ '}

DD

$=$ counts deg-hrs/day

DENSITY

$=$ density of air $1 \mathrm{~b} / \mathrm{ft}^{3}$

DGDAY

= cumulative degree-days for heating, $65^{\circ} \mathrm{F}$ base

DGDAYO

= degree-day value one hour ago

DGHR

$=$ cumulative degree-hours for heating, $65^{\circ} \mathrm{F}$ base

DGHRO

= degree-hour value one hour ago

$\mathrm{DN}(\mathrm{L}, \mathrm{I}, \mathrm{K})$

= transfer function coefficient for the particular construction type used in walls or roof (user supplied data)

DRYBLB

= outside drybulb air temperature, ${ }^{\circ}$

DTIME

= fraction of hour for air conditioner load calculation 
'E'

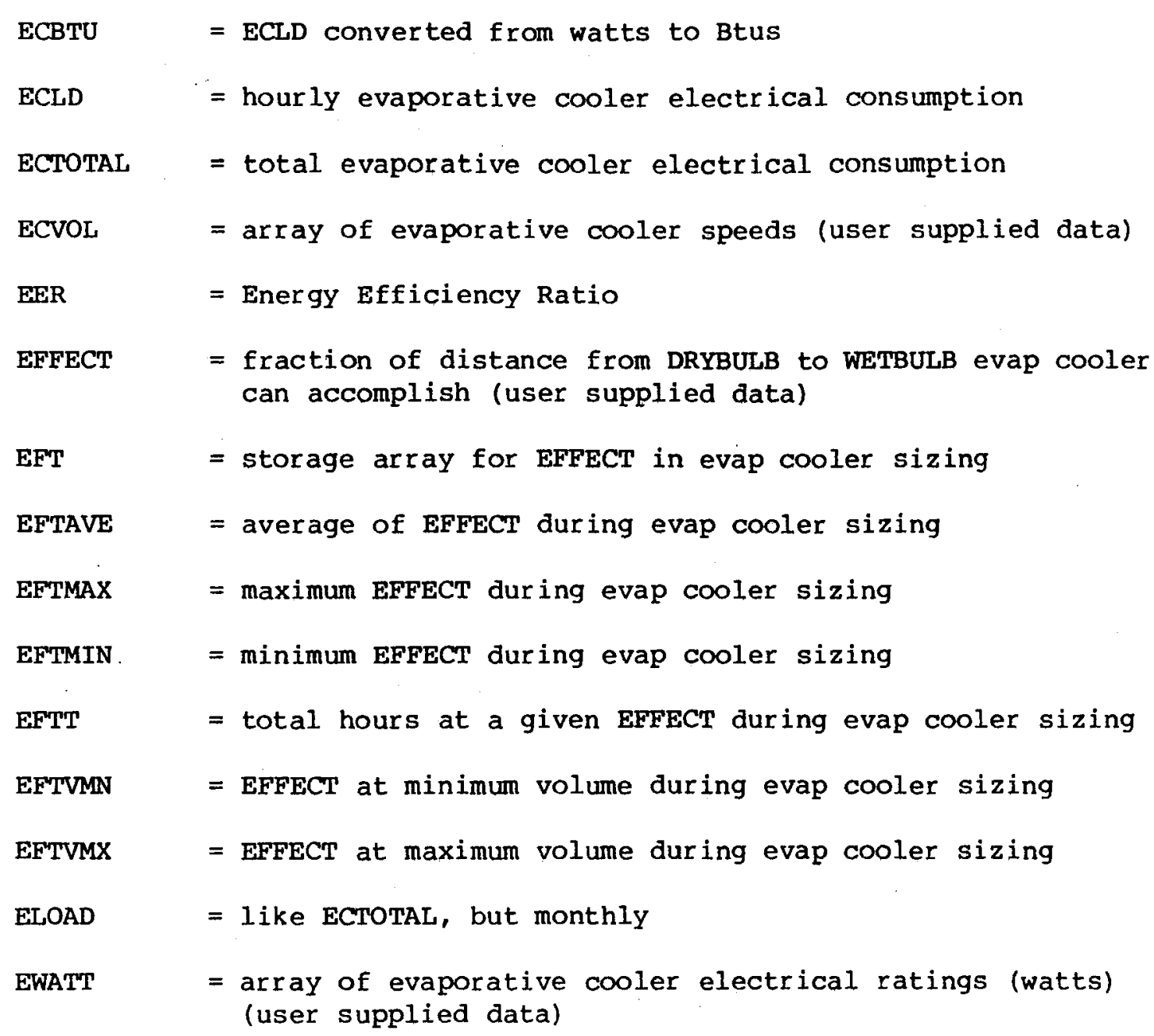




$$
\text { ' F' }
$$

F

FANVOL

FLCPRT

FLCTOT

FLECT

FLLOSS

FLOAD (NHR)

FLOWAR

FLPORT

ELTOT

FRAC

$\operatorname{FR}(I, I)$

FZCC
$=$ the difference between north and south heat inputs or losses for the following components: solar heat gain at windows + total heat transfer rate at walls less steady state conductance-area products at walls and windows. Used to calculate air-convection.

= CFM of air conditioner fan (user supplied data)

= heat loss through floor due to air conditioner operation, Btuh

= net heat gain (loss) through floor during air conditioner operation, Btuh

= total floor cooling load in evap cooling

= heat transfer rate through the floor, Btuh

= heat cumulative furnace load for month, to generate load curve, KBTU

= effective area at doors through which air flows, assuming that buoyancy currents exhibit unidirectional flow through top and bottom 2 feet of doorway only

= portion of furnace load due to floor losses, Btuh

$=$ net heat gain (loss) to house through floor, Btuh

= a scaling factor based on THI or TLOW. FRAC $=($ TTB - THI $) /($ TTB - TWBOLD $)$ for cooling and FRAC $=($ TLOW - TTB $) /($ TTBOLD-TTB $)$ for heating

fraction of wall ' $I$ ' which is constructed of component ' $L$ '.

= the equilibrium temperature which north and south halves approach; FZCC is the difference in steady state "UA" values plus $T$ times the steady state losses divided by the house specific heat. Used to calculate air-convection. 
' $G$ '

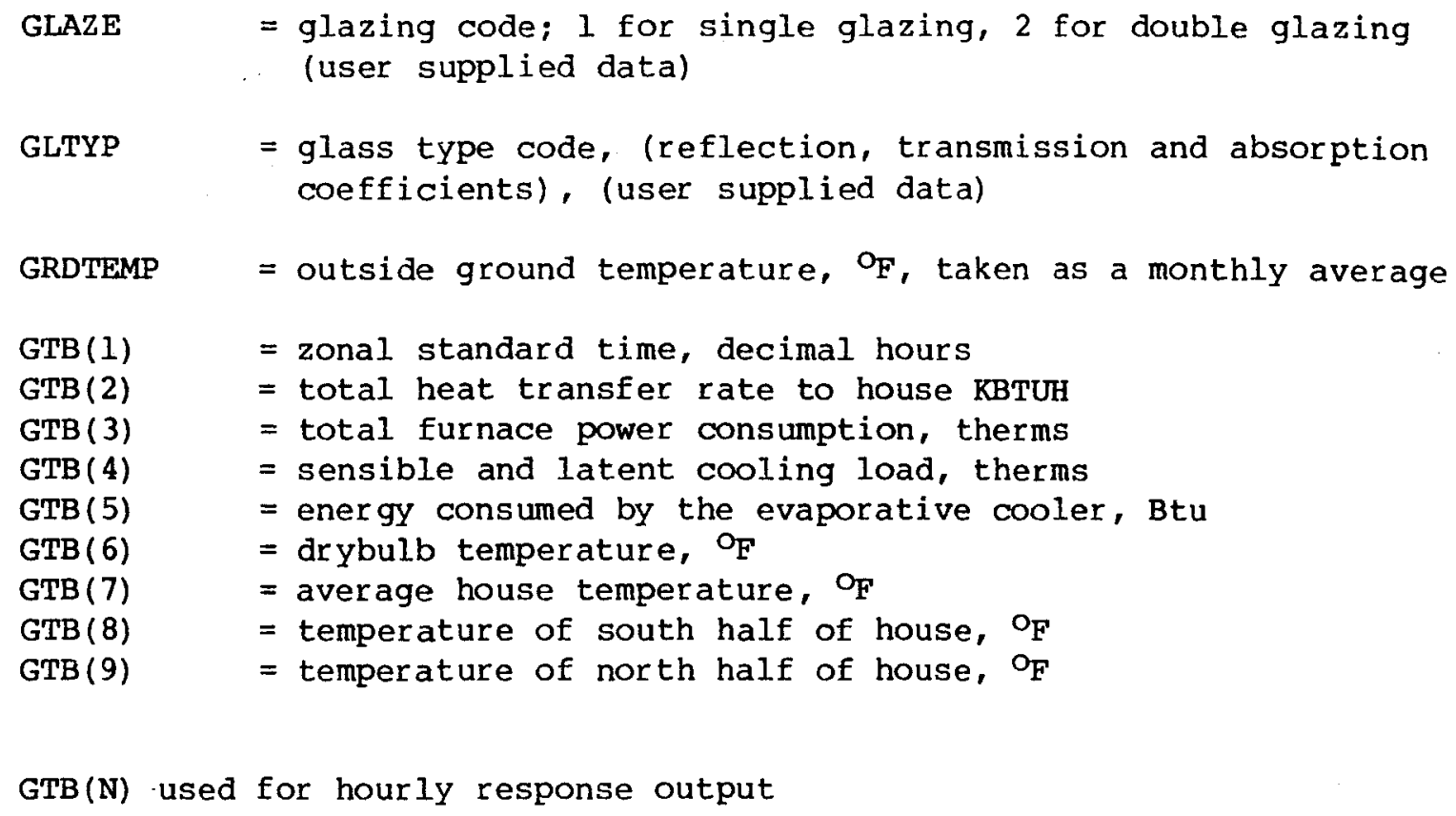


' $\mathbf{H}^{\mathbf{}}$

H

HCOIL

HEAT

$\operatorname{HGRM}(I, K)$

HGRMF $(L, I, K)$

HH

HIN

HLATNT (NHR)

HNIGHT

$=$ the energy content of moist air at TTB with a $0^{\circ} \mathrm{F}$ reference for water vapor, in Btu/lbm of dry air

= minimum exit enthalpy from air conditioner

= hourly furnace power consumption, Btu

= heat gain to room per unit wall area, Btuh/SqFt, where $I=1-5$ is the wall locator subscript, and $K=1-8$ is the backward time step index for calculation of temperatures and heat transfer rates using transfer function method

= fraction of heat gain to room per unit wall area from $L^{\text {th }}$ component, where $L=1$ means air and $L=2$ means studs

= convective heat transfer rate per unit wall area, Btuh/SqFt, used to initialize heat transfer calculations

= enthalpy of the air drawn into the cooling unit, Btu/lbm

= hourly latent cooling load generated in the house, Btuh

= cumulative power consumption of the furnace between midnight and $0800 \mathrm{HRS}$

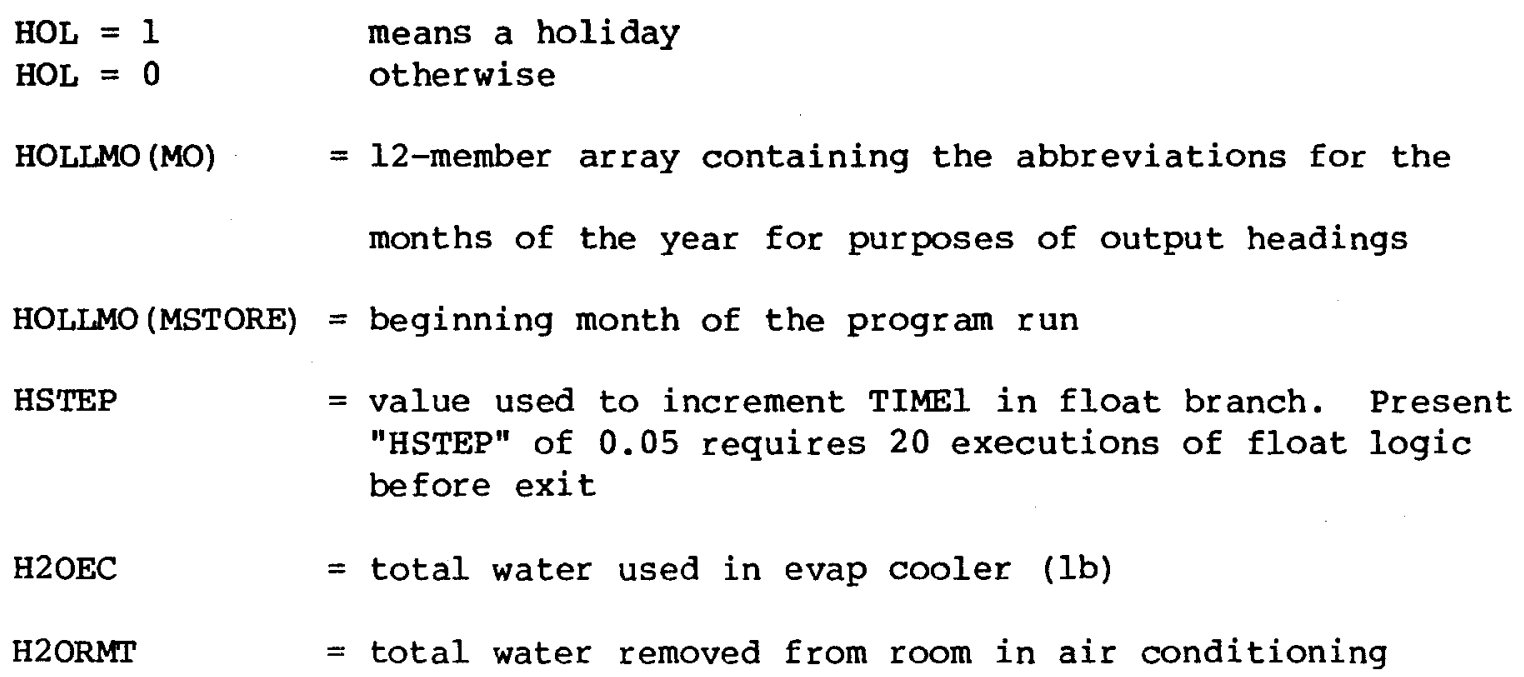


'I'

\begin{tabular}{|c|c|c|}
\hline IAMCOL & $=$ & flag for nightime cooldown \\
\hline ICOOL & $=$ & flag for cooling season comfort chart \\
\hline IFLAG & $=$ & 1 ; air-conditioning is available \\
\hline IFLAGI & $=$ & $\begin{array}{l}\text { 1; stores degree-day and degree-hour data on external } \\
\text { magnetic tapes. (user supplied data). }\end{array}$ \\
\hline IFLAG2 & $=$ & $\begin{array}{l}\text { 1; prevents venting or air-conditioning when TTB }>\text { THI } \\
\text { Usually left as IFLAG } 2=0 \text {. (user supplied data). }\end{array}$ \\
\hline IFLAG3 & $=$ & 1 ; permits venting if DRYBLB < THI \\
\hline IFIAG4 & $=$ & $\begin{array}{l}\text { 1; data for load apportioning bar graph punched on } \\
\text { cards (see Appendix 4), (user supplied data) }\end{array}$ \\
\hline IFLAG5 & $=$ & $\begin{array}{l}\text { 1; graph of data for first four days of each month printed } \\
\text { with output (user supplied data) }\end{array}$ \\
\hline IFLAG6 & $=$ & $\begin{array}{l}\text { 1; load curves for "average day" of each month printed } \\
\text { with output (user supplied data) }\end{array}$ \\
\hline IFLAG7 & $=$ & not currently used \\
\hline IFLAG8 & $=$ & evaporative cooling flag \\
\hline IFLAG9 & $=$ & air conditioning flag \\
\hline IFLAG10 & $=$ & nightime cooling flag \\
\hline IFLAGII & $=$ & economics package flag \\
\hline IFLGEC & $=$ & $\begin{array}{l}\text { tells main program evap. cooler is running (lets } \\
\text { temperature drop) }\end{array}$ \\
\hline IHEAT & $=$ & flag or heating season comfort chart \\
\hline IMPOS & $=$ & impossible evap cooling for a given house temperature \\
\hline IMPOSS & $=$ & impossible evap cooler sizing for a given house temperature \\
\hline INFCPOR & $=$ & $\begin{array}{l}\text { portion of heat gain or loss due to infiltration due } \\
\text { to cooling operation, Btuh }\end{array}$ \\
\hline INFCTOT & $=$ & $\begin{array}{l}\text { net gain(loss) due to infiltration during air conditioner } \\
\text { operation, Btuh }\end{array}$ \\
\hline INFIL & $=$ & $\begin{array}{l}\text { when multiplied by temperature difference (i.e. DRYBULB-TTB) } \\
\text { gives heat load induced by infiltration INFIL=A }+B^{*} \text { WDATA }(7) \\
\text { Btuh/ }{ }^{\circ} F\end{array}$ \\
\hline
\end{tabular}




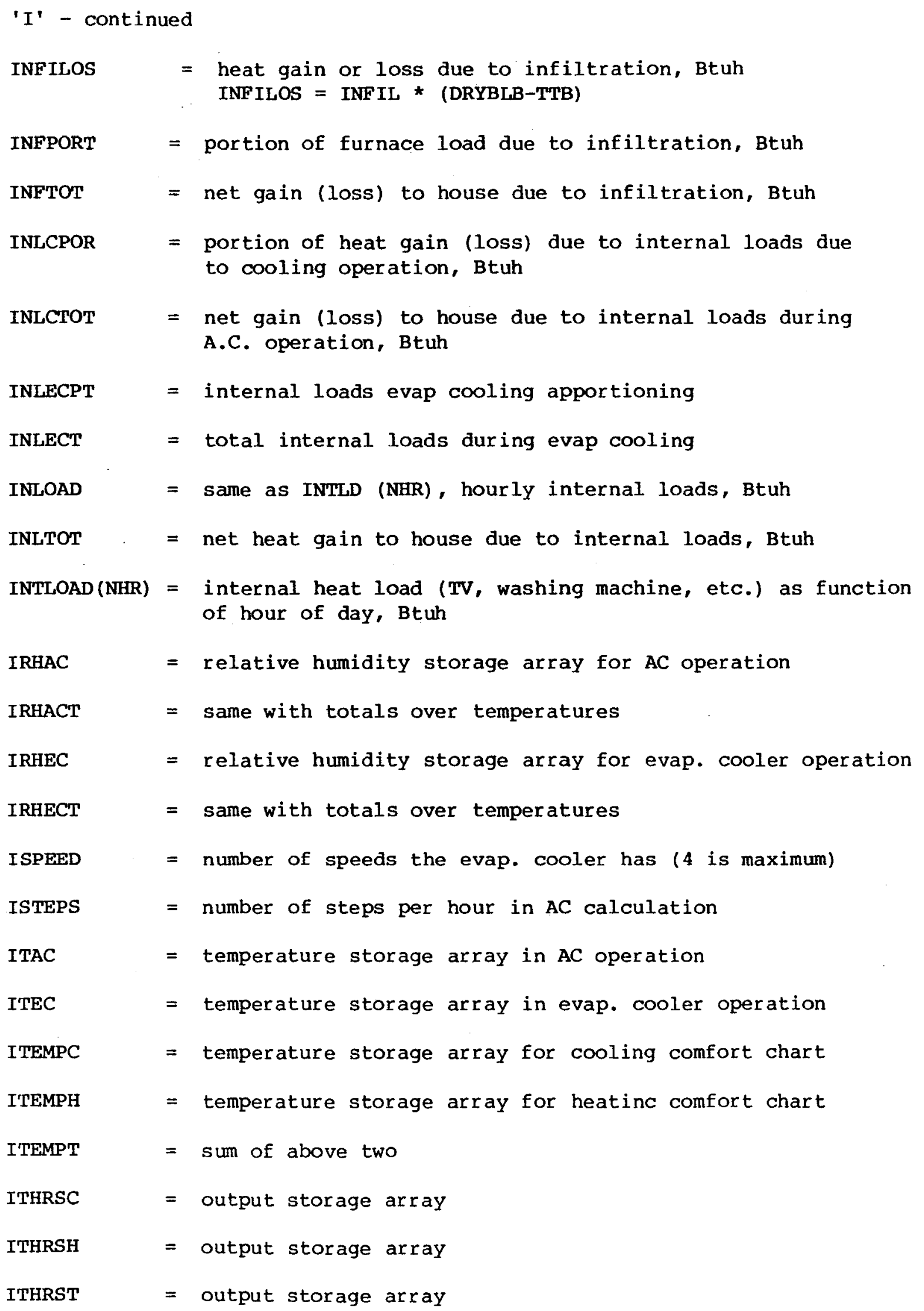


' $I$ ' - continued

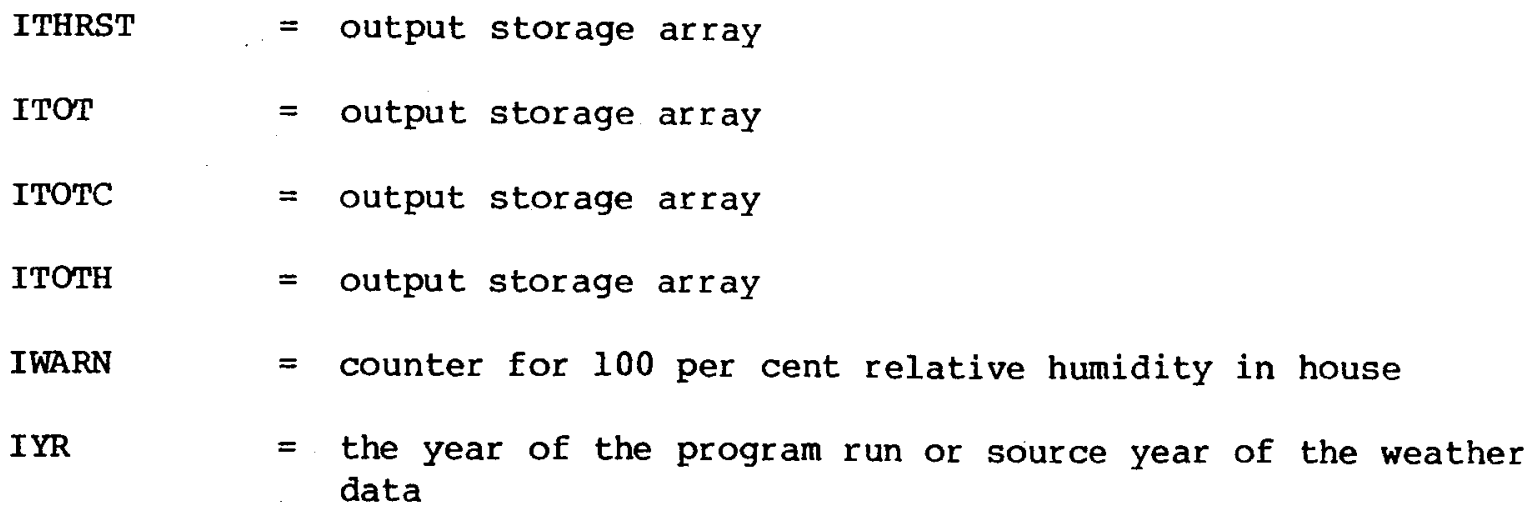
data 
'J'

J1

$=$ an integer counter for use in calculating $k_{\text {eff }}$ of house 
' $\mathrm{K}$ '

K

$=$ the time subscript used for computing heat transfer rates. Eight steps back in time are taken.

KDAY

$=$ the current value of the day of the month.

KDAYND

= the value of KDAY at which the program is to end (user supplied data)

KFLAG

= power consumption flag. Results in an hourly response notation for the following operating conditions and output variables:

BLANK; blank space--house temperature is floating, no power being consumed,

KLAXON; \$--furnace is on,

KAIRON; *--air conditioner or evaporative cooler is on,

KOVRLD; $\star *$-air conditioner or evaporative cooler unable to handle cooling load.

KVENT; +--house is venting

= current day of month as far as program operation is concerned 


$$
\text { 'L' }
$$

L

= wall component numbering subscript, $\mathrm{L}=1$ means air and $L=2$ means stud component
LEGEND ( 36)
= an array used to echo input comment cards to the end of the output format. These cards may contain any information the user desires concerning weather, house construction, etc. (user supplied data)
LOADAC = summation of sensible building load during $\mathrm{AC}$
LOADEC = summation of sensible building load during evap. cooling
LOSS
= total heat transfer rate to house less solar heat gain through windows but including internal loads, Btuh 
' $M{ }^{\prime}$

MMO

= integer check to determine whether a month is odd or even

MO

$=$ the value of the current month of the year, 1-12

MOEND

$=$ the month at which the program is to end, (user supplied data)

MSTORE

= current value of month as far as a program operation is concerned 
'N'

$\begin{array}{ll}\text { NDAY } & =\text { ending Julian day of program } \\ \text { NHR } & \text { an integer index used throughout the main program; } \\ & \text { NHR }=1+\text { INT(ZST) } \\ = & \text { number of hours during which the AC turned on } \\ \text { NHRAC }= & \text { number of hours during which evap. cooling is on } \\ \text { NHREC }= & \text { number of hours at each evap cooler speed } \\ \text { NHRVOL }= & \text { the time from bed to breakfast, considered off-hours } \\ \text { NIGHT }= & \text { solar power arriving through fenestration into north } \\ \text { zone of house } & =\begin{array}{l}\text { an integer counter used to indicate the total number } \\ \text { of hours of net heat gain through windows. Only used } \\ \text { Oct-Apr }\end{array} \\ \text { NSUN } & \text { a } 12-\text { member array containing the number of days in each } \\ & \text { month }\end{array}$


'O' 


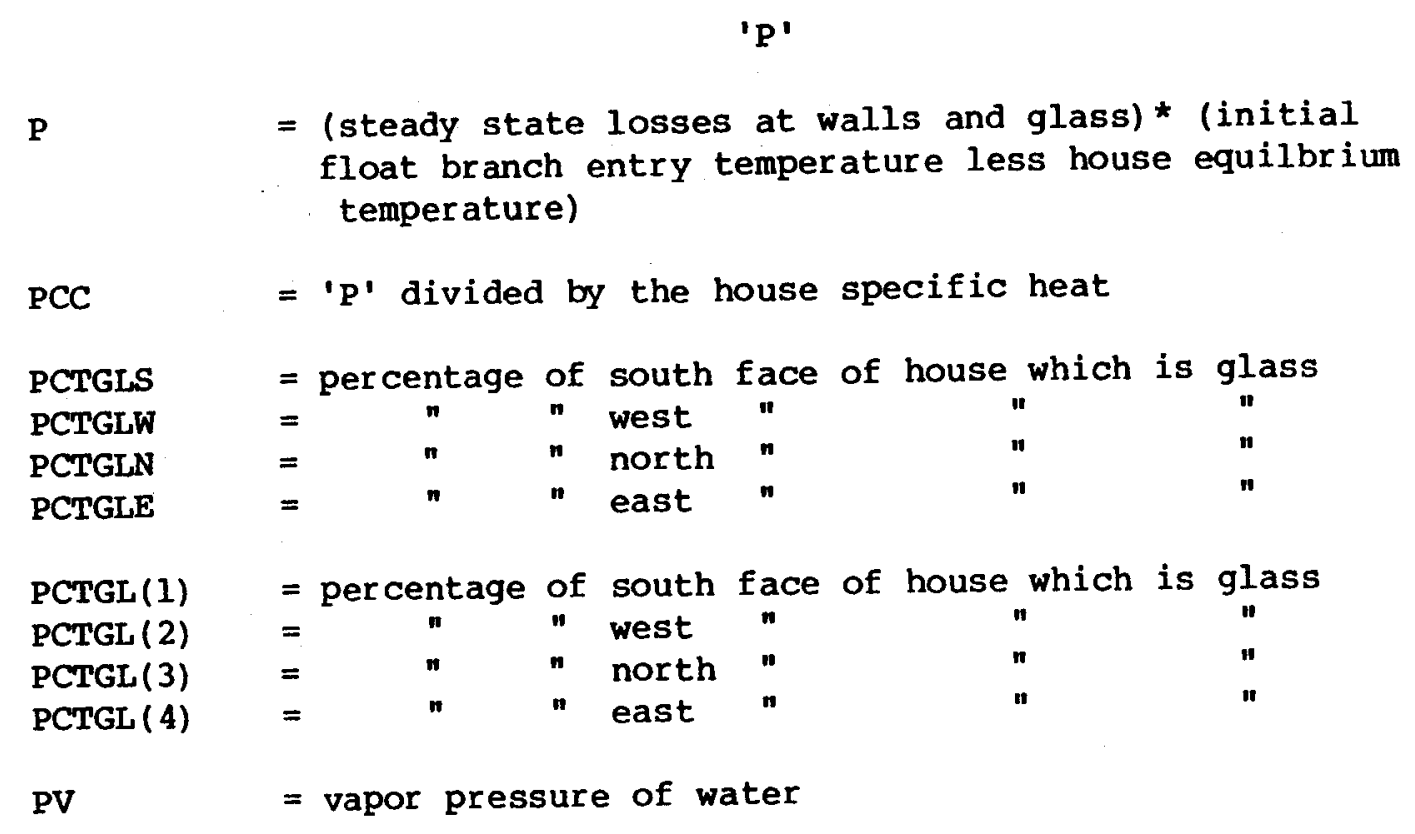




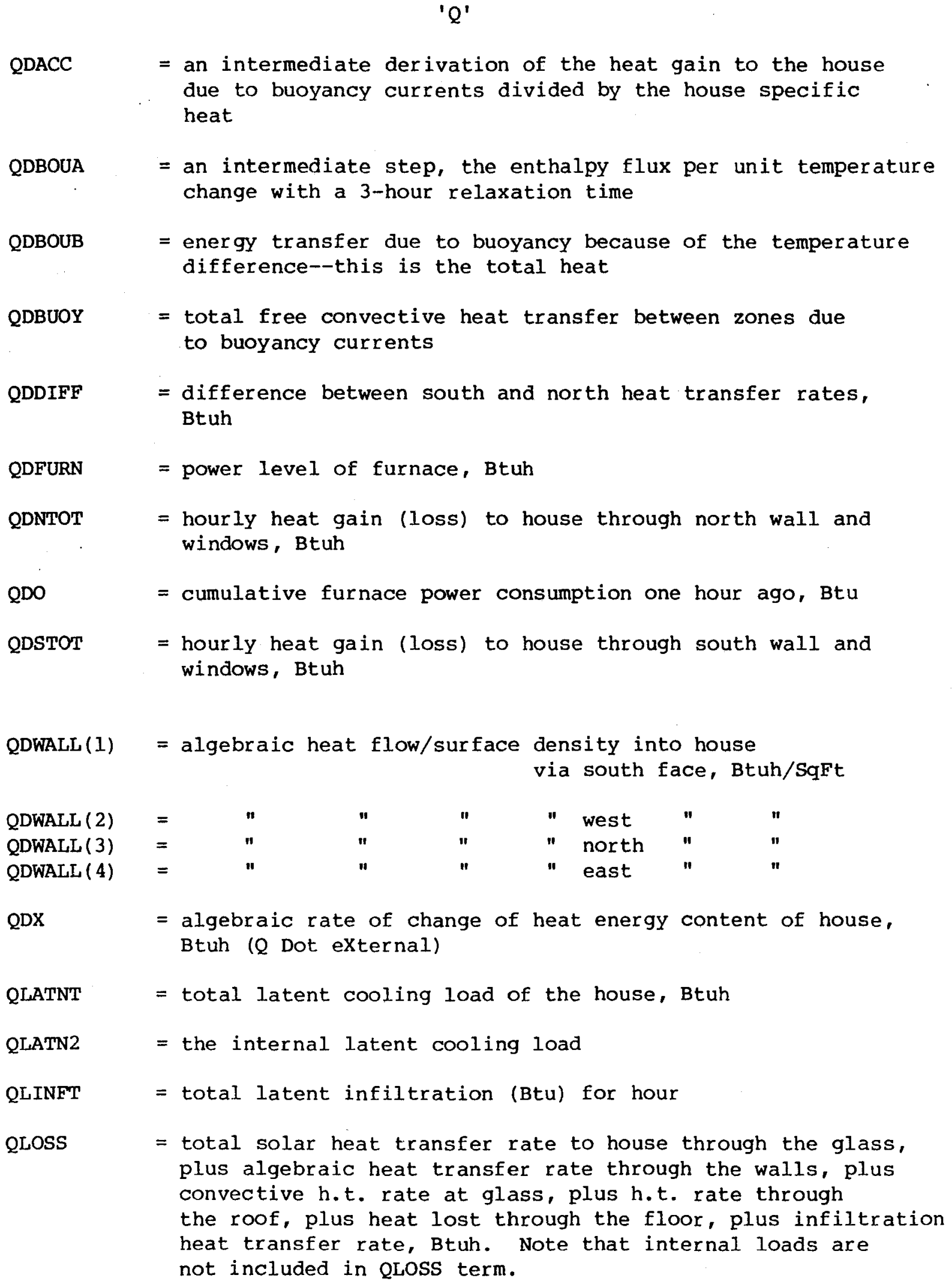




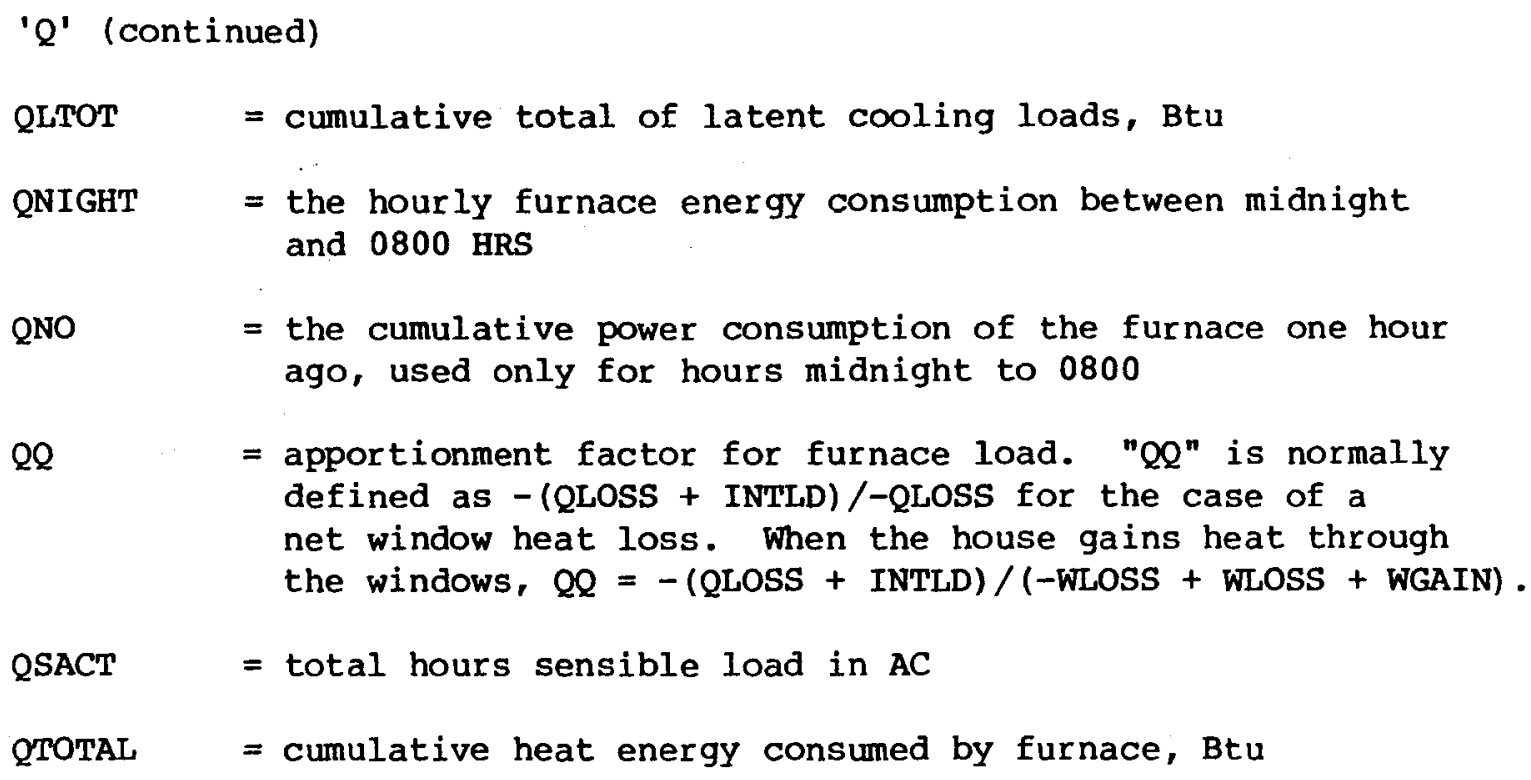




\section{' $R$ '}

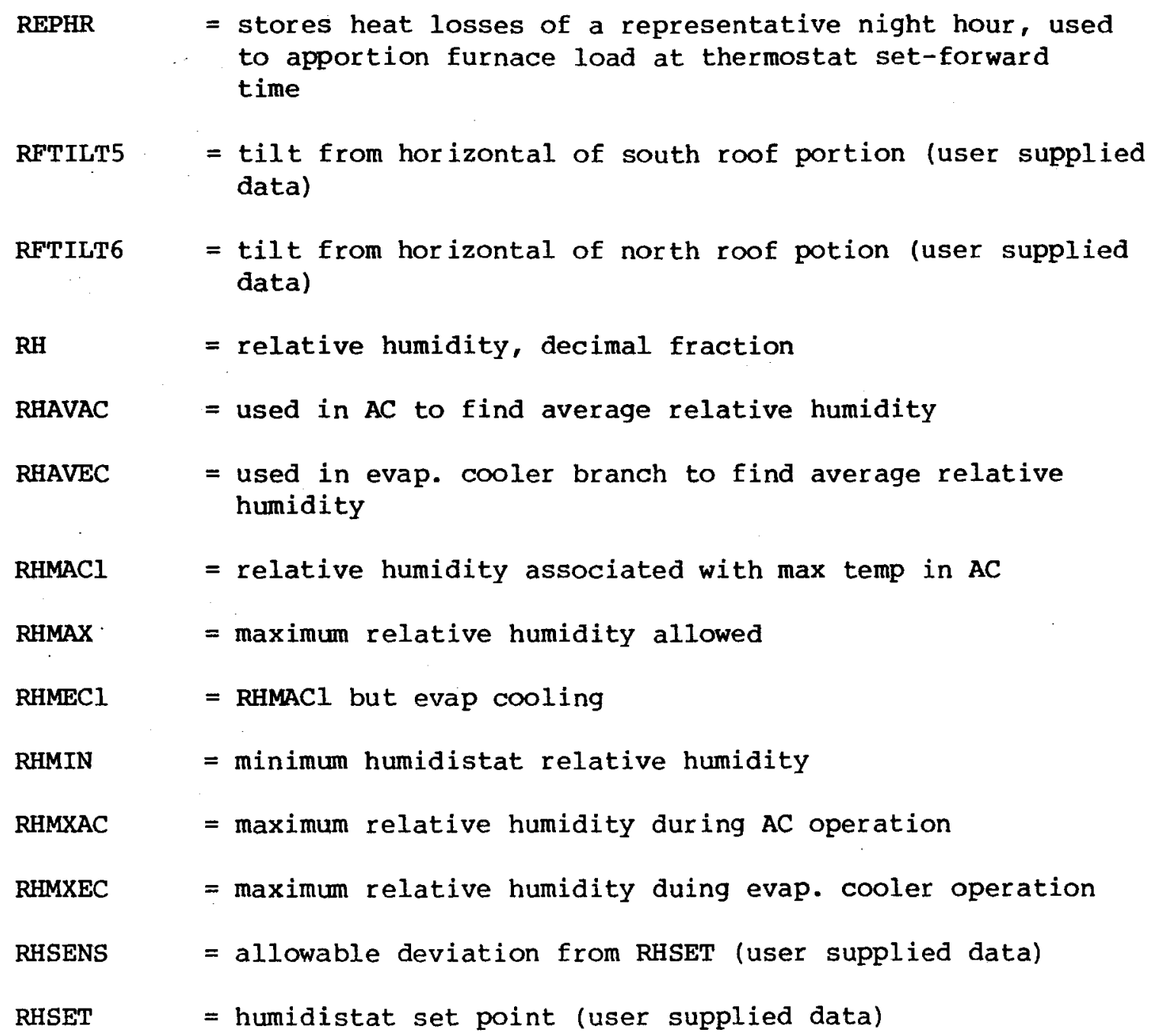


= shading coefficient, $(.95$ if window is not shaded) to account for dirt and dust that accumulates. SHADCF is less than unity if window is shaded by drapes or blinds. (user supplied data)

SHGSUM

= directional solar heat gain sums per unit area of glass, Btuh-Sq $\cdot \mathrm{Ft}$

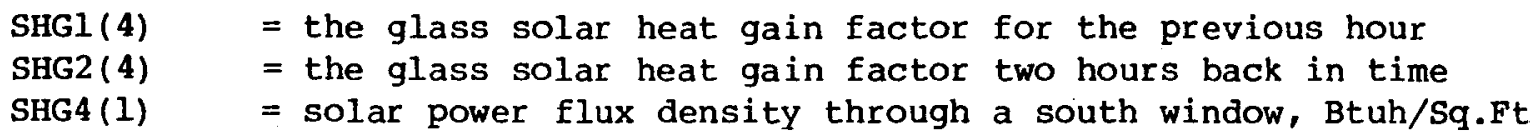


' $\mathrm{T} '$

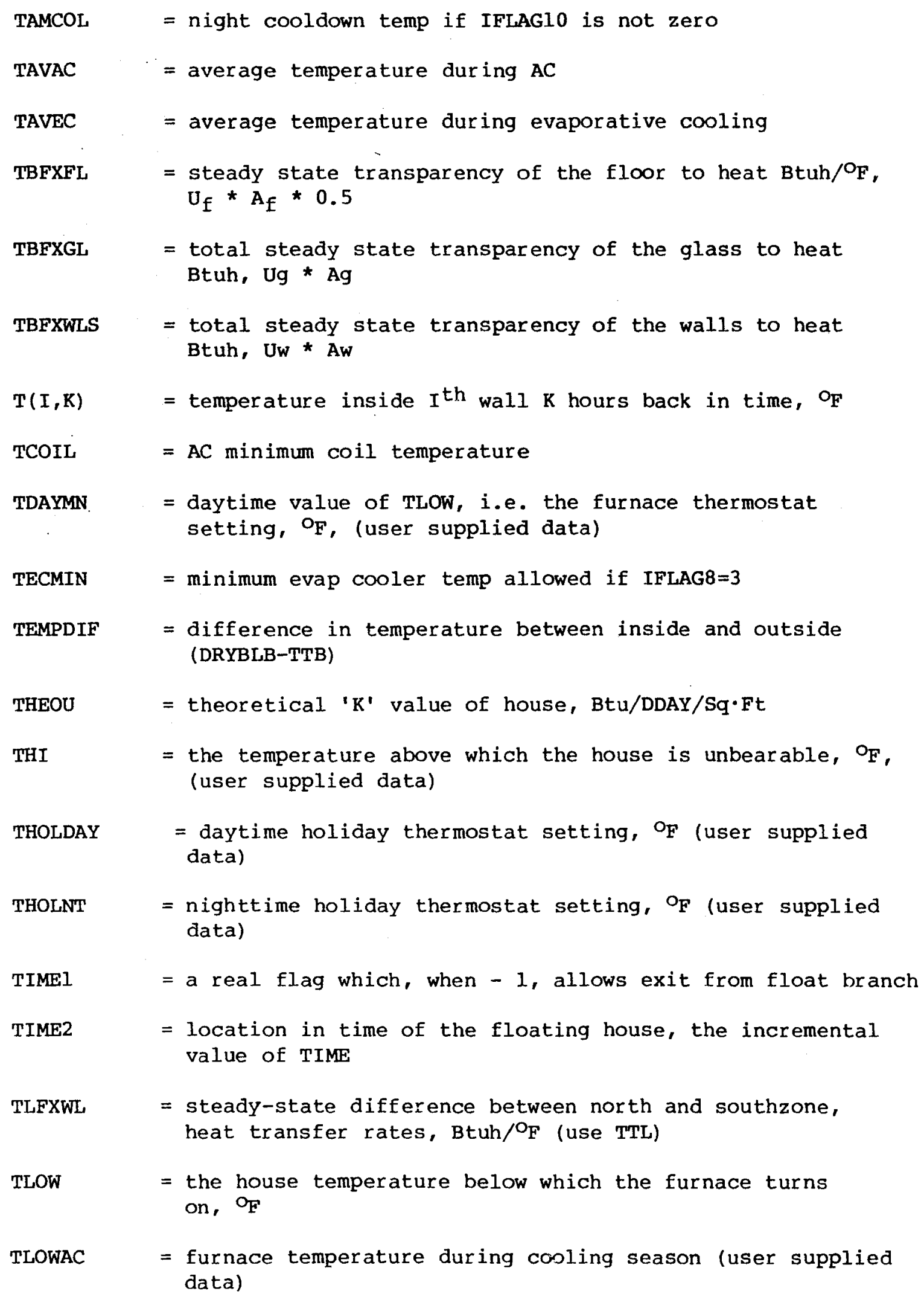




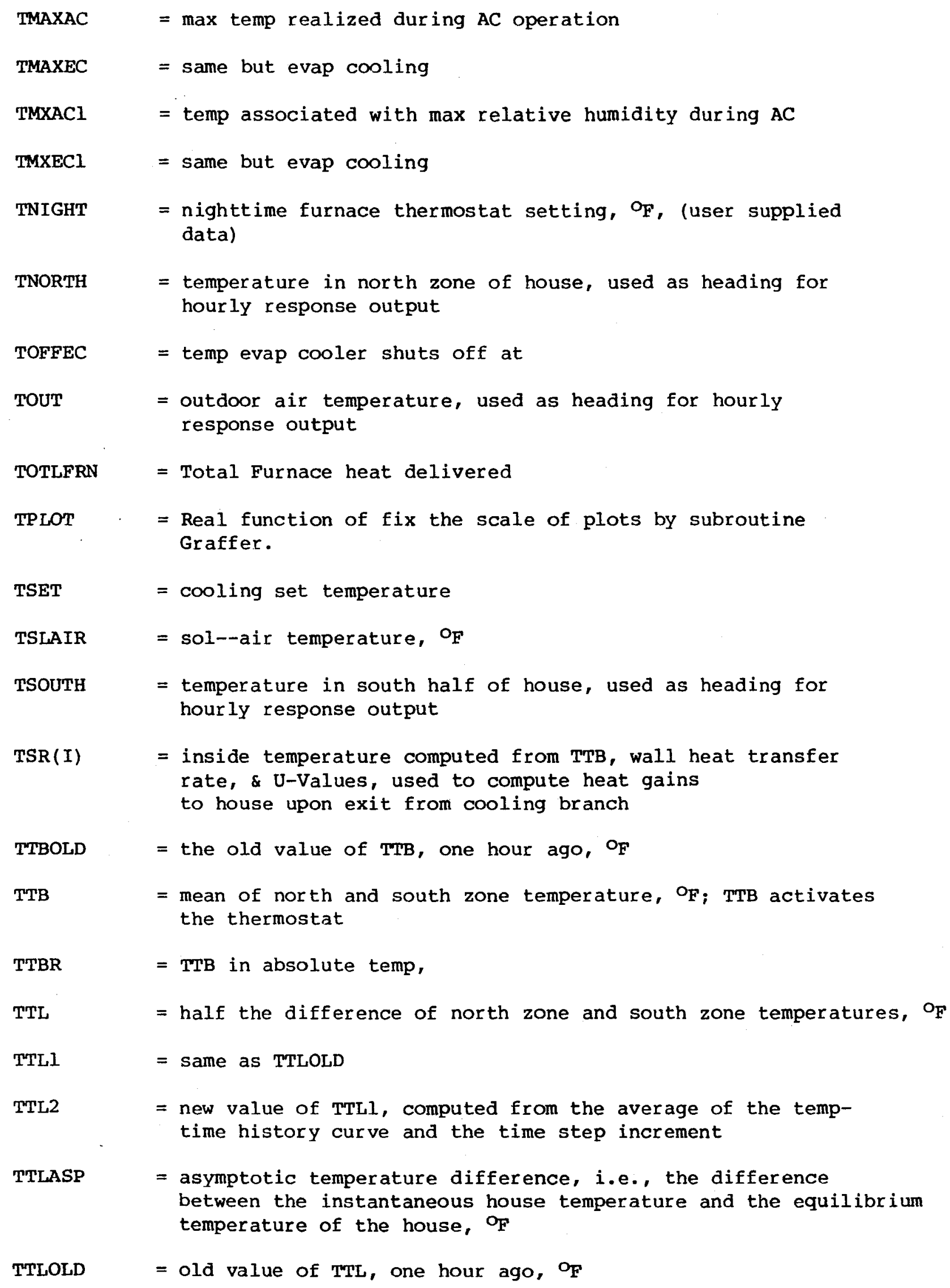




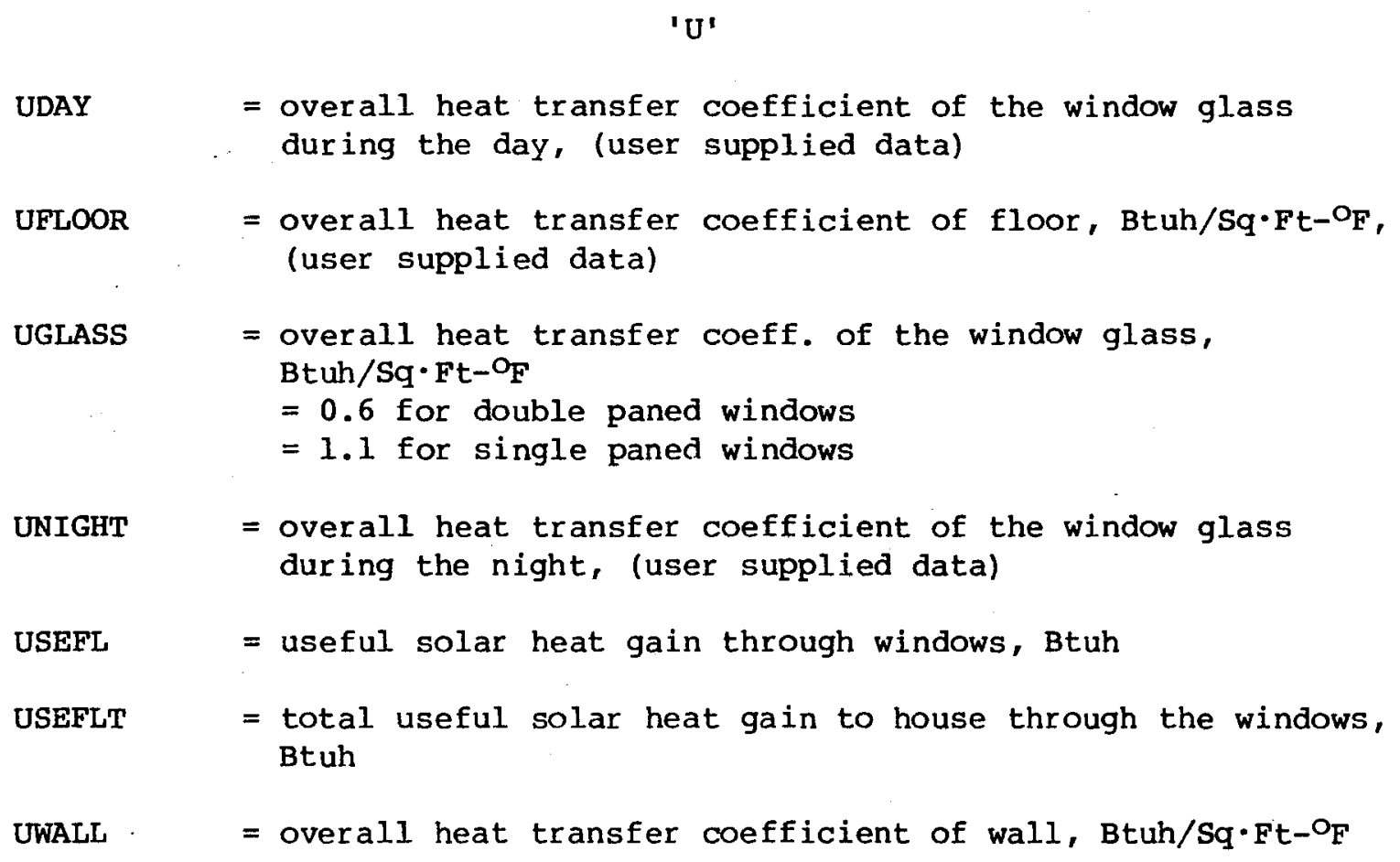




$\begin{array}{ll}\mathrm{V} & \text { ' } \mathrm{V} \text { ' } \\ \text { VBOUY } & \text { volume of moist air, cu. ft./lbm of dry air } \\ = & \text { flow velocity of a buoyancy current as predicted from } \\ & \text { pressure difference between north and south zones of } \\ & \text { house } \\ = & \text { driving force behind buoyancy currents due to density } \\ & \text { differences alone } \\ \text { VBOUYB }= & \text { volume associated with minimum effect during evap cooler } \\ & \text { sizing (CFM) } \\ \text { VLEFMN }= & \text { volume associated with maximum effect during evap cooler } \\ & \text { sizing (CFM) } \\ \text { VLEFMX }= & \text { average volume during evap cooler sizing (CFM) } \\ \text { VOLAVE }= & \text { storage array for CFM during evap cooler sizing } \\ \text { VOLM }= & \text { maximum CFM during evap cooler sizing } \\ \text { VOLMAX }= & \text { minimum CFM during evap cooler sizing } \\ \text { VOLMIN }= & \text { volume of house } \\ \text { VOLROM } \quad=\end{array}$


' $W '$

W

\begin{tabular}{|c|c|}
\hline WALLAR (1) & $=$ amount of non-glass area on south face of house, sq. Ft \\
\hline WALLAR (2) & west \\
\hline WALLAR (3) & north \\
\hline WALLAR (4) & east \\
\hline WALLAR (5) & south roof \\
\hline WALLAR (6) & $=$ (user supplied data) \\
\hline WDATA (1) & $=$ outside air temp. from drybulb ${ } F$, from weather tape \\
\hline WDATA (2) & $" \quad$ wetbulb ${ } \mathrm{F}$. \\
\hline WDATA (3) & $=$ dewpoint \\
\hline WDATA (4) & $=$ atmospheric pressure, inches $\mathrm{Hg}$ \\
\hline WDATA (5) & $=$ cloud amount \\
\hline WDATA (6) & $=$ cloud type \\
\hline WDATA (7) & $=$ wind speed, knots \\
\hline WDATA ( 8) & $=$ humidity ratio $1 \mathrm{~b} / 1 \mathrm{~b}$ \\
\hline WDATA (9) & $=$ density, $1 b / f t^{3}$ \\
\hline WDATA (10) & $=$ enthalpy, Btu/Ib \\
\hline WINECT & $=$ total window heat flux during evap cooling \\
\hline WGAIN & $\begin{array}{l}=\text { total solar heat gain to the house through its glass, } \\
\text { Btuh }\end{array}$ \\
\hline WINGAIN ( I) & $\begin{aligned} &= \text { solar heat gain to the house through glass on } I^{\text {th }} \text { wall, } \\
& \text { Btuh }\end{aligned}$ \\
\hline WINLOSS ( I) & $\begin{aligned}= & \text { convective heat transfer rate from the house through } \\
& \text { glass on Ith wall, Btuh }\end{aligned}$ \\
\hline WINNET ( I ) & 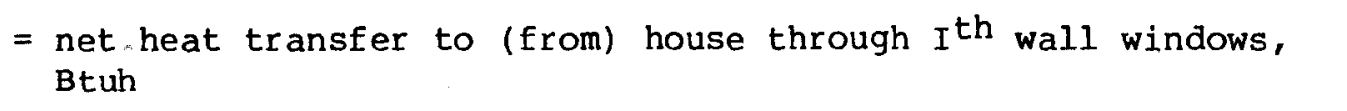 \\
\hline WINNETC ( I) & $\begin{aligned}= & \text { net heat gain (loss) to house through windows on } I^{\text {th }} \\
& \text { wall during air conditioner operation, Btuh }\end{aligned}$ \\
\hline WINPORT & $=$ that portion of furnace load due to window losses, Btuh \\
\hline WLCPORT & $=$ heat gain or loss through walls due to cooling operation, Btuh \\
\hline WLCTOT & $\begin{aligned}= & \text { net gain (loss) to house through walls during air conditioner } \\
& \text { operation, Btuh }\end{aligned}$ \\
\hline WLDOTQ & $\begin{aligned}= & \text { algebraic heat into house, Btuh, through walls } \\
& =\text { WALLAR(1) * QDWALL }(1)+\ldots+\text { WALLAR }(6) * \text { QDWALL (6) }\end{aligned}$ \\
\hline WLECPT & $=$ wall loads evap cooling apportioning \\
\hline FFCT & $=$ total wall heat flux during evap cooling \\
\hline
\end{tabular}




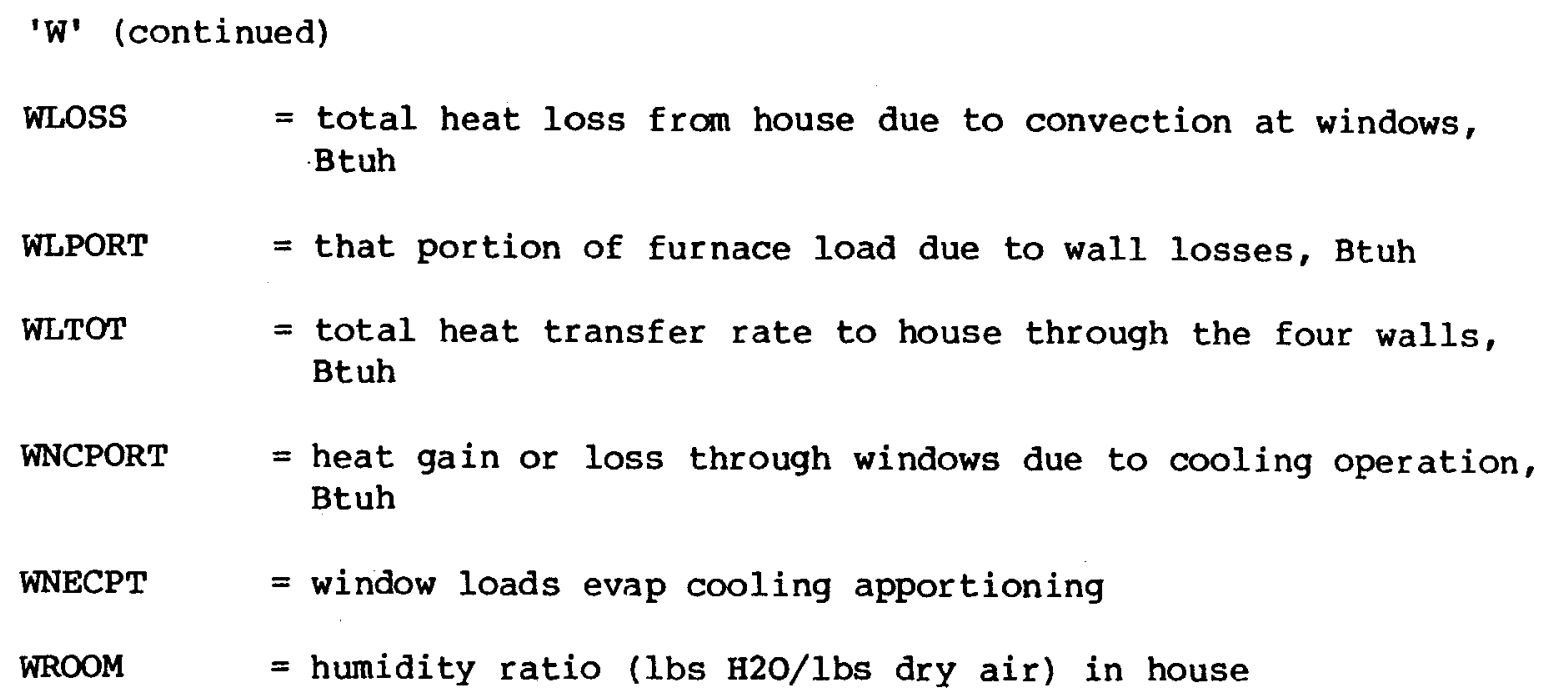
Btuh 
' $\mathrm{X}$

XMAX

= limits of $\mathrm{x}$ axis of outPuT graph

XMIN

$=$ "

u

I 
YMAX

= limits of y axis (Btuh) of OUTPUT graph

YMIN

= limits of $y$ axis (Btuh) of OUTPuT graph 


\section{' Z'}

z

= the steady-state "UA" products for windows and walls multiplied by the house average equilibrium temperature "AA/BB"--essentially $\mathrm{T}$ * steady-state losses

= zonal standard time at the site, in hours (0-23)

ZSTORE

= varies from 1 to 24, the stored value of zonal standard time used in the monthly cumulative furnace and air conditioner loads accounting output summary. 


\section{IMPORTANT VARIABLES IN TWOZONE SUBROUTINES AND FUNCTIONS}

(Only important variables from TWOzONE subroutines and functions are listed here. But all the subroutine and function names are included in case the user wishes to write any notes in front of any of them)

$\underline{\text { ACDGDY }}$

$$
\begin{aligned}
& \text { ACDGDY = accumulated cooling degree-days } \\
& \text { BASE = base temperature used in the calculation } \\
& \text { IBUF = array of weather data }
\end{aligned}
$$

ACDGHR

$$
\begin{aligned}
& \text { ACDGHR = accumulated cooling degree-hours/day } \\
& \text { IBASE = base temperature used in the calculation } \\
& \text { IBUF = array of weather data }
\end{aligned}
$$

$\underline{\mathrm{CCM}}$

CODE

\section{COOLIT}

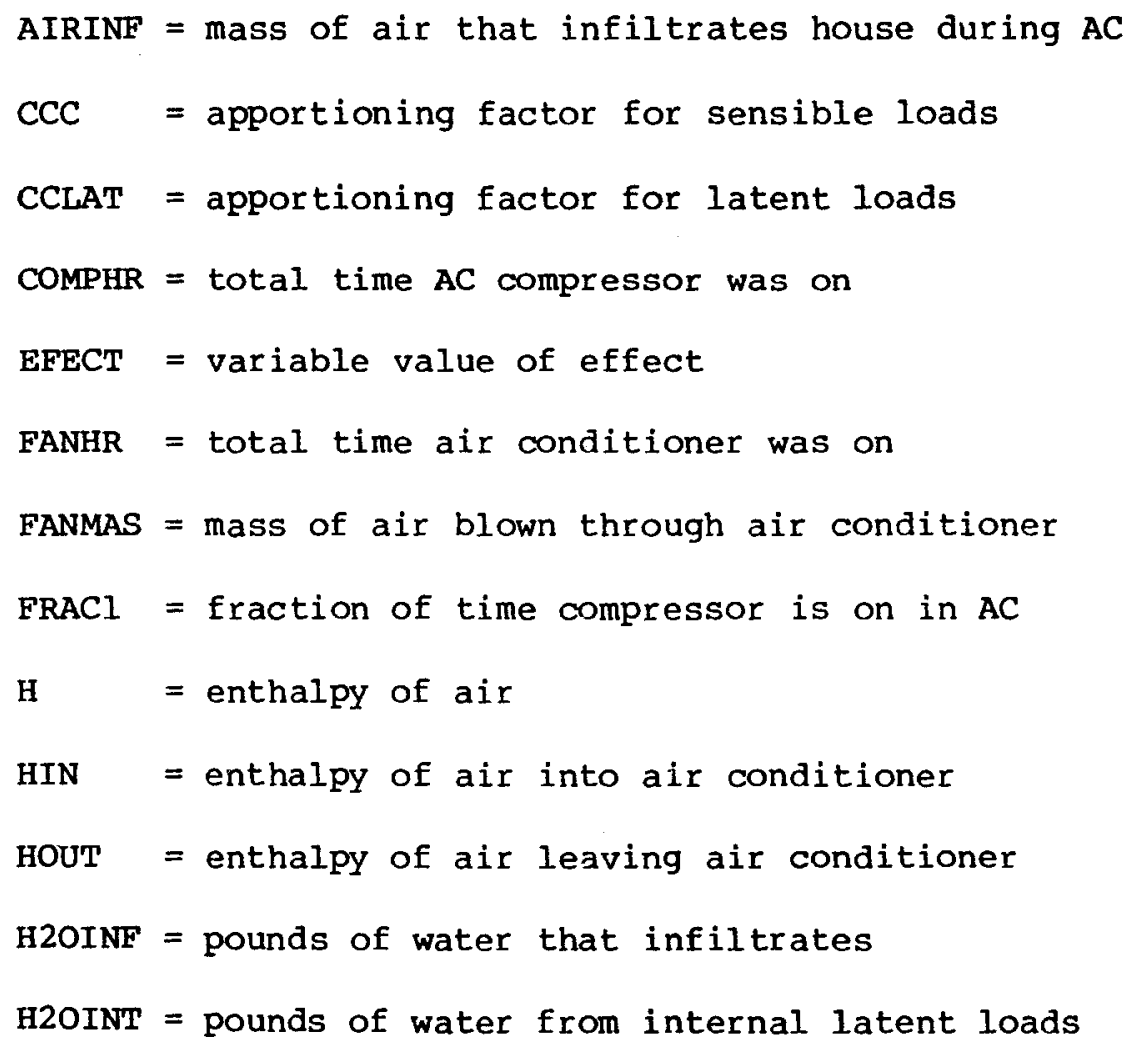




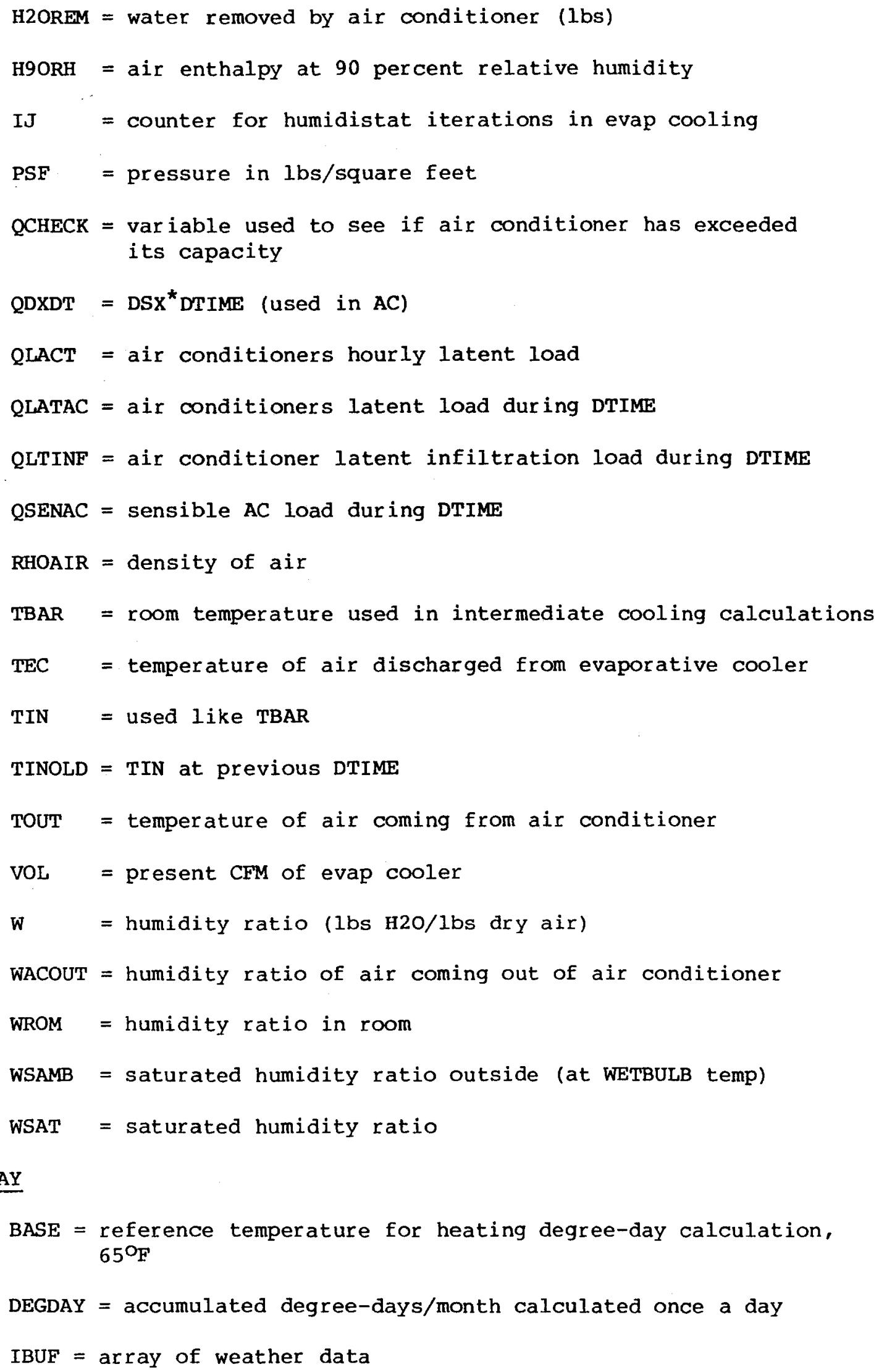
$65^{\circ} \mathrm{F}$

DEGDAY = accumulated degree-days/month calculated once a day IBUF = array of weather data 
$\underline{\text { DEGHR }}$

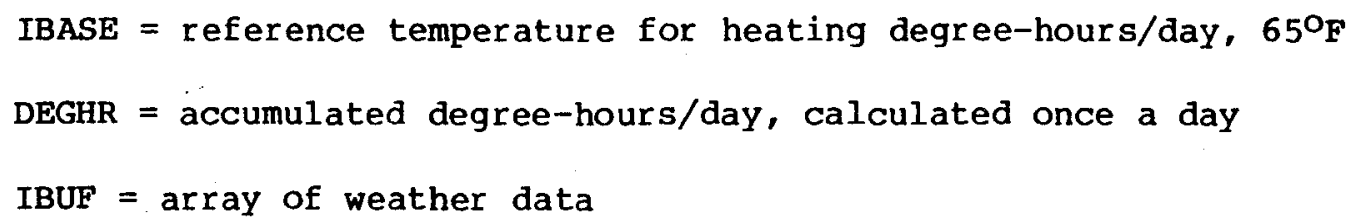

\section{FIXSET}

\section{GLASS}

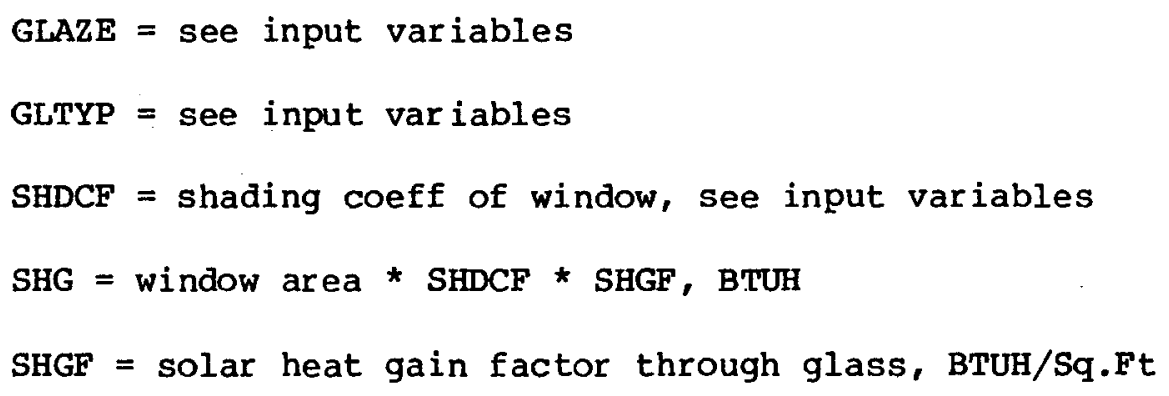

\section{GRAFFER}

HOLIDAY

\section{KALEND}

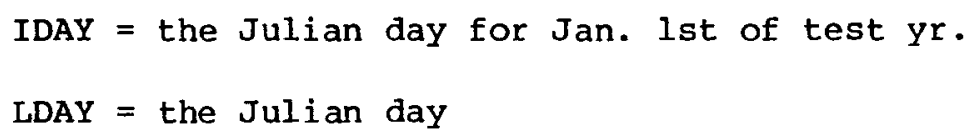

$\operatorname{NAME}(L, I)=$ alphanumeric description of $\mathrm{L}^{\text {th }}$ component of $\mathrm{I}^{\text {th }}$ wall PSYI

$$
\begin{aligned}
& \mathrm{CDB}=\text { drybulb temp, }{ }^{\circ} \mathrm{C} \\
& \mathrm{CWB}=\text { wetbulb temp, }{ }^{\circ} \mathrm{C}
\end{aligned}
$$


$\underline{\text { SUN }}$ - (continued)

S(13) $=\cos (z)$, cosine of zenith angle, (angle between incident beam and vertical), for a horizontal surface only.

$S(14)=\cos (\mathrm{W})$, cosine of angle between incident beam and $\mathrm{N}-\mathrm{S}$ axis of earth

$S(15)=\operatorname{cosine}(S)=\operatorname{SQRT}\left(1-\cos ^{2}(\mathrm{z})-\cos ^{2}(\mathrm{~W})\right)$

$\mathrm{S}(16) \quad=$ ALPHA $=$ cosine of wall tilt angle

$S(17)=$ BETA $=\sin ($ WA $) * \sin ($ WY $)$, a measure of how much the surface has been raised from horizontal and pivoted east or west

$S(18)=$ GAMMA $=\cos (W A) * S I N(W Y)$, a projection of the tilted surface onto a $\mathrm{N}-\mathrm{S}$ line

$S(19)=$ cosine of angle of incident beam radiation

$\mathrm{S}(20)=$ the solar altitude angle, in degrees from the horizon

$S(21) \quad=$ the solar azimuth angle, in degrees from south

S(22) = diffuse sky radiation on a horizontal surface, $S(22)$ $=\mathrm{BS} * \mathrm{CCM}$.

$S(23)=$ diffuse ground reflected radiation, $S(23)=B G \&$ CCM. $S(23)=$ GROUND REFLECTIVITY * (DIFFUSE SKY RAD, on a HORIz. SURF. + DIR. NORMAL RAD. * $\cos (z))$.

$S(24)=$ direct normal radiation, $S(24)=$ IDN * CCM. $S(24)=$ SOLAR FACTOR 'A' * CLEARNESS NUMBER \& CLOAD COVER MODIFIER EXP(SOLAR FACTOR 'B" /COS $(z)$ )

S(25) = total solar radiation intensity--direct, diffuse, and diffuse ground reflected components

$S(26)=$ diffuse sky radiation intensity--S(26) $=S(22)$ * DECLINATION ANGLE.

$S(27) \quad=$ ground reflected diffuse radiation intensity $S(27)=$ DIFFUSE GROUND REFLECTED RADIATION

* (1. - COS (WALL TILT ANGLE)) $/ 2$

$\mathrm{S}(28) \quad=$ sundeclination angle, degrees

S(29) = equation of time, in minutes

$S(30) \quad=$ SOLAR FACTOR 'A'

$S(31)=$ SOLAR FACTOR 'B'

$S(32) \quad=$ SOLAR FACTOR ' $\mathrm{C}:$ '

Variables $S(28)$ thru $S(32)$ are same as in NBSLD, page 53a. ${ }^{8}$

$\mathbf{S}(33)=$ CLOUD COVER MODIFIER

$S(34) \quad=$ intensity of direct solar radiation on surface

$S(34)=$ IDN * CCM * COS OF INCIDENCE ANGLE

S(35) = hour angle, in degrees, mornings positive, afternoons negative.

$\mathrm{x}=2 \mathrm{n} / 366$, where $\mathrm{n}$ is the Julian day

$\mathrm{XS}=$ solar factor 'B'/cosine of zenith angle

$\mathrm{XI}=$ magnitude of sunrise or sunset hour angle, degrees

$\mathrm{x} 2$ = magnitude of hour angles, degrees 
SUN - continued

$Y=$ sun declination angle, radians

$Y Y=$ latitude, north positive, radians

TAR

WARNUM

WTHR

SHGF $=$ solar heat gain through glass, Btu/Sq.Ft

WRSHF = solar energy incident on external surface of wall or roof, Btuh/Sq·Ft

WXDATA

X-LABEL

Y-LABEL

GRAFPAC

JDAY

NUMARG 


\section{SUBROUTINE AND FUNCTION PROGRAM DESCRIPTIONS}

REAL FUNCTION ACDGDY (MO, RDAY) - Calculates the air-conditioning degreedays with a base temperature of $78^{\circ} \mathrm{F}$, or user's choice.

REAL FUNCTION ACDGHR(MO, KDAY) - Calculates the air-conditioning degree hours with a base temp. of $78^{\circ} \mathrm{F}$, or user's choice.

FUNCTION CCM(SALT, NTYPE, TC) - Calculates a cloud cover modifier term

(for use in subroutine SUN) which is dependent on the solar altitude angle, the cloud type, and the total sky cover. Data for CCM factors CCl through CC4 are taken from the NECAP Engineering Manual, pg, 324.5 Note that $\mathrm{CCl}$ and $\mathrm{CC} 3$ are for solar altitude angles of less than 45. Depending on the value of NTYPE, cirrus and cirrostratus clouds or stratus clouds are assumed. For figuring NTYPE, the lowest cloud types are used. CCM used when calculating the amount of solar insolation striking a given surface.

COOLIT (TTB, QDX, CLD, ECLD) - Calculates the cooling load and new house temperature when given the old temperature and the sensible and latent heat loads. The subroutine will simulate either an air conditioner or an evaporative cooler depending on which flags the user sets in the input deck. Data is stored for output at the end of the run. For a more detailed description, see Appendix I. CODE - used to label axes in the program output. REAL FUNCTION DEGDAY (MO, KDAY) - This function calculates the heating degree-day value for a data base of $65^{\circ} \mathrm{F}$, or user's choice. REAL FUNCTION DEGHR(MO,KDAY) - This function calculates degree hours on any day from a base temp of $65^{\circ} \mathrm{F}$, or user's choice for purposes of heating load calculations. 
REAL FUNCTION DEGNITE (MO, KDAY) - Calculates the degree hours for the first eight hours after midnight, with a base temp of $65^{\circ} \mathrm{F}$, or user's choice.

ECON - The subroutine ECON is called at the end of the main program if IFLAGll has been set greater than or equal to 1 in the input deck. It calculates resource use and costs by fuel category for the current run and compares with the base case data if available. If all base case fuel uses were set to zero in the input deck, BFLAG is set to 1 and control is returned to the main program, where a base case report is printed. If non-zero value is found, the beginning and end dates of the current run are compared with those of the base case to insure that legitimate loads comparisons can be made. If the dates differ, control is returned to the main program with BFLAG set to zero. This causes the printing of a user error message. If the dates agree, the subroutine goes on to calculate economic statistics which evaluate the alternative conservation strategy and compare it to the base case. These statistics are returned to the main program, with BFLAG set to 2. This causes the printing of an economic report.

The input to ECON is contained in cards 34,35 , and 36 of the input deck. A blank for any of the values read from the input deck will cause an abort. No default values are assigned. Either FANP and COMPP or EER in card 36 are used. EER takes precedence if it is set greater than zero.

The other inputs to ECON come from the main program and the subroutine COOLIT. These include the heating load (QTOTAL, HEAT), number of Kwh used by the evaporative cooler (GTB(5), ECOOL), the cooling load (ACTOTAL, ACOOL), AC compressor hours (COMPHR), and AC fan hours (FANHR). 
The subroutine begins by scaling several factors and calculating the DINF array, which is the discount-inflation factor for each fuel. Heating, cooling, and total fuel use and costs are calculated as linear functions of the equipment and economic parameters and the loads. This is an approximation used to simplify the input to the program. If the current run is a base run, control returns to the main program and these results are used in a base case report. If the current run is a legitimate comparison run, ECON then calculates the costs for the base case fuel uses.

In the next sections replacement years and a study life are calculated from the lifetimes of the options. In no case does the life of the comparison exceed 25 years, as per ERDA guidelines. The capital costs of replacement are reduced to present values and totaled. The residual value of the equipment at the end of the study life is calculated using straight-line depreciation, and then discounted to present value. The incremental capital cost of the alternative is then found. This equals the present value of the extra capital outlays necessary. The loop that follows calculates the present value of the cost of fuel and differential maintainance for the length of the study. In both the base and alternative cases the fuel costs computed earlier are multiplied by the appropriate discount-inflation factor for each year and then accumulated. These are later combined with the present value of maintenance to arrive at the present value of all the years' savings. The discounted payback period is equal to the number of years needed for the discounted yearly savings to equal the incremental capital cost of the alternative. If the incremental cost is negative (a net capital savings) the payback period is meaningless and left set to 
zero. If the payback period exceeds the study life, it is set to 9999 to indicate that it goes beyond the bounds of the study. The final calculations provide the savings-per-investment ratio, the number of Btu's saved per year, and the number of Btu's saved per annual discounted investment dollar. Control returns to the main program, where a final report is printed out, including explanatory labels. ENVELOPE - used by GRAFFER SUBROUTINE FIXSET (A,B,C,D,E, F, G,N) - Calculates values of heat loads from a representative hour during the night time thermostat setback for use when apportioning so that the furnace load can be apportioned correctly in the morning. The next entry is from the heating branch via statement Tw0z0484. The logic is repeated, and new values of the variables listed above are stored for furnace load apportionment. Factors A through $G(I)$ are defined as the previously stored variables AA through GG(I), so that the latest values of hourly losses are always in storage.

$\mathrm{N}=1$ stores information

$\mathrm{N}=2$ retrieves information

This routine is also used for holiday setbacks. SUBROUTINE GLASS (SHGF) - This subroutine is called by subroutine WTHR for the purposes of establishing the solar heat gain factor for the window glass of the house. "GLASS" first defines variables TR(7) through TR(9), and then calls subroutine TAR(TR) to compute transmission, absorption and reflection coefficients of the window glass for both direct and diffuse components of solar radiation. Using data from subroutines SUN(I) and TAR(TR), subroutine GLASS initializes variables $\mathrm{SH}(1)$ through $\mathrm{SH}(17)$ and supplies these as input 
data to NBSLD subroutine SHG(SH). "SHG" calculates the solar heat gain through the windows, $\mathrm{SH}(18)$, by actually setting up a resistance network for the window pane(s) - SH(18) is returned to subroutine GLASS, which defines the solar heat gain factor, SHGF, to be equal to SH(18). The SHGF parameter is returned to subroutine WTHR for computation of the room response to the solar radiation. GRAFFER - Generates the printer plot the program OUTPUT. SUBROUTINE HOLIDAY (KDAY, MO, IYR, HOL) - This subroutine checks each day to see if it is a holiday according to federal Monday holiday law. It establishes "HOL," the holiday indicator, which is employed in the core of the program to alter furnace logic according to holiday thermostat settings.

FUNCTION JDAY (KDAY, MO, IYR) - Calculates the Julian day, conducts a check to see if the test year is a leap year, and supplies the Julian day in correct format. For example, March 2, 1976, would be written 76062 for program use. SUBROUTINE KALEND (MO, KDAY, IYR) - For tape input only, this subroutine calculates the Julian day, subtracts one day from the Julian day, and uses this as a check for program termination. (One year of data is the maximum amount allowed.) KALEND then positions the weather tape. RANGER - chooses an appropriate scale for graffer. SUBROUTINE READP - The purpose of subroutine READP is to read data from the INPUT deck concerning the type and fraction of each wall component, read the transfer function coefficients for each component of the walls and ceiling, sum the $\mathrm{BN}, \mathrm{CN}$, and $\mathrm{DN}$ values and conduct a check on their validity, calculate U-VALUES for the walls and ceiling from these 
transfer function coefficients, read a schedule of internal loads, and execute a program termination control routine.

The program is presently set up for two-component wall, which is analyzed for eight hours backward in time. It is assumed that all walls are constructed alike -- the ceiling may be defined differently. SUBROUTINE PSY1 (DB, WB, PV, W, H, V, RH) - Calculates vapor pressure (PV), humidity ratio (W), enthalpy (H), volume (V), relative humidity (RH), and dew-point temperature when the dry-bulb temperature (DB), wet bulb temperature (WB), and barometric pressure (PB) are given. PB must be in inches of Mercury. (RE: NBSLD subroutine PSY1). Used during air-conditioning.

FUNCTION PVSF(X) - Calculates the relative humidity as a function of temperature and vapor pressure in inches of mercury. Called by PSYI. SUBROUTINE SHG(SH) - Refer to the discussion of subroutine GLASS(SHGF) . SUBROUTINE SKINS (MO, KDAY, NHR, TTB, TTL) - This subroutine computes the hourly heat transfer through walls and roof.

SUBROUTINE SUN(I) - This is a major subroutine which can be subdivided into two parts:

$\underline{\text { PART I - SUN2/SUN144 }}$

This section computes solar angles and all other parameters necessary to calculate the intensity of direct solar radiation on each wall.

PART II - SUN146/SUN189

Part II employs tangents of angles calculated in subroutine TANGLE to compute the amounts of shadowing and shading of walls due to neighboring houses, trees, and overhangs at ceiling and windows. 
SUBROUTINE TAR(TR) - Its function is to compute the transmission, absorption and reflection coefficients of window glass for direct and diffuse components of solar radiation for the case of single or double-glazed windows. SUBROUTINE WTHR (MO, KDAY, NHR) WTHR calls:

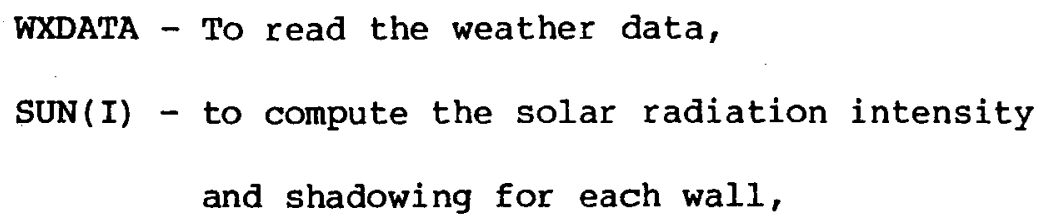

Subroutine WTHR uses this information to compute the effective solar heat gain through GLASS using exponential delay with a threehour time constant, and to compute the solar heat gain through walls and roof.

SUBROUTINE WXDATA (MO, KDAY, NHR, WDATA) - This subroutine reads the weather tapes, converts the weather data to real numbers, and supplies these data to subroutine WTHR. TWOZONE requires ten weather variables as input: drybulb and wetbulb temperatures, dew point, barometric pressure in inches of mercury, cloud amount, cloud type, wind speed in knots, humidity ratio, density, and enthalpy. The program currently employs test reference year tapes obtained from NOAA. 1 For California, CTZ tapes are also available. On the LBL system, the weather tapes are stored in a packed format in the CALERDA weather library. To read non-packed tapes, a different subroutine is available. 
REFERENCES

1. ASHRAE, Test Reference Year, Tape Format and Documentation, U.S. Dept. Commerce, NOAA Form 79-344, Sept. 1976.

2. Dean, E. and Arthur Rosenfeld. "Modeling Natural Energy Flows in Houses," Energy and Buildings 1:1 May 1977, pp. 19-26.

3. MacPhee, C. (ed.) ASHRAE Handbook of Fundamentals, American Society of Heating, Refrigerating and Air Conditioning Engineers, NY, 1972, or 1977 .

4. Mitalas, G. P. \& J. G. Arseneault, NBS Use of Computer Science for Environmental Engineering Related to Buildings, Ed. T. Kusuda, USDC: Building Science Series 39, Oct. 1971, "Fortran IV Program to Calculate $\mathrm{z}$ - Transfer Functions for the Calculation of Transient Heat Transfer through Walls and Roofs," pp 633-67.

5. NECAP Engineers Manual.

6. Stephenson, D. G. and G. P. Mitalas, Calculation of heat conduction transfer functions for multi-layer slabs; submitted to ASHRAE for presentation, January, 1971.

7. Wall, L.W., Tom Dey, Ashok J. Gadgil, Alan B. Killy and Arthur H. Rosenfeld 'Conservation Options in Residential Energy Use: Studies Using the Computer Program TWOZONE,' LBL, UCB, report LBL-5271.

8. Kusuda, NBSLD, the Computer Program for Heating and Cooling Loads in Buildings, U.S. Department of Commerce, National Bureau of Standards, NBS Building Science Series, 69, July 1976. 
APPENDIX I: Subroutine COOLIT

Author: Steven Gates

Subroutine COOLIT simulates the operation of either an air conditioner and/or an evaporative cooler. This subroutine is called by the cooling branch of the main program. Subroutine PSY1 is called by COOLIT for psychometric calculations.

INPUT

Hourly input to this subroutine is house temperature (TTB), heat fluxes (QDX, WLDOTQ, CLDOTQ, INLOAD, INFILOS, WLOSS, WGAIN), scheduled internal latent heat gains (HLATNT), internal humidity ratio (WROOM), weather data (WDATA), the fraction of the hour during which cooling is needed (FRAC), and the present time (NHR).

Evaporative cooling parameters initialized in the main program at the beginning of the run are mode flags (IFLAG8, IFLAG9, IFLAG10), relative humidity control values (RHSET, RHMAX, RHMIN), the maximum possible effective wet bulb depression (EFFECT), evaporative cooler speeds and wattages (ECVOL (4), EWATT(4), ISPEED), and the temperature at which the cooler turns off.

Air conditioning parameters initialized in the main program at the beginning of the run are the mode flags (IFLAG8, IFLAG9, IFLAG10), the air conditioner capacity (ACAPAC), fan volume (FANVOL), the number of parts the hour will be broken into for latent load stability (ISTEPS, DTIME), sensible and latent infiltration coefficients (A, B, ALAT, BLAT) a stability factor for adjusting ISTEPS and DTIME if the air conditioner is being sized (STABLE), and minimum coil temperature and enthalpy (TCOIL, HCOIL). 
Miscellaneous input includes the nighttime summer cooling temperature (TAMCOL), and the hours of the day that the occupants go to bed and get up (BED, BRKFST). Parameters initialized by the main program are RHMAX, RHMN, ISPEED, ISTEPS, DTIME, and STABLE. The rest are specified by the user.

OUTPUT

Hourly output from COOLIT consists of the house temperature at the end of the hour (TPB), the air conditioning or evaporative cooling load (CLD, ECLD), and the humidity ratio (WROOM).

Evaporative cooling variables stored for the main program for output at the end of the run are heat gains (window, wall, ceiling, floor, infiltration, and internal-load), apportioning variables (WINECT + WNECPT, WLECT + WLECPT, CLECT + CLECPT, FLECT, INFECT, INLECT + INLECPT) , comfort analysis (temperature + relative humidity) variables (ITEC, IRHEC, IRHECT, TAVEC, TMAXEC, RHMECl, RHAVEC, RHMXEC, TMECl) for a comfort table of temperature vs relative humidity, the amount of water used in the cooler (H2OEC), and, if flagged, sizing variables (VOLM, EFT, EFTT, VOLMAX, EFTVMX, VOLMIN, EFTVMN, EFTMAX, VLEFMX, EFTMIN, VLEFMN, VOLAVE, EFTAVE) for a sizing table.

Air conditioning variables stored for the main program for output at the end of the run are heat gain and apportioning variables (WINNETC + WNCPORT; WLCTOT + WLCPORT, CLCTOT + CLCPORT, FLCTOT, + INFCPOR, INLCTOT + INLCPOR), comfort analysis variables (ITAC, IRHAC, IRHACT, TAVAC, TMAXAC, RHMAC1, RHAVAC, RHMXAC, TMXACl) for a temperature vs relative humidity comfort table and, if flagged, sizing variables (ACSIZE, CLDMAX, CLDMIN) for a sizing table. 


\section{MODES OF OPERATION}

The mode flags, IFLAG8, IfLAG9, and IFLAG10, determine how the cooling equipment is to be operated. IFLAG8 determines the evaporative cooler mode. IFLAG8 $=0$ (or not specified) does not allow evaporative cooling. IFLAG8 $=1$ runs the cooler on the basis of internal temperature only. IFLAG8 = 2 runs the cooler on the basis of both house temperature and internal relative humidity (i.e., a humidistat). IFLAG8 $=3$ is like IFLAG8 = 2 but also assigns a minimum temperature to the air leaving the cooler (this is not a control currently available on evaporative coolers but may be useful if it is desired to cool a house at night without circulating uncomfortably cold air). IFLAG8 $=4$ sizes the evaporative cooler to whatever size is necessary to hold the house at THI. IFLAG8 $=5$ is like IFLAG8 $=4$ but sizes on the basis of both internal relative humidity and temperature. When one of the sizing modes is specified, a sizing chart of volume vs EFECT (number of hours at each volume and effectiveness) is printed at the end of the $r u n$. If IFLAG8 $=4$, the user specifies effectiveness (usually around 0.8 ), if IFLAG8 $=5$, the routine specifies the effectiveness as a function of the desired relative humidity, RHSET.

IFLAG9 determines the air conditioner mode. IFLAG9 $=0$ (or unspecified) does not allow air conditioning, unless overridden by IFLAG10. IFLAG9 = 1 runs the specified air conditioner in the mode determined by other flags (see table below). IFLAG9 $=2$ sets the size of the air conditioner to whatever capacity is needed in order to handle all the sensible and latent load and keep the house at THI. When IFLAG9 = 2, a chart of the number of hours at each air conditioner capacity is printed 
at the end of the run. Whenever IFLAG9 is not equal to zero, a chart of temperature vs. relative humidity is printed at the end of the run. IFLAGlo determines the night time cooling mode between the hours of BED and BRKFST. IFLAG10 $=0$ (or unspecified) does not allow any special cooling strategies at night. IFLAG10 $=1$ allows the house to vent down to the temperature set by TAMCOL during the cooling season. IFLAGI0 $=2$ sets the cooling thermostat temperature to TAMCOL at night. IFLAGI0 $=3$ runs the evaporative cooler at night (set temperature $=$ TAMCOL) and the air conditioner during the day (set temperature $=\mathrm{THI}$ ). IFLAG10 $=2$ will override IFLAG9 $=0$ if IFLAG8 $=0$. IFLAGI0 $=3$ will always override IFLAG9 $=0$.

IFLAG8, IFLAG9, and IFLAGI0 are used in combination to determine the cooling strategy of the air conditioning months. Some combinations are useful while others may give meaningless results. The following table is a summary.

TABLE OF COOLING MODES

IFLAG8， IFLAG9， IFLAG10

0

1

2

3

4

5

$$
0
$$

0

0

0

0

0
0

0

0

0

0

0
COMMENTS

No $A C$, no evaporative cooling, no special night-time venting-strategy

Normal evaporative cooling controlled to THI

Evaporative cooling controlled to RHSET and THI

Evaporative cooling controlled to TECMIN in the cooler, RHSET and THI in the house.

Sizes the cooler on the basis of temperature Sizes the cooler on the basis of both relative humidity and temperature. 
TABLE OF COOLING MODES (continued)

IFLAG8， IFLAG9， IFLAGI0

COMMENTS

$\begin{array}{lll}0 & 1 & 0 \\ 0 & 2 & 0 \\ 0 & 0 & 1 \\ 0 & 0 & 2 \\ 1 & 0 & 3\end{array}$

$1,2,3 \quad 1 \quad 0,1,2,3$

$1,2,3 \quad 2 \quad 0,1$

$0 \quad 2 \quad 0,1$

$4,5 \quad 0 \quad 0,1$

$4,5 \quad 0 \quad 2,3$

Air conditions to THI.

Sizes the air conditioner to THI

Vent the house to TAMCOL at night

during the cooling season

Run cooling equipment to TAMCOL at night during the cooling season

Runs the evaporative cooler to TAMCOL at night and the air conditioner to THI during the day.

Runs the evaporative cooler preferentially over the air conditioner in the modes specified. If the house temperature rises above THI, or the relative humidity is greater than RHSET + RHSENS, the air conditioner of specified capacity is turned on.

Runs the evaporative cooler preferentially over the air conditioner in the modes specified. If the house temperature rises above THI, or the relative humidity is greater than RHSET + RHSENS, an air conditioner of required capacity is turned on (this is a sizing run for the air conditioner in this operating mode).

Sizes the air conditioner in the modes specified

Sizes the evaporative cooler in the modes specified

Program will give meaningless data. Equipment should not be operated at night during sizing runs 
TABLE OF COOLING MODES (continued)

IFLAG8， IFLAG9，IFLAG10

\section{COMMENTS}

0

$2 \quad 2,3$

As above, sizing should not be done when operating the cooling equipment at night.

$4,5 \quad 1,2 \quad 0$

Meaningless, since air conditioning

will never be turned on during an evaporative cooler sizing $r$ un (the converse is not true).

Flags to be set to 0 may be left blank in the INPUT DECR. 


\section{CALCULATION OF VARIABLES COMMON TO THE EVAPORATIVE COOLING}

\section{AND AIR CONDITIONING BRANCHES}

Humidity Ratio ( $W$, sometimes specifically WROOM, WSAT, WAMB, etc.)

Humidity ratio $w$ is defined as the lbs of $\mathrm{H}_{2} \mathrm{O} / \mathrm{lbs}$ dry air. A typical value is .01 . The mass fraction of water in moist air is then $W /(1+W)$ and the mass fraction of the dry air is $1 /(1+W)$.

Relative Humidity ( $\mathrm{RH}$, in percent)

To calculate the internal relative humidity when the internal humidity ratio (WROOM) and internal temperature are known, the psychrometric routine PSYl is called with the internal temperature as both the drybulb and wetbulb argument. The humidity ratio returned is the saturated humidity ratio (WSAT) at room temperature. The percent relative humidity is then

$$
\mathrm{RH}=\mathrm{WROOM} / \mathrm{WSAT} * 100 .
$$

Dry Air Density (RHOAIR)

RHOAIR is calculated using the gas law $d=P / R T$. To calculate the density of moist air, the gas constant $R$ must be a composite value based on the weighted mass fractions of air and water

$$
\begin{aligned}
R_{\text {total }}= & R_{\text {air }} * 1 /(1+W)+R_{\mathrm{H}_{2} 0} * W /(1+W) \\
& \text { where } W \text { is the humidity ratio. I-2 } \\
= & \left(R_{\text {air }}+W^{*} R_{\mathrm{H}_{2} 0}\right) /(1+W)
\end{aligned}
$$

The density of dry air is then equal to the total density multiplied by the mass fraction of air.

$$
\begin{aligned}
\text { RHOAIR } & =\frac{P}{R_{\text {total }}{ }^{\star T}} * \frac{1}{1+W} \\
& =\frac{P}{\left(R_{\text {a ir }}+W^{\star} R_{\mathrm{H}_{2} 0^{*}}\right)^{\star T}}
\end{aligned}
$$


In Twozone,

$$
\begin{aligned}
\text { RHOAIR }=\operatorname{WDATA}(4) * 70.749 /((53.352 \\
+\operatorname{WROOM} * 85.778) *(\mathrm{~T}+460 .)) \\
\text { when } \left.\operatorname{WDATA}(4)=\text { barometric pressure, (in. of } \mathrm{H}_{\mathrm{g}}\right) \\
70.749=(1 \mathrm{~b} . \text { per Sq.Ft. }) /(\text { in. of } \mathrm{Hg}) \\
53.352=\mathrm{R}_{\mathrm{air}} \\
85.778 \quad=\mathrm{R}_{\mathrm{H}_{2}} \mathrm{O} \\
\mathrm{T}=\text { Temperature }\left({ }^{\circ}\right)
\end{aligned}
$$

\section{Specific Heat of Moist Air}

The specific heat of moist air is equal to the sum of the weighted specific heats of air and water

$$
C_{\mathrm{p}}=.24 * 1 /(1+\mathrm{W})+.444 * \mathrm{~W} /(1+\mathrm{W}) \quad \mathrm{I}-5
$$

\section{EVAPORATIVE COOLING BRANCH}

\section{Theory}

Evaporative cooling is based on the principle that air can be cooled by allowing water to evaporate into it adiabatically. The amount of water than can be evaporated into a unit mass of air (and thus the degree of cooling) is a function of the temperature of the air and the amount of water already in the air. Air at a given temperature is considered to be saturated when no more water can be evaporated into it. In the following discussion, it is assumed that the reader is familiar with the psychrometric chart.

The most common method of measuring the degree of saturation of air is by measuring the drybulb and wetbulb temperatures of the air. The drybulb temperature is that temperature normally read on a thermometer. The wetbulb temperature is the temperature of the same air after it 
has been adiabatically saturated with water. As water evaporates into air, the drybulb temperature falls and approaches the wetbulb temperature. An evaporative cooler operates on this principle by drawing air through moist pads. As the water in the pad evaporates into the air, the air temperature falls. The change in air temperature, or wetbulb depression, is a function of the difference between drybulb and wetbulb temperature and of the effectiveness EFFECT of the pads in saturating the air with water. EFFECT $=\Delta W / \Delta W(\max )$. Where $\Delta W$ is the change in the humidity ratio of incoming air. A typical value of EFFECT is 0.8 . $\triangle T=$ EFFECT $*$ (DRYBULB - WETBULB $)$

The temperature TEC of the air leaving the Evaporative cooler is then TEC $=$ DRYBULB - EFFECT * (DRYBULB - WETBULB $) \quad I-6$ This cooled air is blown into the house and allowed to escape through cracks, partially opened windows, etc. Since the air entering the house from the evaporative cooler may not be much cooler than the house, a large volume of air is usually required to keep the house cool, usually a complete house air change every two-three minutes. The temperature change in the house during the period the evaporative cooler is operating is a function of the temperature of the air entering the house from the evaporative cooler, and the heat flux into the house (but without any infiltration terms, since it is assumed that the evaporative cooler pressurizes the house).

$\underline{\text { Model }}$

The Evaporative Cooler branch deals only with the average temperature of the North and South zones (denoted by T or TTB below). The performance of the Evaporative Cooler is approximated by the following procedure. 
(Here we introduce the convenient nomenclature of initially introducing dashes in the original FORTRAN variable names, to make them easily comprehensible. We will drop the dashes later.)

1) The temperature $\mathrm{T}-\mathrm{EC}$ of air entering the house via the Evaporative Cooler is calculated.

2) The heat-flux $Q D X$ into the house during the present hour is obtained from the main program. The infiltration term is subtracted off since the house is pressurized due to the Evaporatice Cooler fan.

3) Using this heat-flux, and the volume, temperature, density and specific heat of air from the Evaporative Cooler, the house temperature of the current hour is calculated (see below).

QDX has been calculated using the eight hour history of inside and outside surface temperatures and heat fluxes of each wall and roof plus gains from sunlight and internal loads, minus the losses through glass (windows) and floor. Thus QDX itself depends to some extent on the inside air-temperature at the present hour. In the above model, we have taken QDX to be a fixed quantity. (This amounts to accepting a linear, rather than exponential behavior for the inside air temperature during the present hour, so far as the effect of QDX is concerned.) We have made this simplifying approximation after making sure that the more exact treatment, though considerably hairy, leads to difference of less than 18 in the energy-consumption of the Evaporative Cooler. Thus, the simplified heat balance equation to be solved is,

$$
\begin{aligned}
\mathrm{CC} * \frac{\mathrm{dT}}{\mathrm{dt}=} & (\mathrm{QDX}-\text { INFLOS }) \\
& + \text { ECVOL } * 60 .{ }^{\star} \mathrm{d}^{\star} C \mathrm{CP}^{\star}(\mathrm{TEC}-\mathrm{T})
\end{aligned}
$$


where

$$
\begin{aligned}
\mathrm{T} & =\text { house temp, later called TTB (see below) } \\
\mathrm{cC} & =\text { effective heat capacity of house }
\end{aligned}
$$$$
\text { QDX - INFILOS = heat flux/hour }
$$

ECVOL = cubic feet of air per min from evap cooler (EC-VOL)

$d=$ density of air from cooler

$c_{p}=$ specific heat of air from cooler

We next collect terms in $\mathrm{T}$ on the left-hand side of the equation.

$$
\begin{aligned}
\frac{d T}{d t} & + \text { ECVOL *d*C } p * 60 / C C * T \\
& =(Q D X-I N F I L O S) / C C+\text { ECVOL } * d * C_{p} * 60 * T E C / C C
\end{aligned}
$$

The solution to this differential equation is

$$
\begin{aligned}
\mathrm{T}=\mathrm{C} * \operatorname{ExP}\left(-\mathrm{ECVOL} * \mathrm{~d} * \mathrm{C}_{\mathrm{p}} \star 60 * t / C C\right) \\
\\
+\frac{\mathrm{QDX}-\text { INFILOS }}{\text { ECVOL } * d * C_{\mathrm{p}} \star 60}+\mathrm{TEC}
\end{aligned}
$$$$
\text { I-9 }
$$

when $t=0, T=$ house Temp $=$ TTB. This fixes the value of the constant $C$.

$$
C=T T B-\frac{Q D X-I N F I L O S}{E C V O L^{\star} d^{\star} C_{p^{\star}} 60}-T E C
$$

substituting $I-10$ in $I-9$ yields

$T=T_{T B}{ }^{*} \operatorname{EXP}\left(-E C V O L^{\star}{ }^{*} C_{p}{ }^{\star} t * 60 / C C\right)$

$$
+\left(\frac{\mathrm{QDX}-\mathrm{INFILOS}}{\mathrm{ECVOL}^{\star} \mathrm{d}^{\star} \mathrm{C}_{\mathrm{p}} \star 60}+\mathrm{TEC}\right) \star\left(1-\operatorname{EXP}\left(-\mathrm{ECVOL} * \mathrm{~d}^{\star} \mathrm{CP} * t * 60 / \mathrm{CC}\right)\right)
$$

when $t=1$ hour

$$
\begin{aligned}
T= & T^{*} B^{\star} \operatorname{EXP}\left(-\mathrm{ECVOL}^{\star} \mathrm{d}^{\star} \mathrm{C}_{\mathrm{p}}{ }^{\star 60} / \mathrm{CC}\right) \\
& +\left(\frac{\mathrm{QDX}-\text { INFILOS }}{\text { ECVOL } \mathrm{d}^{\star} \mathrm{C}_{\mathrm{p}}^{\star} 60}+\mathrm{TEC}\right) \star\left(1-\operatorname{EXP}\left(-\mathrm{ECVOL}^{\star} \mathrm{d}^{\star} \mathrm{CP} \mathrm{p}^{\star} 60 / \mathrm{CC}\right)\right)
\end{aligned}
$$


This equation is the basis for calculating the new house temperature in COOLIT. TTB, QDX, INFILOS, and $\mathrm{Cc}$ are variables given to COOLIT from the main program. ECVOL, $d, c_{p}$, and TEC pertain to air inside the evaporative cooler and must be calculated before solving for the new house temperature.

Selection of Cooler Fan Speed

During normal evaporative cooler operation (no humidistat controlling relative humidity inside the room), the variables named above are used to calcute TTB at the end of the hour, with ECVOL at the lowest speed. If TTB is above the thermostat setting THI, the cooler switches to the next higher speed and the calculation is repeated. The cycle is repeated until TTB is less than or equal to THI or the cooler is at its highest speed.

Evaporative Cooling While Controlling Relative Humidity

Simulating an evaporative cooler with a humidistat is a little more involved. The relative humidity $(\mathrm{RH})$ in the house is a function of temperature (TTB) and humidity ratio (WROOM), where all the moisture is assumed to come solely from the evaporative cooler. The relative humidity in the room must be controlled by adjusting WROOM. This is accomplished by adjusting the effective wetbulb depression, EFECT, that occurs in the cooler. However, when WROOM is changed by adjusting EFECT, then TEC, $d, c_{p}, T T B$, and ECVOL may also change. The relations are as follows:

$\mathrm{RH}=\mathrm{f}(\mathrm{TTH}, \mathrm{WROOM})$

WROOM $=f($ DRYBULB, WETBULB, EFECT)

or

EFECT $=f(D R Y B U L B$, WETBULB, WROOM) 
but

$$
\begin{aligned}
\text { TEC } & =f(\text { DRYBULB }, \text { WETBULB }, \text { EFECT }) \\
\text { TTB } & =f\left(\text { TTB }_{\mathrm{O} I \mathrm{~d}}, \mathrm{QDX}, \text { ECVOL }, \text { TEC }\right) \\
\text { ECVOL } & =f(\text { TTB })
\end{aligned}
$$

An inverse relationship exists between WROOM and TTB for a desired relative humidity. If the relative humidity at TTB is too high and WROOM is lowered by lowering EFFECT, TTB rises.

COOLIT uses an iterative technique for solving the above set of equations. Based on the temperature at the beginning of hour, WROOM is calculated for the desired relative humidity. From WROOM, the necessary EFECT is calculated and then TEC, ECVOL, and finally TTB for the end of the hour. Based on this new TTB and WROOM, the relative humidity is recalculated and compared to the desired relative humidity. If it is not close enough, WROOM is recalculated for the desired relative humidity at the new TTB. However, since TTB will rise or fall depending on whether WROOM is lowered or raised, substituting in this new value for WROOM will probably overshoot the desired relative humidity. Therefore, WROOM is set equal to the average of the WROOM at the new TTTB and the WROOM at the old TTB. This averaged WROOM reduces overshoot and helps the routine to converge faster. The number of iterations required to satisfy the relative humidity criterion is related to the size of the tolerable relative humidity range (set by RHSENS in the input deck). Larger values of RHSENS take fewer iterations and save computer time. A reasonable input value for RHSENS is 5 ( $R H$ is measured in percent, see Eq. I-1). The relative humidity will then be controlled to RHSET \pm RHSENS, in 1-2 iterations. 


\section{Evaporative Cooler Sizing}

Remember that a "Sizing Runs" does not actually select a size, merely produces an hourly table of "ECVOL" vs. Time, (see sample OUTPUT). During sizing runs, TTB is assumed to be constant at THI and $\mathrm{dT} / \mathrm{dt}=0$. The house temperature equation is then solved for the volume required to keep TTB constant for a given heat flux and TEC.

$$
\text { VOL }=(Q D X-\text { INFILOS }) / \mathrm{d}^{*} \mathrm{C}_{\mathrm{p}}{ }^{*}(\mathrm{THI}-\mathrm{TEC})
$$

If TEC is equal to THI, VOL is infinite. If TEC is greater than THI, VOL is negative. These two situations are impossible and the hours that these situations occur are counted as impossible hours and no sizing is done. TTB is still set at THI at the end of the hour so that the proper heat flux will be available at the next hour when sizing might be possible.

If sizing is to be done for a cooler with a humidistat, EFECT (and TEC) is adjusted for the proper humidity ratio at THI.

\section{Shutdown During the Hour}

If the house temperature falls below TOFFEC (T-Off-Evap.-Cooler, from card 9 of INPUT deck), the cooler shuts down during the hour. The fraction of the hour the cooler ran must be calculated so that the electricity and water consumption can be calculated.

The house temperature equation is solved for time with $\mathrm{T}$ set at TOFFEC. 
Refrigerative Air Conditioning Branch

Theory

The load seen by a vapor compression cycle air conditioner is a combination of sensible and latent heat removal loads. A sensible load is associated with the heat extracted in changing the temperature of air, and a latent load is associated with the heat extracted in condensing water out of the air onto the coil of the air conditioner. Latent loads occur when the air immediately adjacent to the coil is cooled to its dewpoint temperature (1008 relative humidity). The local temperature of this air is below the average temperature of the air moving through the coil, consequently condensation can occur even though the average temperature is higher than the dewpoint temperature. The average temperature at which condensation starts to occur is a function of the type of coil, the number of rows of tubes in the coil, and the face velocity of the air moving into the coil. This would be a difficult problem to model in this program; therefore COOLIT assumes that condensation (and latent load) begins when the air is cooled to an average temperature corresponding to 908 relative humidity. On the psychrometric chart this model of the air conditioner operation corresponds to cooling first along a constant humidity ratio line till the 908 relative humidity curve is reached. Moisture then starts to condense out of the air as the air is further cooled along the constant 908 relative humidity curve to the final temperature and enthalpy.

The latent load seen during an hour of air conditioning is a nonlinear function of room temperature, humidity ratio, room volume, fan speed, coil temperature, and air conditioner capacity. The matter is further complicated because the room humidity ratio is a function of latent 
heat gains internally (from occupants) and from infiltration (which in turn is a function of windspeed, outside humidity ratio and inside humidity ratio), and air conditioner latent heat extraction rate. The internal humidity ratio may vary substantially during the hour. Because of this, the latent load calculated at the beginning of the hour may be very different from the latent load seen at the end of the hour. An easy way to handle this in a numerical solution is to break the hour into smaller time steps. This is done in coolit. The Model

The sensible and latent load calculation in COOLIT proceeds as follows: At the beginning of each time step the enthalpy (H-Inside, called HIN), of the air entering the air conditioner is calculated as the function of the inside air temperature (TIN) and room humidity ratio (WROOM) . Using I-5 we have

$$
\text { HIN }=0.24 * \text { TIN }+(1061+0.444 * \text { TIN }) * \text { WROOM } \ldots \text { I-14 }
$$

HIN is then related to both the enthalpy the air will have when it is cooled to 908 relative humidity ( $\mathrm{H} 90 \mathrm{RH})$ and to the mass flow rate of air going through the coil (FANMAS) in order to determine if the air conditioner has sufficient capacity to cool the air further. If it does not, all the load is sensible. If it does, then both sensible and latent cooling occur. The exit enthalpy (HOUT) is then calculated

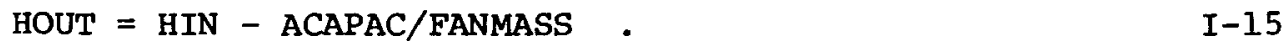
The program calculates the exit temperature of the air differently depending on whether the exit air enthalpy is on the constant humidity ratio line (sensible load only) or on the 908 relative humidity curve (sensible and latent loads) as determined above. The TOUT for sensible cooling only is calculated from the ASHRAE equation 


$$
\text { TOUT }=(\text { HOUT }-1061 . * \text { WACOUT }) /(0.24+0.444 \text { * WACOUT }) \quad \text { I-16 }
$$

where WACOUT $=W-A C-$ OUT $=$ humidity ratio of air coming out of the $A C$ unit = WROOM, since we are not extracting any moisture from the air.

The HOUT for sensible plus latent cooling is calculated from a fit to the 908 relative humidity curve on the psychrometric chart at sea level

$$
\text { TOUT }=.0384 * \text { HOUT } \star \star 2+3.446 * \text { HOUT }-2.58
$$

With HOUT being calculated from equation I-15 above. TOUT is calculated in this manner during sensible plus latent cooling because the humidity ratio of the air leaving the air conditioner is not yet known. This humidity ratio (W-AC-OUT) can be found after TOUT is calculated by the ASHRAE equation WACOUT $=($ HOUT $-0.24 *$ TOUT $) /(1061 .+0.444 *$ TOUT $) . \quad$ I-18 The sensible air conditioning load (Q-SEN-AC) and latent load (Q-LAT-AC) are then calculated for this time step QSENAC $=$ FANMAS $*($ TIN $*(0.24+0.444 *$ WROOM $)$

$$
- \text { TOUT*(0.24+0.444*WACOUT) }) \quad \text { I-19 }
$$

QLATAC $=$ FANMAS $* 1061 . *($ WROOM-WACOUT $) \quad$ I-20

The new room air temperature is calculated by the statement

$$
\operatorname{TIN}(\text { new })=(\text { QDXDT }- \text { QSENAC }) / C C+\operatorname{TIN}(\text { old }) . \quad I-2 I
$$

where QDXDT = QDX*DTIME, where DTIME is typically $1 / 4$ hour or less. If TIN is below the thermostat setting (THI) of the A.C. unit, the sensible plus latent loads are scaled so that TIN $=$ THI. WROOM at the end of this time step must now be recalculated. The total amount of water in the room is next calculated. We use the notation H20 (for $\mathrm{H}_{2} \mathrm{O}$ ), and set $\mathrm{H}_{20 \mathrm{ROM}}=1 \mathrm{~b}$. of water vapor in room. At the beginning 
of the time step H2OROM (=WROOM*RHOAIR*VOLROM) is decreased by the amount of water removed by the air conditioner (REM = removed) H2OREM (=FANMAS* (WROOM-WACOUT)) and is increased because of the internal latent load H20INT (e.g. from occupants) and infiltration H20INF (=AIRINF* $\left(W_{\text {ambient }}-\right.$ WROOM $\left.)\right)$. H20ROM at the end of the time step is then H20ROM(new) $=$ H2OROM(old) + H20INF + H20INT - H2OREM I-22 and

WROOM $=$ H20ROM $/($ WOLROM $*$ RHOAIR $)$ $I-23$

This sequence is repeated until the end of the hour is reached. At the end of the hour, the total cooling load (CLD) is set equal to the total of the sensible plus latent loads over the whole hour.

A previously mentioned, the hour is broken up into smaller time steps DTIME so that the latent load can be calculated more accurately. It was shown in a prototype version of coolit that the latent load calculation can be very unstable with time steps $=1 \mathrm{hr}$ or $1 / 2 \mathrm{hr}$, and can actually yield negative latent loads and negative relative humidities. A negative relative humidity will result if the latent load calculated at the beginning of the time step for a given humidity ratio is large enough so that all the water in the room will be removed during that time step, based on that humidity ratio.

The number of time steps needed for the calculation to be well behaved is a function of the humidity ratio, the fan speed, the air conditioner capacity, the coil temperature, and the volume of the room. The volume of the room, the humidity ratio, and the air conditioner capacity are the most important factors. Room volume and humidity ratio are a measure of how much water is in the room. Air conditioner capacity and humidity ratio are a measure of how quickly the water 
can be extracted. It was determined experimentally that the routine will always be stable with four time steps per hour when a 36000 Btu air conditioner is operated in a 1444 square foot house. For conditions other than this, the number of time steps is calculated (in Twozone) by the equation

ISTEPS $=$ Integer of $(3 *($ ACAPAC* 1444$) /(3600 *$ ARFLOR $)+1) \quad$ I-24

We take into account the temperature of the cooling coils (T-COIL) as follows.

If we are in the sensible-only part of heat extraction it is clear that the temperature of the air leaving the A.C. (T-OUT) cannot be lower than TCOIL. If TOUT as calculated by $I-16$ is lower than TCOIL then clearly we cannot extract heat at the rate determined by ACAPAC. We take this into account by running the compressor of the A.C. unit only a fraction of the time.

If we are in the sensible-plus-latent part of heat extraction, we must compare the enthalpy of air leaving the A.C. (H-OUT) with the enthalpy $\mathrm{H}$-COIL of air at 908 relative humidity at temperature TCOIL. If HOUT is less than HCOIL, the same kind of fractioning of compressor running time as described above is done.

If due to overcooling in the previous iteration the temperature TIN of air inside the room has fallen below the thermostat setting THI for the A.C. unit, compressor running-time is again scaled during the current iteration to correct for this.

\section{Sizing the Air Conditioner}

If IFLAG9=2 is specified, then the program sizes the air conditioner (i.e. produces a table of cooling load (CLD) vs. time at the end of the run). TCOIL is set to $50^{\circ} \mathrm{F}$. ACAPAC is set hourly to 2.5 times 
the heat flux for that hour. The factor 2.5 is chosen because experimenting with different weather tapes showed that in extreme cases the latent may be approximately the same as the sensible load for a couple of time steps, but is never substantially larger. The factor 2.5 makes sure that ACAPAC is large enough to handle the total cooling load. ISTEPS is then adjusted for the hour by the equation

$$
\text { ISTEPS }=\text { INT }(\text { ACAPAC * STABLE + } 1.0)
$$

where

$$
\text { STABLE }=4 * 1444 /(36000 * \text { ARFLOR) } \quad \text { (calculated in Twozone) }
$$

The sensible and latent load calculation proceeds exactly as before. At the end of the hour, CLD (not ACAPAC) is stored in an array for the sizing report at the end of the run.

\section{Psychrometric Curve Fits}

The air conditioning routine makes use of several equations which are quadratic curve fits of the psychrometric chart at sea level.

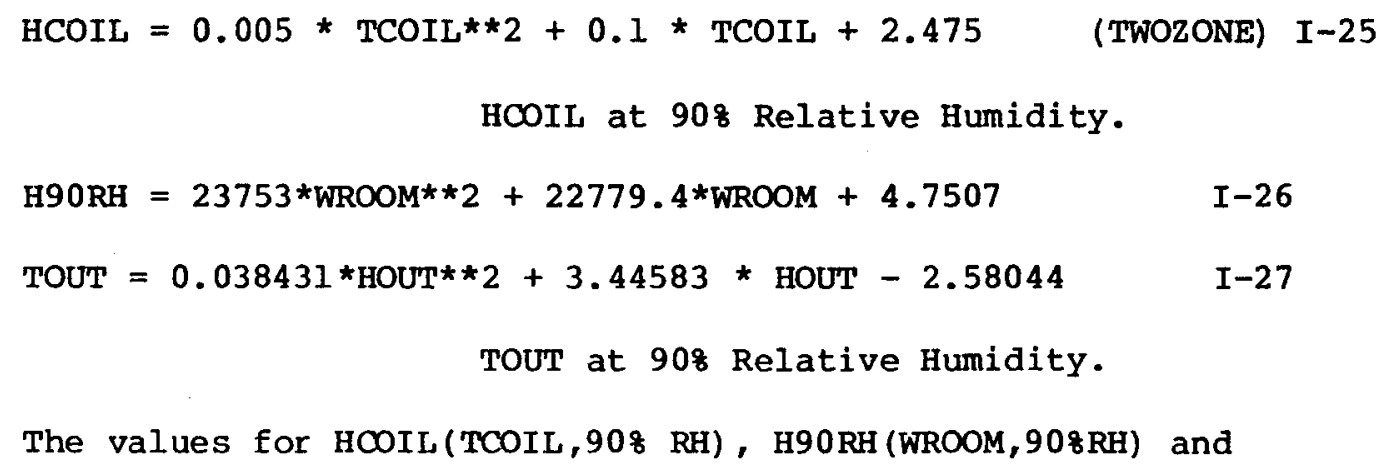


or if the barometric pressure is significantly different from sea level. The barometric pressure sensitivity of these equations has not been determined, but is probably not serious for altitudes less than $4000 \mathrm{ft}$. Calculation of WROOM at the Beginning of the Hour

The air conditioning routine must know WROOM at the beginning of the hour in order to calculate the latent load. The hourly value of WROOM is calculated in TWOZONE during the non-air conditioning hours. At the beginning of the cooling season, WROOM is initialized to the outside humidity ratio. Whenever the house vents, (almost every day) WROOM is again reset to the outside humidity ratio. During the rest of the non-air conditioning hours, a calculation is performed each hour on WROOM to take into account the change in WROOM due to infiltration and internal latent heat gains. The calculation of WROOM is as follows:

$$
\begin{aligned}
& \frac{d}{d t} \text { (H2OROM) } \\
& \quad=\text { AIRINF }\left(W_{\text {amb }}-\text { WROOM }\right)+\text { H2OINT }
\end{aligned}
$$

or

$$
\begin{aligned}
& \frac{d}{d t}(\text { WROOM * RHOAIR * VOLROM })= \\
& \text { AIRINF }\left(W_{\text {amb }}-\text { WROOM }\right)+\text { H2OINT }
\end{aligned}
$$

rearranging,

$$
\frac{d \text { WROM }}{d t}+\frac{\text { AIRINF } * \text { WROM }}{\text { VOLROM*RHOAIR }}=
$$

$$
\text { (AIRINF * } \mathrm{W}_{\text {amb }}+\mathrm{H} 20 \text { INT) } /(\text { VOLROM * RHOAIR) }
$$

where we have denoted the new value of WROOM by WROM.

Using the integrating factor 


$$
\operatorname{EXP} \int \frac{\text { AIRINF }}{\text { VOLROM * RHOAIR }} d t
$$

the solution to this equation is

$$
\begin{aligned}
& \text { WROM }=C * \text { EXP }-(\text { AIRINF } * t) /(\text { VOLROM } * \text { RHOAIR }) \\
& + \text { (AIRINF * Wamb + H20INT)/AIRINF }
\end{aligned}
$$

when $t=0$, WROM $=$ WROOM and this determines the value of $c$.

$$
C=\text { WROOM }-(\text { AIRINF * Wamb }+ \text { H20INT) } / \text { AIRINF }
$$

for $t=$ one hour the solution is then

$$
\begin{array}{r}
\text { WROM }=(\text { WROOM }- \text { Wamb }- \text { H20INT/AIRINF }) * \operatorname{EXP}(- \text { AIRINF } /(\text { VOLROM * RHOAIR })) \\
+ \text { Wamb + H20INT/AIRINF }
\end{array}
$$

with AIRINF $\neq 0$.

When the evaporative cooler runs, WROOM is set by the humidity ratio of the air blown into the house by the cooler. 


\section{APPENDIX II}

\section{BCD COEFFICIENT GENERATING PROGRAM}

The coefficients used in the heat transfer functions of TWOZONE are obtained by the Mitalas and Arseneault method.4,5 (See reference 4 for detailed theory and operating instructions. References Preceed Appendix I) .

This program will derive the z-transfer functions for two types of boundary conditions. The form of boundary parameters must be specified.

1) Boundary conditions of the first kind (temperature given for both surfaces.) A) ramp input, ICASE $=1$. This is the only case used by TWOZONE

B) frequency response, ICASE $=2$

2) Second kind of boundary condition (flux given for both surfaces.)
A) step input, ICASE $=3$
B) ramp input, ICASE $=4$
C) frequency input, ICASE $=5$

TWOZONE models the heat flow through a stud wall by computing the heat-flow through the two paths assumed to be in parallel: The heat flow through the wall area filled with studs and the heat flow throgh the wall area filled with insulation (or just air-space). These two 'components' of the wall are typically 158 and 858 of the total wall area for a wood-frame wall of a light construction house. TWOZONE will need the z-transfer functions for both the 'components' of a wall/roof. One must input the layers separately for each component to obtain the relevant $\mathrm{z}$-transfer functions. 
The information required by the program for each multilayer slab (wall or roof) can be obtained from the ASHRAE handbook. 3 The following data are needed for each layer (of each component*) of a wall or roof:

1. layer thickness

2. conductivity

3. density

4. specific heat

5. resistance

The output from the program will include a punched deck of the BCD coefficients required by the TWOzONE program.

INPUT DECK FORMAT

CARD I format (Fl0.3, I3)

Column 1-10 DT = sampling time internal, $1 \mathrm{hr}$. for TWOzONE

Column 13 PFLAG = punch flag to obtain data for TWOZONE on punched cards 1 = yes$$
2=\text { no }
$$

CARD 2 format (80Al)

Description of the slab for title purposes only. CARD 3 always blank, must be included.

If there are $M$ layers, $I=1,2, \ldots . M$, we need one card for each layer $I$. This card will be at position $(I+3)$ in the deck. Begin with the outside layer.

CARD $(I+3)$ format $(5 \mathrm{~F} 10.4,30 \mathrm{Al})$

Column 1-10 XL(I) = layer thickness

$11-20 \mathrm{XK}(\mathrm{I})=$ conductivity

'component' specifies either insulation space or stud space. 


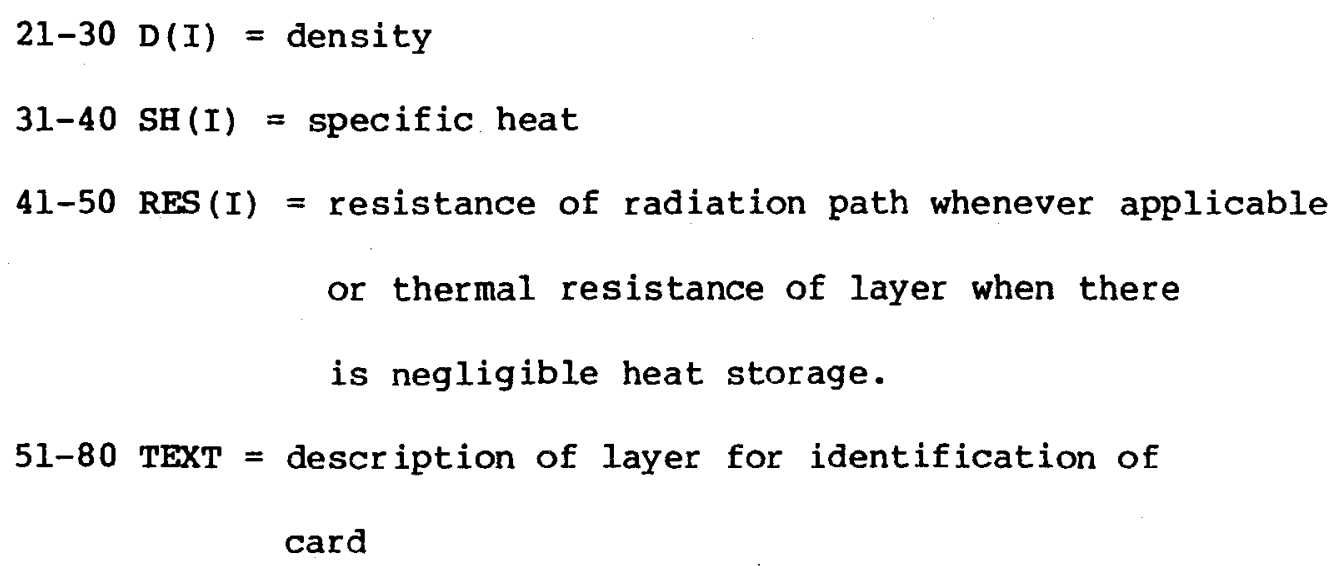

(All these data are supplied in "British" units if the resulting coefficients are to be used in TWOzONE.)

CARD $(M+4)$. We have gone through all the layers $I=1, \ldots M$; we are now at card $M+4$, which is left blank, but must be included.

CARD $(M+5)$ format $(2 I 1)$

Column 1 ICASE = see program description above; ICASE $=1$ for TWOZONE

$2 \mathrm{NW}=$ number of frequencies, to be used only when frequency response is involved ${ }^{4}$. Leave blank.

For each slab, add cards 1 through $(M+6)$ to the Input deck. The program will calculate the z-transfer functions for each slab in the input deck.

OUTPUT

The output of the program is a table of the z-transfer functions for each slab defined in the input deck. The program will also punch the 2-transfer functions on cards, three cards of data for each slab in the input deck. These cards are punched in a Format accepted by TWOZONE input deck (see pages 13 and 14 of this manual).

The z-transfer functions for each slab consist of three sequences $B_{n}, C_{n}, D_{n}(n=1,2, \ldots)$ of coefficients of a time series (Hence the name 'BCD coefficient' Generating Program). TWOZONE uses an eight hour 
history of inside and outside surface temperatures and history of the heat flux to compute the heat flux for the present hour through each component of slab by the following equation:

The heat flow at the present hour $(\mathrm{QDX}(1))$ is given by;

$\mathrm{QDX}(1)=\sum_{\mathrm{K}=1}^{8} \mathrm{BN}(\mathrm{K}) \star^{*} \mathrm{TOUT}(\mathrm{K})-\sum_{\mathrm{K}=1}^{8} \mathrm{CN}(\mathrm{K}) * \mathrm{TIN}(\mathrm{K})-\sum_{\mathrm{K}=2}^{8} \mathrm{DN}(\mathrm{k}) * \mathrm{QDX}(\mathrm{K})$

where $\mathbf{A}=$ area of the wall

$\mathrm{K}=$ hour counting index for history of variables

$K=1$ means present hour

$\mathrm{K}=2$ means one hour ago etc.

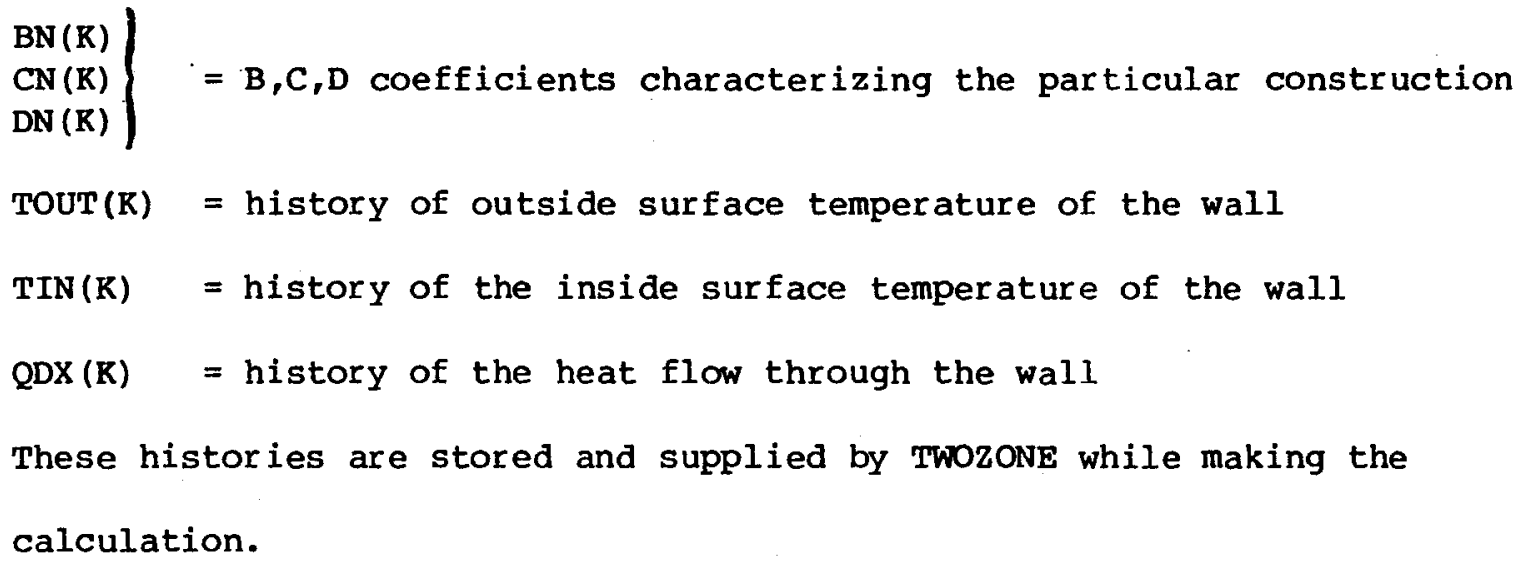


APPENDIX III

WEATHER FILE

\section{Introduction}

TWOZONE requires the following ten hourly weather data values (some of them redundant): drybulb and wetbulb temperature, dew point, barometric pressure, cloud amount, cloud type, wind speed, humidity ratio, density, and enthalpy. Subroutine WXDTA reads weather files and supplies the necessary data to subroutine WIHR. The most recent version of TWOZONE, BLUEL, uses subroutine WXDATA to read packed weather files from the CALERDA weather library. The old subroutine WXDATA has been preserved to read non-packed files, and is available.

TRY weather tapes are available from NOAA. ${ }^{1}$ A "Test Reference Year" (TRY) consists of hourly weather data values for a selected year. The principle of selection is to eliminate years containing months with extremely high or low mean temperatures until only the "TRY" year remains. The weather in the test year is considered a standard for comparison of heating and cooling systems. It is not considered sufficiently typical to yield reliable estimates of average energy requirements over several years.

A manual accompanies TRY weather tapes when ordered from NOAA. The NOAA TRY Weather Data Manual is available from The Director, National Climatic Center, Federal Building, Asheville, NC 28801. Tel. (701) $-254-0961$. 
TRY Tape Format

FORMAT

Each logical record (observation) is 80 bytes long. Archive files are blocked 24 logical records (1920 bytes) per physical tape record. Tapes may be ordered with different blocking factors at no additional cost.

The initial file contains TRY data for 60 stations, 20 stations on each reel of tape. An inventory showing stations and selected years is included in this appendix.

This Appendix also presents a description of the NOAA supplied tape format indicating Tape Fields, Tape Positions and Element Definition.

\section{SPECIAL NOTE}

On the TRY tapes, space has been designated for the inclusion of Solar Radiation values. At the present time this Tape Field will contain 9's.

At the conclusion of the Solar Radiation rehabilitation project it is expected that these data will be added to a small fraction of the TRY tapes.

Work supported by the U. S. Department of Energy. 
Data for each hourly observation is stored in eight words, and constitute one "card image" as follows:

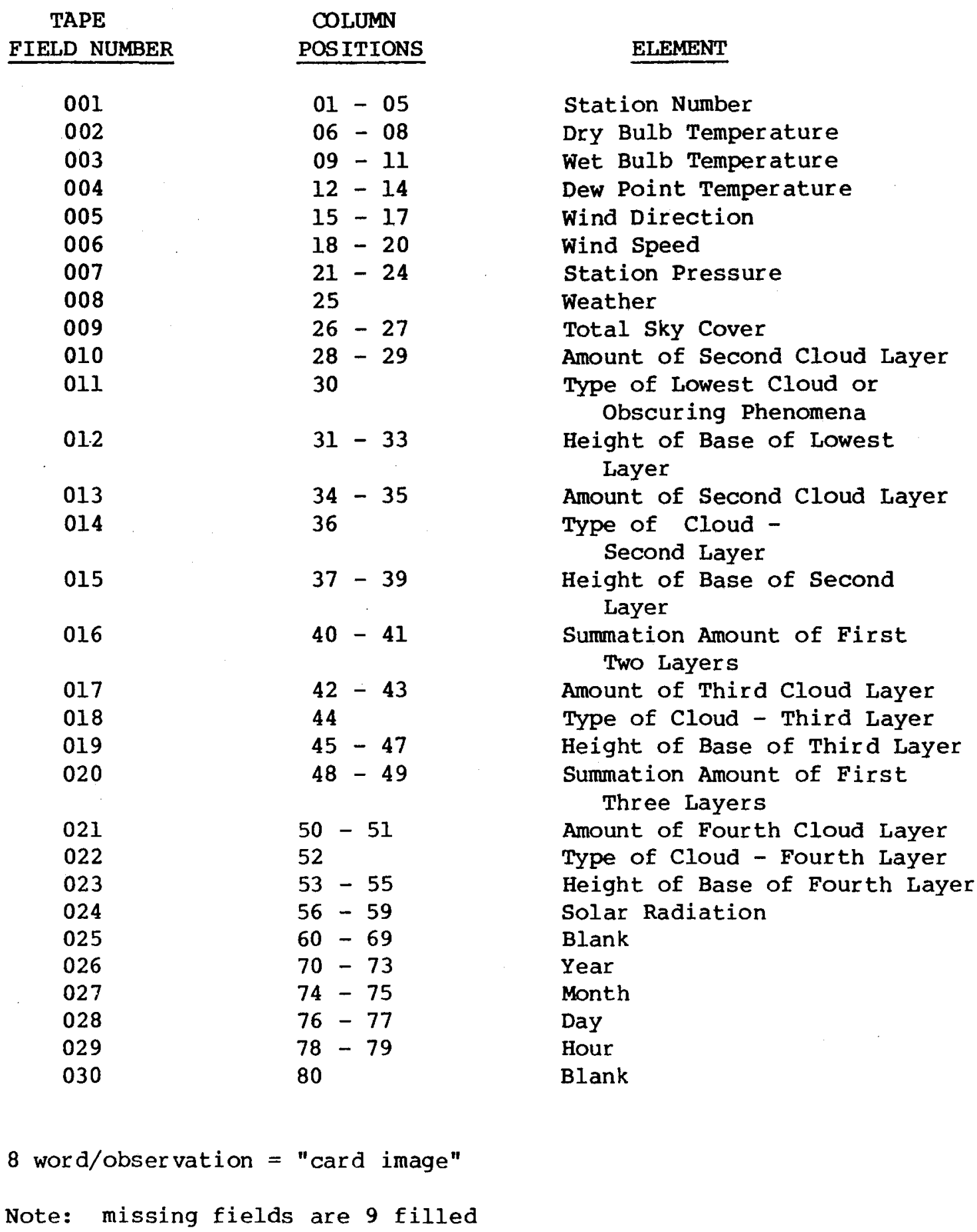


TABLE-1

INVENTORY OF 60 STATIONS on the NOAA tapes ordered by WBAN.

WBAN

NUMBER

STATION

SELECTED TRY

(Tape 1)

03927

03937

03940

12839

12842

12916

12918

12919

12921

13722

13737

13739

13740

13743

13874

13876

13880

13889

13893

13897

Fort Worth, TX

1975

Lake Charles, LA

1966

Jackson, MS

1964

Miami, FL

1964

Tampa, FL

1953

New Orleans, LA 1958

Houston, TX

1966

Brownsville, TX 1955

San Antonio, TX 1960

Raleigh, NC

1965

Norfolk, VA

1951

Philadelphia, PA 1969

Richmond, VA 1969

Washington, DC 1957

Atlanta, GA 1975

Birmingham, AL 1965

Charleston, SC 1955

Jacksonville, FL 1965

Memphis, TN

1964

Nashville, TN

1972

(Tape 2)

13967

Oklahoma City, OK

1951

Tulsa, OK

1973

Columbia, Mo

1968

13983

Dodge City, RS

1971

Kansas City, MO

1968

13988

st. Louis, MO

1972

New York, NY

1951

14732

14733

14735

Buffalo, NY

1974

Albany, NY

1974

Boston, MA

1969

Burlingame, VT

1966

14742

14764

14819

14820

14837

14922

14942

23042

Portland, ME

1965

Chicago, IL

1974

Cleveland, $\mathrm{OH}$

1969

Madison, WI

1974

Minneapolis, MN $\quad 1970$

Omaha, NE 1966

Lubbock, TX 1955

El Paso, TX 1967

23044

Amarillo, TX

1968 
WBAN

NUMBER

(Tape 3)

23050

23174

23183

23188

23232

23234

24011

24018

24127

24131

24143

24225

24229

24233

93193

93814

93819

93821

94823

94847
Alburquerque, NM

1959

Los Angeles, CA

Phoenix, AZ

1973

1951

San Diego, CA

Sacramento, CA

1974

1962

San Francisco, CA

1974

Bismar k, ND

1970

Cheyene, WY

1974

Salt Lake City, UT

1948

1966

Great Falls, MT

1956

1966

1960

1960

1951

1957

1972

1972

1957

Pittsburgh, PA

1968 
We reproduce below the Cal-ERDA packed weathertapes for California available at LBL. (This table is taken from the Cal-ERDA Users Manual, section 8 )

TABLE-2

California Climate Zone Weather File Inventory

\section{Zone}

1. North Coast

2. North Coast Valley

3. San Francisco Bay Area

4. Upper Coast Range Valley

5. Lower Coast Range Valley

\section{Representative Cities}

Crescent City

Eureka

Fort Bragg

Orleans

Scotia

Healdsburg

Napa

Petaluma

Santa Rosa

st. Helena

Ukiah

Berkeley

Hamilton AFB

Oakland

Redwood City

San Mateo

San Rafael

San Francisco

Hollister

King city

Livermore

Los Gatos

Monterey

Salinas

San Jose

Santa Clara

Santa Cruz

Watsonville

Lompoc

Ojai

Oxnard

Paso Robles

San Luis Obispo

Santa Barbara

Santa Paula

Santa Maria
Cal-ERDA Filename

CTZ1

CTZ2

CTZ3

CTZ4

CTz5 
Zone

6. Los Angeles Beach

7. San Diego

8. Santa Ana

9. Los Angeles City

10. San Bernadino

11. Northern Zone
Representative Cities

Culver City

Laguna Beach

Los Angeles Airport

Newport Beach

Santa Monica

Torrance

Chula Vista

Escondido

San Diego

E1 Toro

Long Beach

Santa Ana

Yorba Linda

Burbank

Los Angeles Civic Center

Pasadena

San Fernando

San Gabriel

Beaumont

Corona

Redlands

Riverside

San Bernadino

San Jacinto

Upl and

Alturas

Chico

Colusa

Marysville

McCloud

Oroville

Orland

Red Bluff

Redding

Susanville

Willows

Yreka
CTz8

CTZ9

CTZ10

CTz6

CTZ7

CTZ11 
Zone

12. Central Zone

13. San Joquin Valley

14. High Desert

15. Low Desert
Representative Cities

Antioch

Cal-ERDA Filename

Auburn

Davis

Lodi

Modesto

Nevada City

Placerville

Sacramento

Stockton

Tahoe City

Vacaville

woodland

Bakersfield

Coalinga

Fresno

Los Banos

Madera

Maricopa

Merced

Porterville

Visalia

Barstow

CTZ14

Bishop

Daggett

Lake Arrowhead

Mt. Wilson

Palmdale

Sandberg

Trona

Twentynine Palms

victorville

Blythe

CTZ15

Brawley

Eagle Mtn.

El Centro

Imperial

Indio

Iron Mtn.

Needles

Palm Springs
CTZ13

CTZl2

\section{C.213}

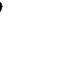

